NBER WORKING PAPER SERIES

\title{
NATIONAL INSTITUTIONS AND SUBNATIONAL DEVELOPMENT IN AFRICA
}

\author{
Stelios Michalopoulos \\ Elias Papaioannou \\ Working Paper 18275 \\ http://www.nber.org/papers/w18275 \\ NATIONAL BUREAU OF ECONOMIC RESEARCH \\ 1050 Massachusetts Avenue \\ Cambridge, MA 02138 \\ August 2012
}

We thank seminar participants at Dartmouth, Tufts, Oxford, Vienna, Brown, Harvard, Princeton, Stanford, UC-Berkeley, UC-Davis, NYU, AUEB, the CEPR Development Economics Workshop,the CEPR-UPF Workshop on the Political Economy of Development and Conflict, the World Bank, the IMF, the NBER Political Economy Meetings, the NBER Summer Institute Meetings in Economic Growth and Income Distribution and the Macroeconomy for valuable comments. We also benefited from discussions with Yannis Ioannides, Rafael La Porta, Antonio Ciccone, Rob Johnson, Raphael Frank, Jim Feyrer, Ross Levine, Avner Greif, Jeremiah Dittmar, David Weil, Sandip Sukhtankar, Quamrul Ashraf, Oded Galor, Ed Kutsoati, Pauline Grosjean, Hans-Joachim Voth, Enrico Perotti, Pedro Dal Bo, Nathan Nunn, Raquel Fernandez, Jim Robinson, and Enrico Spolaore. We are particularly thankful to Andy Zeitlin, Melissa Dell, Andrei Shleifer, Nico Voightlander, Daron Acemoglu, and seven anonymous referees for detailed comments and useful suggestions. We also thank Nathan Nunn for providing the digitized version of Murdock's Tribal Map of Africa. This paper draws on material from Michalopoulos and Papaioannou ("Divide and Rule or the Rule of the Divided?" 2011). All errors are our sole responsibility. The views expressed herein are those of the authors and do not necessarily reflect the views of the National Bureau of Economic Research.

NBER working papers are circulated for discussion and comment purposes. They have not been peerreviewed or been subject to the review by the NBER Board of Directors that accompanies official NBER publications.

(C) 2012 by Stelios Michalopoulos and Elias Papaioannou. All rights reserved. Short sections of text, not to exceed two paragraphs, may be quoted without explicit permission provided that full credit, including $(\subset$ notice, is given to the source. 
National Institutions and Subnational Development in Africa

Stelios Michalopoulos and Elias Papaioannou

NBER Working Paper No. 18275

August 2012, Revised August 2013

JEL No. N17,O10,O4,O43,Z10

\begin{abstract}
We investigate the role of national institutions on subnational African development in a novel framework that accounts both for local geography and cultural-genetic traits. We exploit the fact that the political boundaries in the eve of African independence partitioned more than two hundred ethnic groups across adjacent countries subjecting similar cultures, residing in homogeneous geographic areas, to different formal institutions. Using both a matching-type and a spatial regression discontinuity approach we show that differences in countrywide institutional structures across the national border do not explain within-ethnicity differences in economic performance, as captured by satellite images of light density. The average non-effect of national institutions on ethnic development masks considerable heterogeneity partially driven by the diminishing role of national institutions in areas further from the capital cities.
\end{abstract}

\author{
Stelios Michalopoulos \\ Brown University \\ Department of Economics \\ 64 Waterman Street \\ Providence, RI 02912 \\ and NBER \\ smichalo@brown.edu \\ Elias Papaioannou \\ London Business School \\ Regent's Park \\ Sussex Place \\ London NW1 4SA \\ United Kingdom \\ and NBER \\ papaioannou.elias@gmail.com
}




\section{Introduction}

Few other issues have received more inquiry in the social sciences than "what are the fundamental determinants of comparative development?" The institutional view asserts that poorly performing institutional structures, such as lack of constraints on the executive, poor property rights protection, as well as inefficient legal and court systems are the ultimate causes of underdevelopment (see Acemoglu, Johnson, and Robinson (2005) for a review). Yet other works downplay the role of formal institutions, emphasizing instead the importance of geographical features, informal cultural norms, genetic, and epidemiological traits (see Spolaore and Wacziarg (2013) for a review).

This paper investigates the role of national institutions on comparative development in Africa, developing a methodology that exploits in a "quasi-experimental" setting the artificial drawing of African borders -that took place in the European capitals in the mid-late $19^{\text {th }}$ century, well before African independence and at a time when Europeans had hardly settled in the regions whose borders were designing. The drawing of colonial boundaries partitioned in the eve of African independence more than 200 ethnicities across two (or more) countries. Taking advantage of this historical accident, we compare economic performance in adjacent regions belonging to the historical homeland of the same ethnic group, but falling in different countries and are thus subject to different formal institutions. This identification strategy accounts both for differences in the natural environment (as the two neighboring regions have similar geography-ecology) and for ethnic-specific cultural and anthropological traits (as people from the same background reside at the two sides of the border).

Our identification strategy entails two major challenges. First, we need to identify in a systematic way ethnic homelands partitioned by national borders. The second challenge derives from the sparsity of economic performance indicators at the local (country-ethnicity) level. On the first issue we exploit anthropological data from the pioneering work of George Peter Murdock (1959), who has produced a map portraying the spatial distribution of African ethnicities in the mid/late 19th century (Figure 1a). Projecting Murdock's map on contemporary national boundaries (Figure 1b), allows us to identify in a systematic manner ethnic groups that have been split by the national borders. On the second issue, to overcome the paucity of economic data across African regions we build on the recent contribution of Henderson, Storeygard, and Weil (2012) and measure development at the ethnicity-country level using satellite images of 
light density which are available at a fine grid.

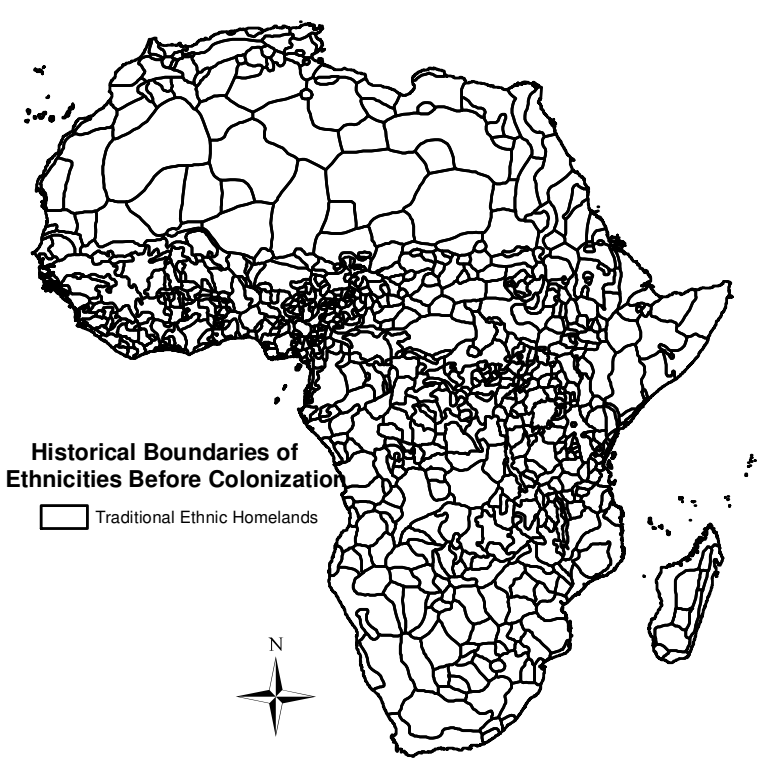

Figure 1a: Ethnic Boundaries

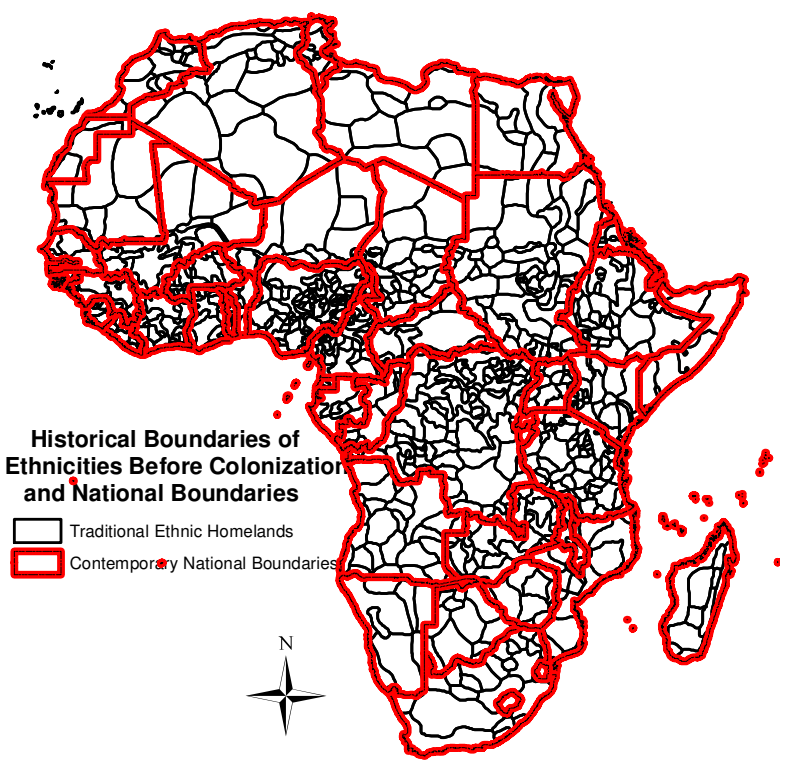

Figure 1b: Ethnic and Country Boundaries

Figures $2 a-2 b$ illustrate our approach using as example the Ambo, an ethnic group partitioned between Angola (a country scoring quite low in most proxies of national institutions) in the North and Namibia (an institutionally advanced African country) in the South. In our empirical analysis we investigate whether differences in national institutions between adjacent countries explain differences in economic performance (as proxied by luminosity) within the historical homeland of the same ethnic group. We perform our analysis at two levels of aggregation; across partitioned ethnic areas in each country (Figure 2a) and across pixels falling in the homeland of split groups (Figure 2b). For the Ambo luminosity is higher in Namibia, the more institutionally developed country.

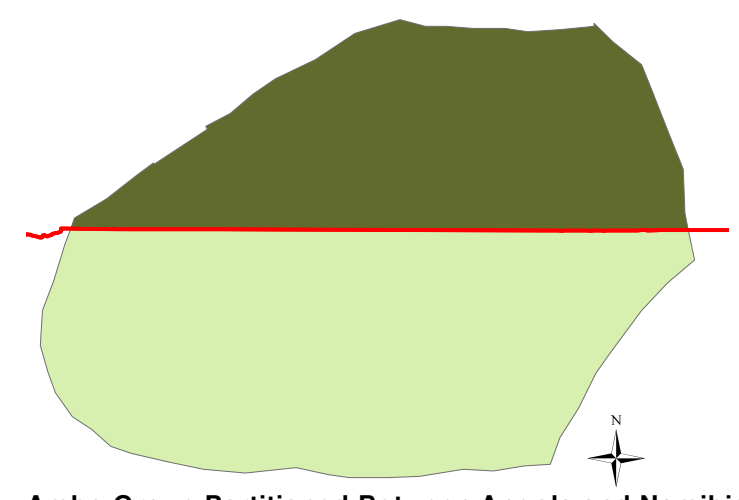

Ambo Group Partitioned Between Angola and Namibia Light Density in 2007-2008

Mean Luminosity for Ambo's partition in Angola: 0.0504
Mean Luminosity for Ambo's partition in Namibia: 0.162

Figure 2a

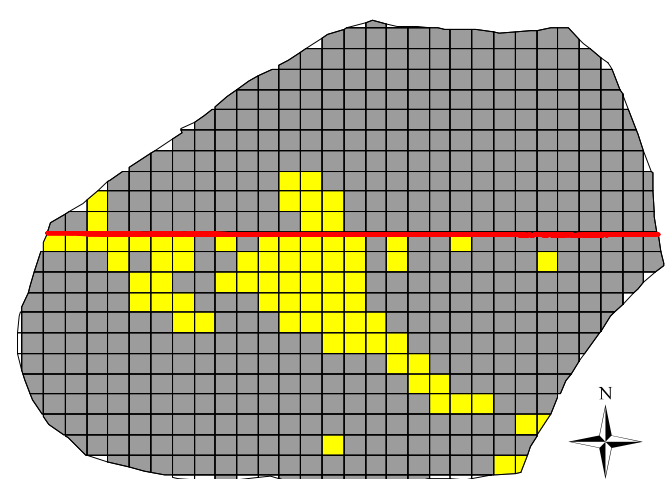

Ambo Group Partitioned Between Angola and Namibia

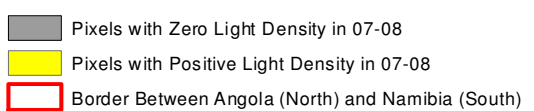

Figure 2b 
Yet, this is not the case for the Kaonde and the Anyi groups split by the Zambia - Democratic Republic of Congo border and the Ghana - Ivory Coast border, respectively. As Figures $2 c$ and $2 d$ show, a larger faction of the ethnic homeland of both groups is lit in the Democratic Republic of Congo and in Ivory Coast, although national institutional quality is significantly higher at the other side of the border (in Zambia and Ghana, respectively).

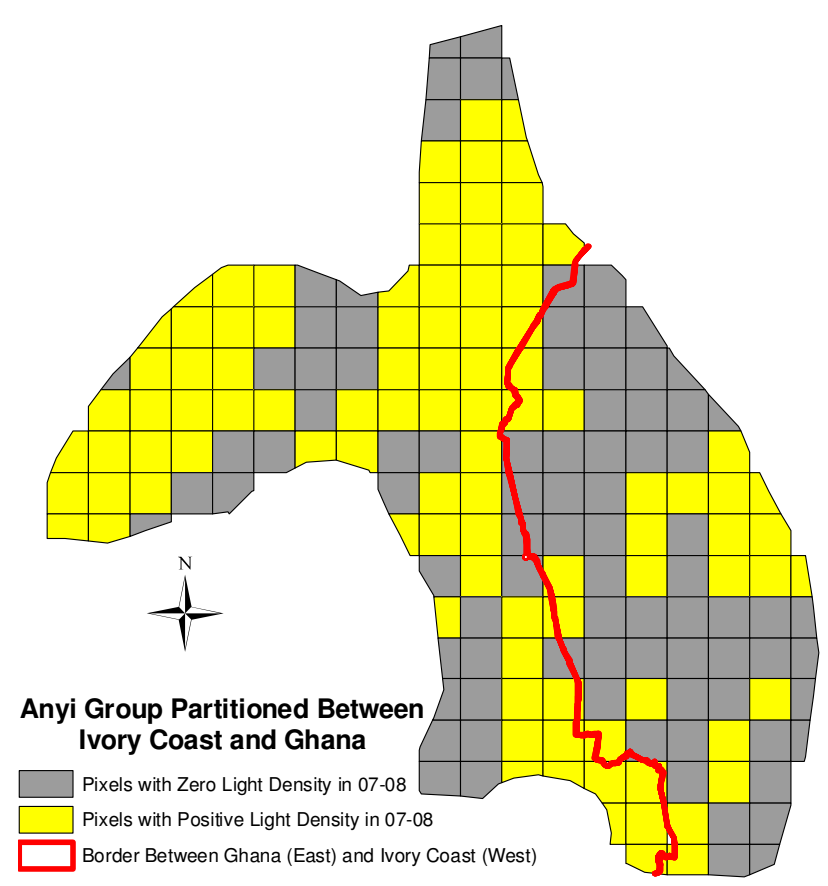

Figure 2c

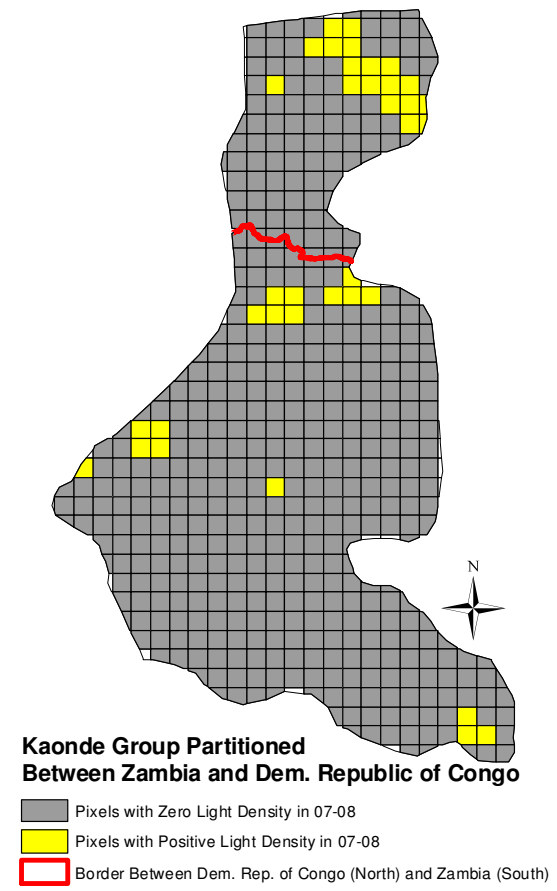

Figure 2d

Results Summary Our analysis that spans all African partitioned ethnicities reveals new empirical regularities. First, we document that differences in national institutions across the border do not systematically translate into differences in economic performance within partitioned ethnicities. While there is a significant positive correlation between national institutions and development across ethnic homelands, once we properly account for geographicecological and ethnic-specific differences via the inclusion of ethnicity fixed effects, the correlation weakens considerably and becomes statistically indistinguishable from zero. This pattern obtains both when the unit of analysis is a partitioned ethnic region (see Figure $2 a$ ) and when we take advantage of the finer structure of the luminosity data to obtain multiple observations within each partition (see Figures $2 b, c, d$ ); moreover when we conduct a spatial regression discontinuity (RD) analysis that identifies the (local) effect of national institutions at the border we also find a close-to-zero effect. The lack of a systematic association between national 
institutions and regional development within partitioned African homelands cautions against extrapolating from the positive cross-country correlations.

Our results go against the conventional wisdom in economics on the causal impact of national institutions on development, in Africa at least; yet they are consistent with the African historiography that de-emphasizes the importance of colonial and contemporary countrywide institutions in the hinterland (e.g., Herbst (2000), Davidson (1992)). Moreover, our findings are in line with recent works that emphasize traits besides formal institutions, such as cultural norms, family ties, or important historical episodes (see Algan and Cahuc (2013), Alesina and Giuliano (2013), and Nunn (2013) for recent reviews).

Second, we show that the insignificant correlation between national institutions and ethnic development masks considerable heterogeneity. We find that the average effect of institutions is economically negligible and statistically insignificant for approximately $60 \%$ of partitioned ethnicities. Yet, for some groups, consisting of approximately $20 \%-25 \%$ of the sample, a significant positive association emerges, whereas for the remaining ones the withinethnicity association turns negative. Overall, the uncovered heterogeneity provides a useful reminder that generalizing from the findings of case studies focusing on a single border discontinuity can be quite misleading. Meanwhile, it suggests that case studies may be useful for shedding light on the specific circumstances that allow countrywide policies to shape regional development.

Third, building on insights from the African historiography that stress the inability of states to broadcast power in regions far from the capital (e.g., Herbst (2000), Bates (1983)), we examine the spatial distribution of the uncovered heterogeneity. Contrary to the overall pattern, we find that national institutions do correlate with subnational development, but only when both partitions are close to the respective capital cities. We also present complementary evidence on the limited penetration of national institutions expanding our analysis to the universe of African groups; in particular, we show that the explanatory power of national institutions on regional development decays for ethnic homelands (and pixels within groups) further from the capital centers.

Fourth, we augment our analysis on the differential role of national institutions far from the capital using individual-level data from the Afrobarometer Surveys on law enforcement and self-identification (with the nation versus the ethnicity). Our within-country analysis shows that law enforcement weakens monotonically in areas further from the capitals. Moreover, national (as opposed to ethnic) identification is also inversely related to distance to the capital. These results thus further illustrate the limited penetration of country-wide institutions in the hinterland. 
Related Literature Our research nests and advances over several strands of literature that examine the political economy of contemporary comparative development.

First, an influential body of research asserts that through persistence, the institutions that European powers established during colonization are the deep roots of contemporary economic performance (e.g., La Porta et al. (1997, 1998); Acemoglu et al. (2001, 2002)). Yet despite the implementation of ingenious instrumental-variable approaches employed in the cross-country literature, omitted variables and estimate stability remain major concerns (see Glaeser, La Porta, de Silanes, and Shleifer (2004), La Porta, Lopez-de-Silanes, and Shleifer (2008), and Nunn (2012), among others). By exploiting within-country variation, our study circumvents some inherent limitations of the cross-country framework; ${ }^{1}$ moreover, we move beyond average effects and uncover the interplay between national institutions, state presence, and proximity to the capital.

Second, our identification scheme that exploits border discontinuities in institutional arrangements relates to works that study the role of national policies across a particular border. In an early contribution Miguel (2004) compares public policies in health and education across the Kenya-Tanzania border to examine the effect of Tanzanian nation-building efforts. Bubb (2012) investigates how differences in de jure property rights between Ghana and Ivory Coast affect development in border areas finding that in spite of large differences in formal institutions, there are no differences in the actual enforcement of property rights. Cogneau and Moradi (2011) examine differences in education and religiosity across the Ghana-Togo border and link them to different colonial investments; whereas Cogneau, Mesplé-Somps, and Spielvogel (2012) examine access to electricity, consumption, and health at the borders of Ivory Coast with Ghana, Mali, and Burkina Faso, finding mixed evidence on the role of economic and institutional development. Finally, Miles (1994) studies the development of the Hausa after their partitioning (at the Niger-Nigeria border), documenting that differences between French and British policies (mainly regarding the role of local chiefs) endured after independence and had long-lasting effects.

Our study, rather than focusing on the role of national features across a single border or within a single group, examines the role of national institutions on development across all partitioned ethnicities in Africa. Thus our results are less sensitive to the usual "external validity" arguments readily invoked in the context of case studies or works exploiting a single discontinuity. Moreover, our expansive focus sheds light on the underlying heterogeneity and uncovers the limited penetration of national institutions in areas far from the capital. The

\footnotetext{
${ }^{1}$ In this regard our work is mostly related to works that exploit within-country variation on institutions, such as Banerjee and Iyer (2005), Iyer (2010), Laeven and Woodruff (2007), De Long and Shleifer (1993), Dell (2010), Grosjean (2011), Tabellini (2010), and Gennaioli, La Porta, Lopez-de-Silanes, and Shleifer (2013).
} 
latter finding is related to parallel works of Campante and Do (2013) and Campante, Do, and Guimaraes (2013), who link capital city isolation with misgovernance and economic efficiency.

Third, our results relate to the large literature in African political economy (see Bates (2008) and Dowden (2008) for eloquent narratives) that stresses features beyond national institutions; these include colonial investments in education, health and infrastructure (e.g., Huillery (2009) and Jedwab and Moradi (2012)), ethnic partitioning (e.g., Englebert, Tarango, and Carter (2002) and Michalopoulos and Papaioannou (2013a)), fractionalization (e.g., Easterly and Levine (1997) and Alesina, Devleeschauwer, Easterly, Kurlat, and Wacziarg (2003)), inequality across ethnic lines (e.g., Alesina, Michalopoulos, and Papaioannou (2013)), and geography-health (e.g., Nunn and Puga (2012) and Alsan (2012)).

Of most relevance from this body of research is our companion paper (Michalopoulos and Papaioannou (2013c)), where we explore the long-lasting importance of ethnic (as opposed to national) political/institutional traits for contemporary African development. The main finding is that among numerous ethnic-specific features (related, for example, to the type of subsistence economy, occupational specialization, slavery, etc.), the legacy of pre-colonial political centralization appears to be a robust correlate of contemporary regional economic performance (Gennaioli and Rainer $(2006,2007)$ provide similar cross-country evidence). In contrast to these works that highlight the role of historical persistence at the ethnic level, in this paper we examine the role of national institutions, which have been a dominant theme in the growth literature and in policy circles alike. In addition, our finding that national institutions wield significant explanatory power near the capitals, which rapidly diminishes for regions in the hinterland, highlights the importance of ethnic norms and reveals the coexistence of a dual institutional framework within African countries (Lewis (1954), Migdal (1988)). Moreover, a methodological innovation of the present study is that we identify the role of national institutions within partitioned ethnic groups taking advantage of the arbitrary drawing of African borders and thus accounting for any (un)observable ethnic-specific differences across the diverse African tribal landscape. This has significant advantages over works exploiting cross-cultural variation and is motivated by the standard-textbook introduction on the role of national institutions showing the divergence in economic performance within culturally and geographically homogeneous entities, like North and South Korea, or East and West Germany (see Weil (2008)).

In this regard our paper is related to subsequent work by Pinkovskiy (2013), who studies discontinuities in satellite-recorded light density at night across the globe and links them to country-level economic development -and its main correlates (e.g., human capital, institutional capacity, etc.). In line with our findings, Pinkovskiy (2013) shows that borders of African na- 
tions tend to be relatively underdeveloped, with limited penetration of government activities and substantial economic activity concentrated around capital cities. ${ }^{2}$ Moreover, our focus is on discontinuities within partitioned ethnic homelands; as such we effectively account for both geography-ecology and ethnic-specific features, related to history, social structure, and genetics. In fact, the uncovered weak and insignificant correlation between national institutions and subnational development within geographically and culturally homogeneous territories contributes to an emerging body of work that emphasizes the importance of cultural norms, historical persistence, and human and geographic traits for comparative development (see Diamond (1997), Landes (1998), Guiso, Sapienza, and Zingales (2006), Spolaore and Wacziarg (2009), Putterman and Weil (2010), Ashraf and Galor (2013) and Michalopoulos, Naghavi, and Prarolo (2012), among others).

Paper Structure In the next section we describe how we identify partitioned groups and discuss the luminosity data that we use to proxy subnational development. In section 3 we discuss the estimating framework and detail the identification design. In Section 4 we report the baseline estimates on the average effect of national institutions on economic development within partitioned ethnic homelands. We also present spatial regression discontinuity (RD) estimates that quantify the effect of national institutions at the border. In Section 5 we estimate the role of national institutions separately for each split group mapping the overall heterogeneity. In an effort to understand the latter, in Section 6 we explore how proximity to the capital shapes the explanatory power of national institutions on regional development. In section 7 we summarize discussing avenues for future research.

\section{Data}

\subsection{Identifying Partitioned Ethnicities}

Murdock's map (Figure 1a) portrays the spatial distribution of ethnicities across Africa in the mid/late $19^{\text {th }}$; it depicts 826 ethnic areas inhabited upon colonization (in total there are 834 polygons, but 8 regions are classified as "uninhabited"). Intersecting the pre-colonial map with the 2000 Digital Chart of the World (Figure 1b) that portrays contemporary national boundaries we obtain 1,247 country-ethnicity observations (e.g., Ambo in Angola, Ewe in Togo, Zulu in South Africa). We classify an ethnicity as partitioned when at least $10 \%$ of the historical homeland belongs to more than one contemporary state. We drop partitioned areas of less than 100 square kilometers as tiny partitions are most likely due to the lack

\footnotetext{
${ }^{2}$ Note that focusing on Africa is desirable since, in contrast to African borders, in Europe and most other parts of the world national borders have been contested by numerous wars and are the outcome of active state formation and (in)voluntary people's movements.
} 
of precision and projection error. Our procedure identifies 526 partitions that belong to the historical homeland of 227 ethnic groups. We report estimates for 220 partitioned ethnicities (507 country-ethnicity observations), because for six groups (the Ifora, the Kunta, the Berabish, the Atta, the Teda, and the Asben) the local population estimates indicate zero population (in one of the two partitioned areas); moreover, we lose information from the Imragen -which are partitioned between Western Sahara and Mauritania- because we do not have information on national institutions for Western Sahara.

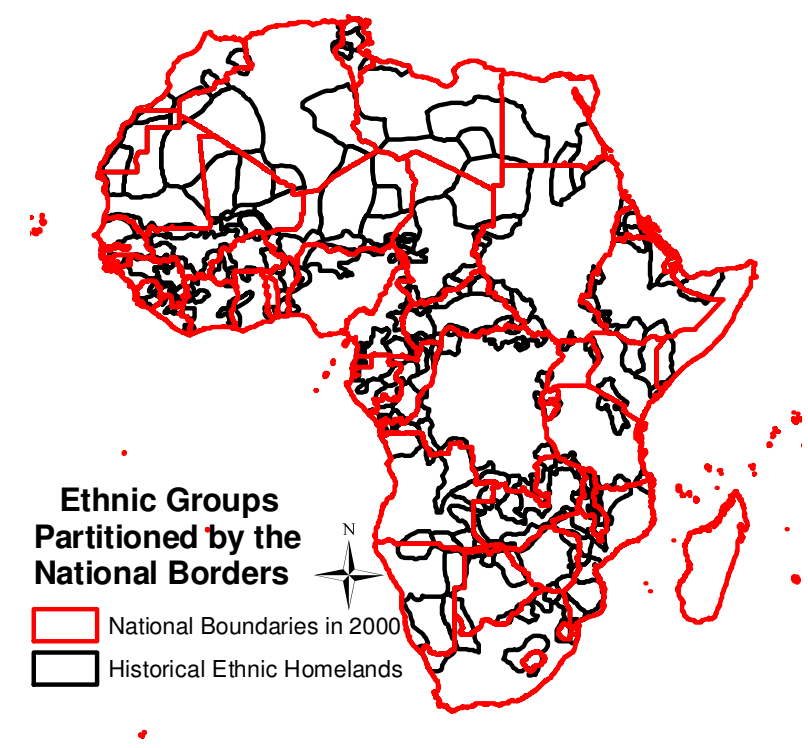

Figure 3a

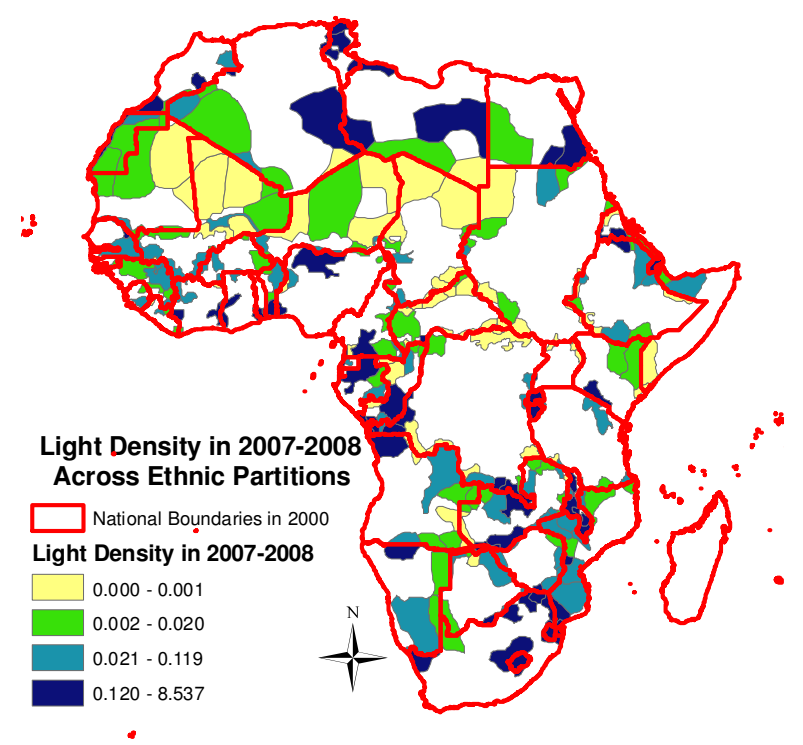

Figure $3 b$

Appendix Table $A$ lists partitioned ethnicities. Examples include the Ewe that have been partitioned between Ghana and Togo (shares $44 \%$ and $56 \%$, respectively), the Esa between Ethiopia and Somalia (shares $52 \%$ and $44 \%$, respectively, while a small fraction falls in Djibouti), and the Yao (Wayao) between Mozambique (65\%), Malawi (13\%), and Tanzania $(22 \%)$. Our procedure reveals that the median country in Africa has $43 \%$ of its population belonging to partitioned ethnicities. This estimate is similar to that of Asiwaju (1985) and Alesina, Easterly, and Matuszeski (2011), who using alternative sources and techniques estimate that on average $40 \%$ of the African population belongs to partitioned ethnic groups. Thus our analysis, while focusing on partitioned homelands, captures a significant fraction of the African population (Figure $3 a$ ).

Case study and anecdotal evidence suggest that in spite of population movements ethnic populations tend to reside in their respective historical homelands. Nunn and Wantchekon (2011) document that close to $55 \%$ of respondents in the Afrobarometer Surveys currently live in their ethnic group's ancestral homeland. In the same vein, Glennerster, Miguel, and Rothenberg (2013) document in Sierra Leone that after the massive displacement of the 1991 - 2002 civil 
war there has been a systematic movement of individuals towards the areas of their ethnic group's historical homeland.

\subsection{Satellite Light Density at Night}

The nature of our study requires data on economic development at the country-ethnic homeland level. Since there are limited geocoded measures of economic development in Africa, we build on the recent contribution of Henderson, Storeygard, and Weil (2012) and use satellite images on light density to proxy local economic activity.

Data come from the Defense Meteorological Satellite Program's Operational Linescan System (DMSP-OLS) that reports time-stable images of the earth at night captured between $20: 00$ and $21: 30$. The measure ranges from 0 to 63 and is available for every 30 -second area pixel (approximately 1 square kilometer). The satellite detects lights from human settlements, fires, gas flares, lightning, and the aurora. The annual composite measure is created by overlaying all daily images captured in a year, dropping images where lights are shrouded by cloud cover or overpowered by the aurora or solar glare (near the poles), and after removing ephemeral lights (like fires, lightning and other noise). ${ }^{3}$ Using these data we construct light density per square kilometer for 2007 and 2008 averaging across pixels that fall within the historical homeland of each ethnic group in each country.

Besides its availability at a very fine geographic level, luminosity is well suited to spatial analyses of development in Africa for some additional reasons. First, most African countries have low quality income statistics, both at the national and the sub-national level (Jerven (2013)). Second, we lack data on regional incomes for most African countries; and while there are some local proxies of poverty and health, these do not map to our ethnicity level unit of analysis.

Despite a series of works that establish a strong within-country correlation (both across time and across regions) between light density at night and GDP in the on-line Supplementary Appendix (Section 1) we provide further cross-validation checks of the luminosity data in our context. ${ }^{4}$ Specifically, using individual-level data from the Afrobarometer Surveys on access to electrification, presence of a sewage system, access to piped water, and education we show that light density correlates strongly with these proxies of public goods and development both

\footnotetext{
${ }^{3}$ See Henderson, Storeygard, and Weil (2012) and Chen and Nordhaus (2011) for technical details on the lights data. Satellite data on light density at night are subject to overglow/blooming; this happens because lights tend to appear larger than they are over water and snow. While this issue is not particularly important in our application as we do not have observations near the poles and covered with snow, in many specifications we control for water area and distance to the coast. Another issue with the light data comes from top coding that usually happens in the capitals of developed countries. Yet, in Africa instances of top-coding are rare.

${ }^{4}$ See Henderson, Storeygard, and Weil (2012), Elvidge, Baugh, Kihn, Kroehl, and Davis (1997), Doll, Muller, and Morley (2006), Michalopoulos and Papaioannou (2013c), and Pinkovskiy (2013), among others.
} 
across Afrobarometer enumeration areas within countries and within ethnic homelands as well as across the border within partitioned ethnicities.

\subsection{National Institutions}

We measure national institutions using data from World Bank's Governance Matters Database (Kaufmann, Kraay, and Mastruzzi (2008)). The World Bank assembles numerous de facto institutional quality measures (originally compiled by various non-governmental organizations and risk assessment agencies) and aggregates them into six categories via principal components aiming to minimize measurement error. We mainly use the rule of law index that reflects the effectiveness of the judiciary and the quality of property rights protection. As many studies on African development focus on graft, we also report results using the control of corruption index. Both variables range theoretically between -2.5 and +2.5 with higher values indicating better functioning institutions and less corruption. To account for reverse causality and measurement error, we use predetermined values of the institutional quality measures, taking the mean over the period 1996-2006 (the results are robust to the choice of year). In our sample the countries with the lowest rule of law are Somalia $(-2.195)$, the Democratic Republic of Congo ( -1.88$)$, and Liberia (-1.73) while South Africa (0.156), Namibia (0.1675), and Botswana (0.615) are the most institutionally developed countries in Africa.

\subsection{Data Patterns}

There is significant variation both in national institutions and luminosity across African borders (Figure 3b). Sharp border discontinuities in rule of law appear in several parts of Africa. For example, in the Botswana and Zimbabwe border (where the Hiechware, the Subia, and the Tlokwa are partitioned); across the Namibia and Angola border (where the Ambo are split); between Kenya and Somalia (where the Bararetta and other Somali tribes reside); and between Gabon and Congo (where the Duma live). Likewise, there are evident changes in luminosity across the border within the homeland of the same ethnic group. On the one hand, despite differences in national institutions, in around $25 \%$ of the sample there are negligible differences in light density across the border. On the other hand, in about $40 \%$ there are more than one log point differences in luminosity. For example, sizable jumps in luminosity appear in the Egypt-Sudan border (where the Ababda and the Barabra are split), in the border between Ghana and the Ivory Coast (where the Assini reside), and between Benin and Togo (where the Popo are split). 


\section{Identification}

\subsection{Estimating Framework}

Specification at the Country-Ethnic Homeland Level Our analysis on the relationship between national institutions and regional development is based on variants of the following specification:

$$
y_{i, c}=a_{0}+\gamma I Q L_{c}+\lambda_{1} P D_{i, c}+\lambda_{2} A R E A_{i, c}+X_{i, c}^{\prime} \Phi+a_{i}+\varepsilon_{i, c} .
$$

The dependent variable, $y_{i, c}$, reflects the level of economic activity in the historical homeland of ethnic group $i$ in country $c$, as proxied by light density. Since a significant fraction (around 30\%) of the (country-ethnicity) observations takes on the value of zero, we use as dependent variable the log of light density adding a small number $\left(\left(y_{i, c} \equiv \ln \left(0.01+\right.\right.\right.$ LightDensity $\left.\left.y_{i, c}\right)\right) .^{5}$ The logarithmic transformation is useful because we use all observations and because we account for some extreme values in luminosity (outliers).

Specification at the Pixel Level We also exploit the fine structure of the luminosity data to obtain multiple observations (pixels) within a partitioned ethnic area in each country; we do so running the following regression equation (variant of (1)).

$$
y_{p, i, c}=a_{0}+\gamma I Q L_{c}+\lambda_{1} P D_{p, i, c}+\lambda_{2} A R E A_{p, i, c}+X_{p, i, c}^{\prime} \Phi+a_{i}+\zeta_{p, i, c} .
$$

The dependent variable, $y_{p, i, c}$, is a dummy that takes on the value one if pixel $p$ is lit and zero otherwise. Each pixel, $p$, falls in the historical homeland of partitioned ethnicity $i$ located in country $c$ (see Figures $2 b-d$ for examples). In our analysis we use pixels of $0.125 x 0.125$ decimal degrees (approximately $12.5 \mathrm{~km} \times 12.5 \mathrm{~km}$ ). Since there are several unpopulated pixels (in the Sahara or in the rainforests) and to make sure that we examine the role of national institutions on development properly, we exclude pixels with zero population. ${ }^{6}$ This results to more than 120,000 observations across all African ethnic homelands, with 42,710 of those belonging to partitioned ethnicities.

While conceptually the unit of our analysis is a partition of a group (Figure 2a), the pixel-level specifications (Figure 2b) are useful for several reasons. First, by looking at the extensive margin of light density we account for the non-linear nature of luminosity. Second, the linear probability models facilitate the interpretation of the estimates. Third, we are able

\footnotetext{
${ }^{5}$ A zero level of light density occurs either because the area is extremely sparsely populated without any electricity or because the satellite sensors cannot capture dimly lit areas. In the previous draft of the paper we added one (rather than 0.01) to the luminosity data before taking the logarithm finding similar results.

${ }^{6}$ The coefficient estimates are similar when we also consider unpopulated pixels and/or if we construct pixels of alternative size.
} 
to control for various -relevant for development- characteristics at a fine level. Fourth, it is straightforward to augment the pixel-level specification with RD polynomials on distance to the national border, so as to estimate the effect of national institutions at the border. Fifth, we can estimate the pixel-level specification for each partitioned ethnicity separately and explore potential heterogeneity on the impact of institutions on development.

Independent Variables $I Q L_{c}$ denotes institutional quality of country $c$, as reflected in the rule of law and the control of corruption measures. For split groups, each partition is assigned to the corresponding country $c$. For example, regional light density in the part of the Egba in Benin is matched to the institutional quality of Benin, while the adjacent area of the Egba in Nigeria is assigned the value of Nigeria.

In most specifications we control for log population density, $P D_{(p), i, c}$, because the association between luminosity and economic development strengthens and because by doing so the estimates capture the role of institutions beyond population density. We also control for the $\log$ of land area, $A R E A_{(p), i, c}$; although most pixels are of the same size, those intersected by the coast line, national and ethnic boundaries are smaller (see Figures $2 b, c, d$ ).

Vector $X_{(p), i, c}$ includes additional controls at the ethnic-homeland level (in (1)) or at the pixel level (in (2)). ${ }^{7}$ The Data Appendix provides variable definitions and data sources. Table 1 reports summary statistics in the sample of partitioned ethnicities (at the country-ethnic homeland level in Panel $A$ and at the pixel level in Panel $B) .{ }^{8}$

Inference In all specifications we employ the approach of Cameron, Gelbach, and Miller (2011) and cluster standard errors along the country and the ethnic-family dimension. Murdock assigns the 826 groups into 96 ethnolinguistic clusters. This double-clustering parameterization accounts for two main concerns related to non-adjusted standard errors. First, within each country we have several ethnic homelands (or pixels) where the country-level rule of law and the control-of-corruption measures take the same value and thus clustering at the

\footnotetext{
${ }^{7}$ Specifically, we control for land suitability for agriculture and average elevation. The latter has affected African development both via goods and slave trades (see Nunn and Puga (2012)). We also control for surface under water to account for blooming in the luminosity data and for the potential positive effect of water streams on development via trade. Moreover, we control for malaria suitability since many studies document its detrimental effect on development (see Gallup and Sachs (2001)). We also include indicators for the existence of oil and diamonds fields to account for the "natural resource" curse (see Ross (2012)). Finally, we add a set of controls measuring the distance from the capital city, the national border, and the coast, respectively. The coefficient on distance from the capital may reflect the impact of colonization and the limited penetration of national institutions due to the poor infrastructure (we formally explore this possibility below). Distance to the border captures the potentially lower level of development in border areas. Distance to the sea coast captures the effect of trade, but to some extent also the penetration of colonization. This is because during the colonial era (and the slave trades) Europeans mainly settled in coastal areas.

${ }^{8}$ In Supplementary Appendix Table 2 we report summary statistics for the full sample of African ethnic homelands, 1, 209 country-ethnic observations and 120,501 pixels.
} 
country-level is required (Moulton (1990)). Likewise, clustering at the ethnic family accounts for intra-ethnic-family correlation in (un)observed features. Second, the multi-way clustering method allows for arbitrary residual correlation within both dimensions and thus accounts for spatial correlation; Cameron, Gelbach, and Miller (2011) explicitly cite spatial correlation as an application of the multi-clustering approach (see Nunn and Wantchekon (2011) and Michalopoulos and Papaioannou (2013c) for applications of the multi-way clustering method in a similar context). We also estimated standard errors accounting for spatial correlation of an unknown form using Conley's (1999) GMM method. The two approaches yield similar standard errors.

\subsection{Validity of Identification Design}

For our identification strategy that compares economic development at the homelands of the same ethnicity in adjacent countries to be valid, one needs that border drawing should not have been influenced by local circumstances and factors that themselves shape or reflect economic well-being (see Angrist and Pischke (2008)). Moreover the ethnic areas across the border need to be similar across all relevant for development dimensions. We have thus investigated these issues in detail.

First, all the anecdotal evidence suggests that colonizers drew African borders in an arbitrary manner (see Wesseling (1996), Asiwaju (1985), Herbst (2000), and Englebert (2009) for eloquent reviews); the delineation of African borders took place in a period (late 19th century), when Europeans had not yet settled (most of) Africa and had limited knowledge of its political and economic geography; moreover, at that time colonizers were mostly assigning spheres of influence via the establishment of protectorates, colonies and free-trade-areas, let alone the borders of future African states. Consistent with the historical narratives on the artificiality of African borders, Alesina, Easterly, and Matuszeski (2011) document that close to $80 \%$ of African borders follow latitudinal or longitudinal lines, the highest percentage across all continents. Moreover, Michalopoulos and Papaioannou (2013a) show that besides land mass and water area, there are no systematic differences between non-split and partitioned ethnicities, across dozens of potentially relevant for development factors, related to geography, natural resources, the disease environment, and historical traits (capturing the intensity of pre-colonial conflict, political centralization, the type of subsistence economy, the intensity of the slave trades, etc.). Yet, since some borders may have been drawn taking into account local conditions, in the Supplementary Appendix we report estimates restricting attention to ethnicities partitioned by borders that follow relatively straight lines (as identified by the "box-count" method of Alesina, Easterly, and Matuszeski (2011)). The results are virtually 
unchanged (see the associated discussion in the Supplementary Appendix and Appendix Tables $9 A$ and $9 B)$.

Second, although research shows that ethnic groups tend to occupy geographically homogenous territories (Michalopoulos (2012)), we investigated whether differences in institutional quality across the border correlate with differences in various characteristics. Table 2 Panels $A$ and $B$ report ethnicity fixed effects estimates ("similarity" regressions) that associate geographic, ecological, and natural resource measures with the rule of law and the control of corruption index, respectively. In Panels $C$ and $D$ we focus on the two largest partitions of the 220 split groups (440 observations) and examine whether there are systematic differences between regions falling in the relatively high and the relatively low institutional quality country. The results are supportive of our identification strategy, as they point out that the two (or more) partitions of partitioned ethnicities are appropriate counterfactuals. Differences in geography-ecology, location, and natural resources across the border within partitioned ethnic homelands are small and not systematically linked to differences in national institutions. ${ }^{9}$

\section{Baseline Results}

\subsection{Preliminary Evidence. Cross-sectional Analysis.}

Before we report the baseline ethnicity fixed effects estimates, we examine the cross-sectional patterns running simple LS specifications that associate regional development with national institutions. Due to reverse causation and omitted variables, these specifications do not identify causal effects; yet they are useful for understanding the raw data patterns. Table 3 - Panel $A$ reports estimates at the country-ethnicity level (1,209 observations), while Panel $B$ reports similar estimates at the pixel level (120, 501 observations). Specification (1) shows that there is a positive and significant correlation between the rule of law index and regional development. In column (2) we control for log population density and log land area, whereas in column (3) we control for distance of each ethnic area (in Panel $A$ ) or each pixel (in Panel $B$ ) to the capital city, the national border, and the coast ("location controls"). While all distance terms enter with significant coefficients, the estimate on the rule of law index retains its economic and statistical significance. In column (4) we augment the model with a rich set of geographic-ecological and natural-resource controls. Conditioning on geography reduces the coefficient on national institutions (approximately by 35\%) though the estimate retains its statistical significance. ${ }^{10}$

\footnotetext{
${ }^{9}$ In Supplementary Appendix Section 2 we report similar specifications at the pixel level and present regression discontinuity graphs showing that there are no jumps at the border within ethnicities across numerous geographic and location feature (Appendix Figures $4 a-4 g$ ).

${ }^{10}$ Land suitability for agriculture, which reflects climatic (temperature and precipitation) conditions, enters most models with a positive and significant estimate. The malaria stability index enters in all specifications with
} 
The results are similar when we use the control of corruption index (in (5)-(8)).

The coefficient in column (4) of Panel $A$ implies that a one-point-increase in the rule of law index (roughly 2 standard deviations), which corresponds to moving approximately from the institutional quality of Angola to that of Gabon, is associated with a 0.70 log points increase in regional luminosity (approximately half a standard deviation) and an 8\% higher likelihood that a pixel is lit.

The correlations in Table 3 echo the findings of cross-country works; although the association between institutional quality and development weakens when one accounts for geography, it remains significant. Yet the fact that a small set of observable geographic features explains a moderate fraction of the cross-sectional correlation between institutional quality and ethnic development suggests that other unobserved or hard-to-measure aspects of geography-ecology and culture may further weaken the association.

\subsection{Ethnicity-Fixed-Effects Estimates}

Having established that regions across the national border that are part of the historical homeland of the same ethnicity are reasonable counterfactuals (in Table 2) and having explored the cross-sectional patterns (in Table 3), we now examine the correlation between national institutions and luminosity within partitioned groups. Table 4 - Panel $A$ gives the results at the country-ethnic homeland level (equation (1)), while Panel $B$ reports the results at the pixel level (equation (2)). For comparability, in odd-numbered columns we report cross-sectional estimates, while in even-numbered specifications we add ethnicity fixed effects. The crosssectional estimates in columns (1) and (5) suggest that border areas that belong to countries with higher institutional quality display higher levels of development. For example, the estimate of the linear probability model in column (1) implies that a one-point increase in the rule of law index increases the likelihood that a populated pixel is lit by approximately $11 \%$.

Yet when we solely exploit within-ethnicity variation, the coefficients on rule of law and control of corruption drop sizably and become statistically insignificant. This is a uniform pattern across all permutations. At the country-ethnic homeland level the estimates fall from 0.65 to 0.19 and from 0.79 to 0.26 . The coefficient drop in the linear probability models is starker; the estimate drops from 0.11 to 0.025 in the case of rule of law and from 0.14 to 0.037 in the case of the control of corruption index. ${ }^{11}$ We also investigated formally whether the

a statistically negative estimate. The coefficient on land area under water is positive and in many specifications significant. Elevation enters with a negative estimate, which is significant in some models. The petroleum dummy enters always with a significantly positive coefficient. The diamond dummy enters with a negative coefficient that is significant in some permutations.

${ }^{11}$ The results are similar when we use the level of luminosity at the country-ethnic homeland level as the dependent variable. In the analogous to columns (1) and (5) cross-sectional models the estimate (standard 
estimates on national institutions are statistically different between the cross-sectional and the within-ethnicity models performing a seemingly unrelated regression (SUR) Hausman-like test; the latter suggests that the difference in the coefficients is statistically significant at standard confidence levels. The insignificance of the ethnicity fixed-effects estimates is not driven by a decrease in the precision of the coefficients, since the standard errors remain largely unchanged (in Panel $A$ ) or even fall (in Panel $B$ ); it is the drop in the coefficient magnitude that is substantial.

Figures $4 a-4 b$ below illustrate the lack of a systematic within-ethnicity correlation between light density and institutional quality at the national level. The insignificance is not driven by a few (influential) observations; the within $R^{2}$ of the unconditional model is tiny, less than 0.02 , implying a negligible economic effect.

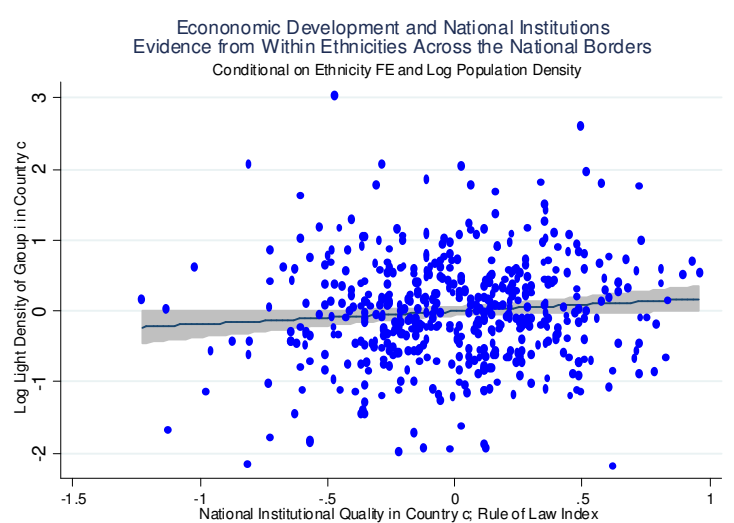

Figure $4 \mathbf{a}$

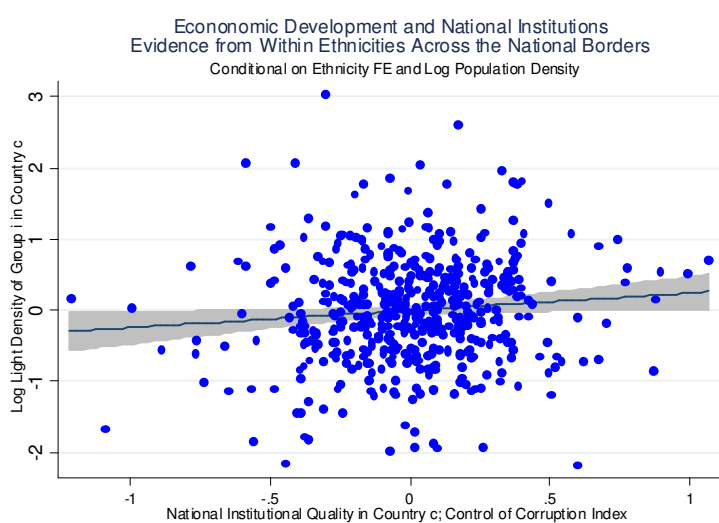

Figure $4 b$

In Table 5 we restrict estimation to areas close to the national border focusing in columns (1)-(2) and (5)-(6) on areas within 50 kilometers from each side of the border (total 100 kilometers), while in columns (3), (4), (7), and (8) we focus on regions within 25 kilometers of each side of the border (total 50 kilometers). The idea of this approach (which is similar in spirit to local regressions in regression discontinuity designs) is that by focusing on areas very close to the border, we further neutralize the role of unobservable factors. While in the cross section there is a strong positive association between national institutions and regional development, the within-ethnicity coefficients of rule of law and control of corruption are small and statistically indistinguishable from zero. This applies both at the country-ethnicity sample (in Panel $A$ ) and at the pixel level (in Panel $B$ ). The lack of significance is not driven by an increase in the standard errors; in all permutations two-standard-error bands in the within-ethnicity estimates exclude the analogous cross-sectional ones. The cross-sectional estimates fall by more error) on the national institutions measures is $0.18(0.09)$ and $0.215(0.1065)$. Once we include ethnicity fixed effects the estimates (standard errors) fall considerably to 0.05 (0.09) and 0.05 (0.13). See Appendix Table 6. 
than two thirds once we add ethnicity fixed effects (from 0.68 to 0.083 in (1) and from 0.86 to 0.09 in (4)). Similarly, the linear probability estimates drop from $0.10-0.14$ to 0.02 , implying tiny economic effects. The statistical and economic insignificance of the coefficient is therefore casting doubt on the causal interpretation of the simple cross-sectional association between national institutional quality and subnational development. ${ }^{12}$

A Note on Ethnicity Fixed Effects Across all model permutations in Tables $4-5$, the ethnicity fixed effects are jointly significant at the $99 \%$ confidence level. Moreover, most of the ethnicity constants are individually highly significant. This suggests that African subnational development has a strong local geographic-ecological or/and ethnic-specific component. Since our focus is on isolating the effect of national institutions from local geographic and cultural traits, we do not examine in detail which aspects of the local environment the ethnicity fixed effects capture. Yet, given the importance of this issue, in the Supplementary Appendix (Section 3) we conduct a preliminary analysis using anthropological data from George Peter Murdock's Ethnographic Atlas (1967) that records various quantitative measures of cultural, economic, and political traits for a large sample of African ethnicities. The cross-ethnicity specifications show that simply conditioning on the degree of pre-colonial political centralization (a key correlate of both economic and institutional development in Africa; see Gennaioli and Rainer (2007, 2006) and Michalopoulos and Papaioannou (2013c)) or/and the type of the subsistence economy (dependence on agriculture and pastoralism, in particular) weakens considerably the cross-sectional coefficient on the national institutions proxy that becomes statistically indistinguishable from zero. These preliminary findings are in accord with recent works on the deep origins of African development that emphasize the key role of ethnic traits, as opposed to national features (see Michalopoulos and Papaioannou (2013b) for a review of recent studies).

\subsection{Regression Discontinuity (RD) Estimates}

We now report the results from the regression discontinuity (RD) approach that identifies the (average) effect of national institutions at the border.

Our RD specification within the two major partitions of each ethnic group takes the following form:

$$
y_{p, i, c}=a_{0}+\gamma I Q L_{c}^{H I G H}+f\left(B D_{p, i, c}\right)+\lambda_{1} P D_{p, i, c}+\lambda_{2} A R E A_{p, i, c}+X_{p, i, c}^{\prime} \Phi+a_{i}+\zeta_{p, i, c} .
$$

\footnotetext{
${ }^{12}$ The insignificance of the coefficient on national institutions is not driven by the double clustering of the standard errors. In many specifications clustering only at the country level suffices to make the estimate statistically indistinguishable from zero at standard confidence levels.
} 
The difference with specification (2) is that since we aim at identifying the effect of national institutions on regional development at the border, we add RD-polynomials of the distance from the centroid of each pixel to the national border $\left(f\left(B D_{p, i, c}\right)\right)$, allowing the coefficients on the polynomial terms to be different for each side of the boundary. $I Q L_{c}^{H I G H}$ is a dummy variable that takes on the value one for pixels falling in the country with the relatively better institutions, as reflected either in the rule of law or in the control of corruption index. ${ }^{13}$ This RD-type design (see Imbens and Lemieux (2008); Lee and Lemieux (2010)) exploits the discontinuity in the quality of national institutions at the border to identify institutions' local average (treatment) effect.

Previous research has employed variants of the above regression equation using different control functions of the running variable (distance to the border in our application) and limiting estimation close to the discontinuity using different bandwidths. Some researchers control for high-order polynomials in the forcing/running variable using all observations (both far and close to the discontinuity), as this approach maximizes the sample and is more efficient (e.g., Lee, Moretti, and Butler (2004)). Others estimate local regressions limiting their analysis to an area close to the discontinuity either including or excluding the polynomial control function (e.g., Dell (2010), Angrist and Lavy (2002)). For completeness, we employ all approaches and experiment with different bandwidths.

Baseline Results Table 6 - Panel $A$ reports the RD results that identify the effect of national institutions on development exactly at the border. In columns (1)-(2) we use all pixels across the two major partitions of split-by-the-border ethnic homelands, controlling flexibly for the distance to the discontinuity using a cubic RD polynomial and a fourth-order RD polynomial, respectively. On average the likelihood that a pixel is lit is just one percentage point higher in the country with the relatively higher institutional quality. The coefficient on the dummy that switches to one for ethnic regions falling in the relatively less corrupt country is even smaller (in (7)-(12)). Specifications (3)-(6) and (9)-(12) report local-linear regression results narrowing estimation to pixels within 50 or 25 kilometers from each side of the border (total bandwidth $100 \mathrm{~km}$ and $50 \mathrm{~km}$, respectively), while including the RD polynomial terms. The coefficient on the high institutional quality country is close to zero (in some specifications is negative) and statistically insignificant. In Panel $B$ rather than including a common to all partitioned ethnicities RD polynomial, we include ethnic-specific polynomial terms on distance to the border (i.e., allowing for the effect of the running variable to be different for each

\footnotetext{
${ }^{13}$ In previous drafts of the paper, we used the value of the rule of law or the control of corruption measures, rather than the high/low institutional quality transformation. The coefficients on the two proxies of national institutions measures in these "difference-in-discontinuities" specifications were small and statistically indistinguishable from zero.
} 
group). The RD estimates on the national institutions measures are small and statistically indistinguishable from zero across all perturbations.

Graphical Illustration Figures $5 a$ and $5 b$ provide a visual illustration of the RD results. The Figures plot the average likelihood that a pixel is lit for bins of 5 kilometer width, conditioning on log pixel area and log population density in areas close to the national border (the vertical line marks the national border). We report results using a 100 kilometer and a 50 kilometer bandwidth, respectively. The Figures also plot predicted pixel-level luminosity from a regression that includes a third-order RD polynomial on distance to the border fitted separately for pixels in the partitions that fall in the relatively high institutional quality country (where distance takes on positive values) and pixels falling in the relatively low institutional quality country (where distance takes on negative values). In line with the RD estimates in Table 6 there are no discernible differences in luminosity crossing the national boundary towards the more institutionally developed country.

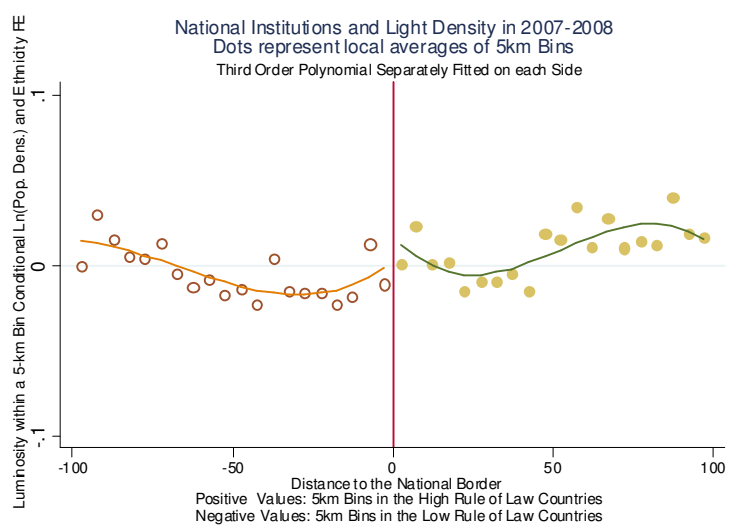

Figure 5a

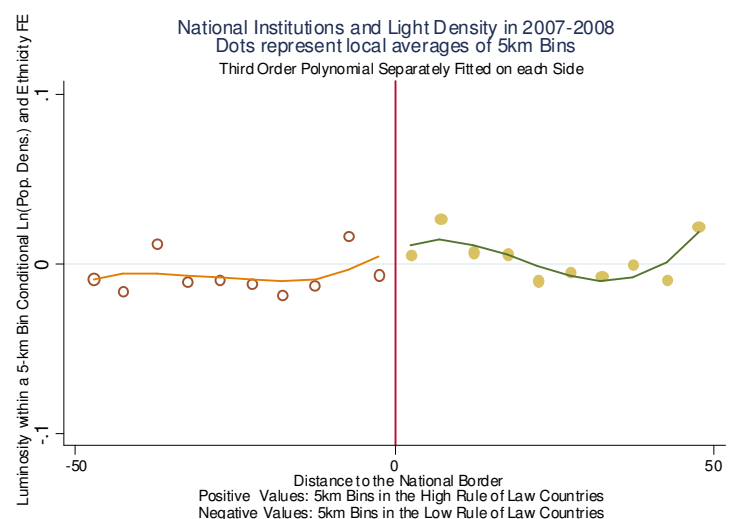

Figure 5b

Large Discontinuities In Table 7 we report RD specifications (with a third and fourth-order polynomial in distance to the national border) as well as simple ethnicity fixed effects estimates for the two-major partitions of groups split between countries with large, defined as higher than the median or larger than the $75 t h$ percentile, differences in rule of law or in graft. By focusing on adjacent countries exhibiting substantial differences in national institutions (e.g., Botswana-Zimbabwe, Kenya-Somalia, Ghana-Ivory Coast) we minimize concerns that the insignificance of the estimates is due to measurement error or/and is driven by small differences in national institutions across the border. The estimated coefficients on the two measures of national institutions are quantitatively small (very close to zero) and statistically insignificant across all permutations. 


\subsection{Sensitivity Checks}

We have performed numerous perturbations to investigate the robustness of the lack of systematic association between national institutions and regional development within partitioned African ethnicities. We report and discuss in detail these robustness checks in the on-line Supplementary Appendix (in Section 4). Specifically, we show that the results are similar when: (1) we express luminosity in levels and estimate the specifications with either OLS or Poisson pseudo-maximum likelihood estimator that accounts for the non-linear nature of the luminosity (see Silva and Tenreyro (2006)); (2) we use the alternative institutional quality measures from World Bank's Governance Database; (3) we use the 2007 values of the rule of law or the control of corruption measures; (4) we restrict estimation to ethnic homelands partitioned by straight-line-like borders; (5) we proxy ethnic development with log population density; (6) we account for population clustering near the border, temporary migration, and bleeding of the lights data by excluding areas very close to the border; (7) we drop observations iteratively from the Northern, Southern, Central, Western, or Eastern Africa, respectively; (8) we replace ethnicity fixed effects with border fixed effects; (9) we experiment with a two-dimensional RD polynomial on latitude and longitude (see Dell (2010)); (10) we perform our analysis in a smaller sample of 32 partitioned ethnicities using data from the 2005 Afrobarometer household surveys on public goods provision and education as the dependent variable.

\section{Heterogeneity}

Our estimates so far summarize the average effect of national institutions on development across all split ethnicities; conducting the analysis for the universe of split groups is useful as it accounts for idiosyncratic features both across specific borders and across ethnicities. Moreover, studying the link between national institutions and ethnic development across all partitioned homelands makes the estimates less prone to "external validity" concerns that characterize case-study evidence. Nevertheless, the richness of the quasi-natural experiment of ethnic partitioning in Africa allows us to estimate the role of national institutions separately for each split group. Doing so will help reveal whether the weak correlation between national institutions and subnational development within groups reflects a generalized phenomenon or conceals considerable heterogeneity. Finding the latter will set stage for exploring the factors that give rise to the observed pattern.

As a first step of moving beyond average effects, we repeated our estimation for groups split within each of the main African regions (using Nunn's (2008) classification). The results (reproduced in Appendix Table 16) suggest that the relationship between national institutions 
and ethnic development varies across African regions. On average for (28) groups split within countries in Southern Africa those partitions belonging to the more institutionally developed nations are more economically developed. However, the opposite is true when we focus within North Africa (though the number of split groups is quite small). In Eastern and Western Africa differences in national institutions have no bearing on the within-ethnicity economic performance, while in Central Africa there is some evidence of a significantly positive association.

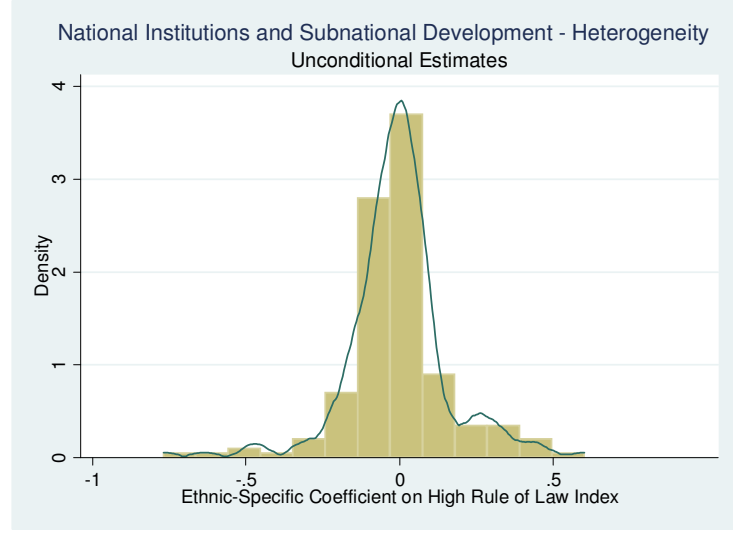

Figure 6a

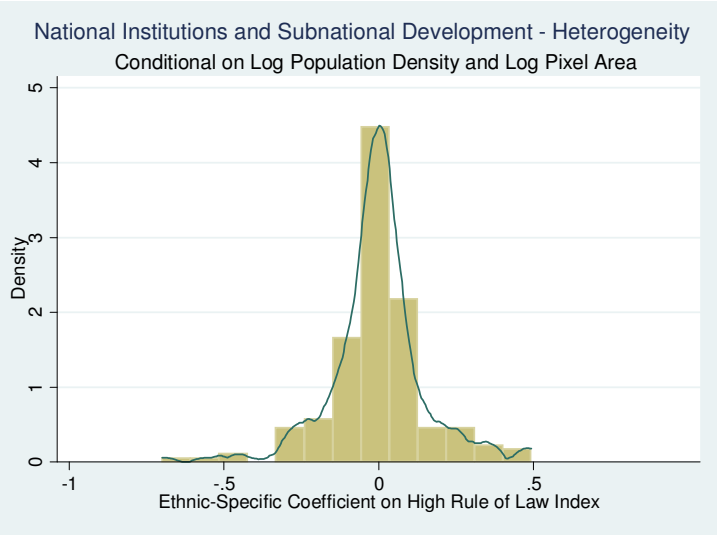

Figure 6b

Perhaps more importantly, we estimate the correlation between national institutions and pixel-level development separately for each split group. Figure $6 a$ reports the distribution of the unconditional estimates on the high rule of law binary index; this is similar to a simple test of means of the likelihood that a pixel is lit on the two sides of the border. Figure $6 b$ plots the distribution of the estimate when we condition on log population density and log pixel area. ${ }^{14}$ (The results are similar when we include additional controls or/and RD polynomials.)

A couple of interesting patterns emerge. First, both the average and the median value of the ethnic-specific estimates are zero; this applies both to the unconditional and to the conditional coefficients. Moreover, the mass of the distribution is centered on zero. Not only the coefficient is small, but for about 120 groups (62.5\%) the absolute value of the $t$-statistic in the conditional estimates is less than 1.60, implying statistically insignificant patterns.

Second, better national institutions translate into a significantly higher regional development for approximately 38 cases (around $20 \%$ of the sample). The Ambo, depicted in Figure $2 b$, is one such example. Other examples where differences in rule of law translate into increased luminosity include the Thonga (split by the border of South Africa and Mozambique),

\footnotetext{
${ }^{14}$ The histogram plots 190 ethnic-specific coefficients. This is because for 30 ethnicities, all pixels on both sides of the border are unlit (hence the role of national institutions cannot be estimated). Examples of ethnicities with zero luminosity on both sides of the border include the Mundu (split by the Sudan-Zaire border), the Koma and the Suro (split by the Ethiopian-Sudan border), and the Karamojong (split between Kenya and Uganda).
} 
the Seke (split between Gabon and Equatorial Guinea), and the Tukulor (split by the SenegalMauritania border).

Third, in approximately $30-34$ cases the coefficient for the high institutional quality country is significant, but with the "wrong" sign; so in roughly $17 \%$ of the sample of partitioned groups, we obtain the counter-intuitive pattern of within-ethnicity development being higher in the country with the relatively worse national institutions. For example, in the homeland of the Anyi in Ivory Coast (rule of law index -1.25) $60 \%$ of populated pixels (132) are lit, while in the more institutionally advanced Ghana (rule of law index -0.23 ), only $30 \%$ of all (89) populated pixels are lit (see Figure $2 c){ }^{15}$

Overall, the uncovered heterogeneity provides a useful reminder that extrapolating from the findings of an analysis that focuses on a single border discontinuity can be quite misleading. At the same time it raises the question about the determinants of the observed variation.

\section{Penetration of National Institutions}

In this section we link the heterogeneous relationship between national institutions and subnational development with the limited reach of African governments in areas far from the capital. First, we discuss the argument of the African historiography on the limited presence of the colonial and national governments in the hinterland. Second, we estimate the baseline empirical model (equation (2)) linking national institutions to development separately for pixels close to and far from the respective capitals. Third, we explore the interaction between capital distance and national institutions in shaping regional development for all African ethnic homelands. Fourth, we test the conjecture regarding the limited reach of the state in remote areas using direct proxies of law enforcement at the regional level.

\subsection{The Argument}

Europeans' presence in Africa was (with some exceptions) limited to the coastline and the capital cities (see Herbst (2000) for a summary). Hence, colonial institutional arrangements, reflected through persistence on today's national institutions, would have limited reach far from the capital cities. Similarly, several African scholars have argued that due to the lack of infrastructure (roads, transportation systems) and the unfavorable geography (desert areas, rugged terrains, rainforests), colonial and post-colonial institutions have minimal impact on the hinterland (Mamdani (1996)). Herbst (2000), for example, reproduces a quote of a senior official

\footnotetext{
${ }^{15}$ One possible interpretation for this finding may be related to the observation that law enforcement declines further from the capital city (see Section 6 below). This implies that in order to benefit from well-functioning institutions economic activity may relocate closer to the capital producing, in some instances the counter-intuitive negative relationship between national institutions and economic development at the border.
} 
in Central African Republic saying that "the State stops at PK 12, twelve kilometers from the capital, Bangui." In his influential work Bates (1983) argues that African national leaders did not even try to extend state's power in the countryside, focusing instead on consolidating power in the capital and the few large urban centers.

Moreover, the Scramble for Africa resulted in many countries having peculiar shapes, further inhibiting the presence of national governments in remote areas (Herbst (2000), Englebert (2009)). For example, the Casamance region in Southern Senegal (where the partitioned Diola-Jola reside) is isolated from Dakar, as Gambia effectively cuts Senegal into two parts. Likewise, the rainforest of Central Africa limits the presence of the government of the Democratic Republic of Congo in the Eastern provinces of North and South Kivu, located hundreds of miles away from Kinshasa. The latter are quite often ruled by local militias and rebel groups.

Furthermore, Europeans mostly ruled from the capitals that were located close to the coast, as colonizers had little interest in settling the hinterland that was controlled with the assistance of local chiefs. Herbst (2000; pp. 16) notes that "rather systematically, Europeans created capitals that moved power toward the ocean and away from the interior centers of power that Africans had slowly created". He lists many examples where colonizers decided to ignore local needs and established capital cities outside preexisting polities. As extreme examples he lists Mauritania and Bechuanaland (Botswana) that were ruled during colonization by capitals outside their nominal territories (Saint-Louis and Mafeking, respectively). ${ }^{16}$

\subsection{National Institutions and Proximity to the Capital. Evidence from Par- titioned Ethnicities}

Baseline Estimates The key hypothesis that emerges from this narrative is that colonial and contemporary national institutions are less likely to be influential in areas far from the capital centers. Yet in the vicinity of the latter, national institutions are likely to be important. In this section we formally explore this conjecture. In Table 8 in odd-numbered columns we estimate the baseline ethnicity-fixed-effects specification for pixels of split groups that are close to the capitals; in even-numbered columns we examine the within-ethnicity association between national institutions and development across pixels that are far from the capital city.

Panel $A$ reports results using all pixels, while Panel $B$ gives local linear regression estimates restricting estimation to pixels within 50 kilometers from each side of the border. In columns (1)-(4) we use as a cutoff the median distance to the capital across all pixels (367.4 kilometers). The estimates on the rule of law and the control of corruption measures in columns (1) and (3) are positive (0.07 and 0.12), considerably larger than the baseline estimates in the

\footnotetext{
${ }^{16}$ Moving the location of the capital was a key question for African leaders at independence. Yet with a few exceptions (Tanzania, Malawi, and Nigeria), most countries did not relocate them.
} 
full sample of split ethnicities (where the estimate was around 0.03 for both measures; see table 4). The coefficient on the control of corruption index is significant at standard confidence levels, while the estimate on the rule of law index is weakly insignificant ( $p$-value 0.15 ). In contrast, when we focus on pixels that are far from the respective capital city on both sides of the national border, the coefficients on the rule of law and the control of corruption index in columns (2) and (4) become much smaller (0.02 - 0.03); both estimates are statistically indistinguishable from zero.

In columns (5)-(8) we use the median relative distance to the capital within each country to distinguish between pixels that are relatively close and relatively far from the capital. ${ }^{17}$ The estimates in columns (5) and (7) on the two proxies of national institutions are positive $(0.105$ and 0.146$)$ and statistically significant, suggesting that better functioning national institutions translate into a higher development within partitioned ethnic homelands, but only when we look at pixels that are relatively close to the respective capital cities. In contrast, the small $(0.01-0.02)$ and statistically insignificant estimates on national institutions in columns (6) and (8) suggest that within partitioned groups for pixels that are relatively far from the capital on both sides of the border there seems to be no association between institutional quality and subnational development. The coefficient in column (7) implies that for pixels of partitioned ethnic homelands that are relatively close to the respective capitals, a one-standard-deviation increase in the control of corruption index (approximately 0.5) increases the probability that a pixel is lit by approximately $7 \%$ (more than half of the average likelihood that a pixel is lit; see Table 1).

A couple of examples help to illustrate these results. Both partitions of the Fon, a group split between Benin and Togo, are close to the corresponding capitals (on average pixels are 100 kilometers away from Porto-Novo and Lome, respectively). Luminosity in the Fon-land in Benin, where the rule of law index equals -0.43 , is on average $53.8 \%$, while luminosity is $24 \%$ in the less institutionally developed Togo, where the rule of law index equals -0.94 . Another example is the Chaga, split by the Tanzanian-Kenyan border; all pixels in both sides of the border are close to Nairobi and Dodoma. 37.5\% of populated pixels of the Chaga in Tanzania are lit (rule of law index equals -0.45 ) while luminosity at the Kenyan side of the border is significantly lower with only $22.8 \%$ of pixels being lit (rule of law index in Kenya is -1.02). Another interesting case is the Ronga, a Shona group split between Mozambique (rule

\footnotetext{
${ }^{17}$ To derive the relative distance within-country we divide pixel-level capital distance by the maximum distance to the capital in each country. This standardization is motivated by the fact that African states are of different land mass (ranging from small ones like Burundi and Benin to very large ones, such as Sudan, Angola, and the Democratic Republic of Congo). Another benefit of using relative (as compared to absolute) distance is that we mitigate concerns that our estimates are driven by large countries which naturally have larger values in absolute capital distance.
} 
of law equals -0.745) and South Africa (rule of law index equals 0.156). Ronga's homeland in Mozambique's has $41.5 \%$ of its pixels lit. Incidentally the capital Maputo falls within its boundaries hence all pixels are classified as close. Yet, in the more institutionally advanced South Africa $64 \%$ of the pixels in the Ronga partition that are close to Pretoria are lit.

It is instructive to put the magnitudes of the coefficients in perspective and obtain a welfare assessment in terms of the affected population. Across African countries (as of 2000) there were roughly 200 million people that reside in the homelands of partitioned ethnicities. Of those 200 million individuals, $45 \%$ live relatively far from the respective capitals with the remaining $55 \%$ reside relatively close to the capitals, where national institutions seem to have a bearing on regional economic performance.

RD Visualization Figures $7 a-7 b$ provide a graphical illustration of the differential association between national institutions and regional development within partitioned groups for pixels that are relatively close (on both sides of the border) and pixels that are relatively far from the capital city (on both sides of the border), respectively.

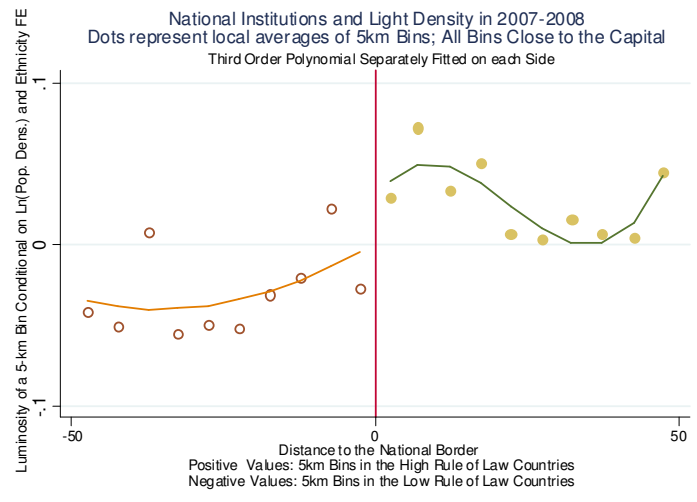

Figure $\mathbf{7 a}$

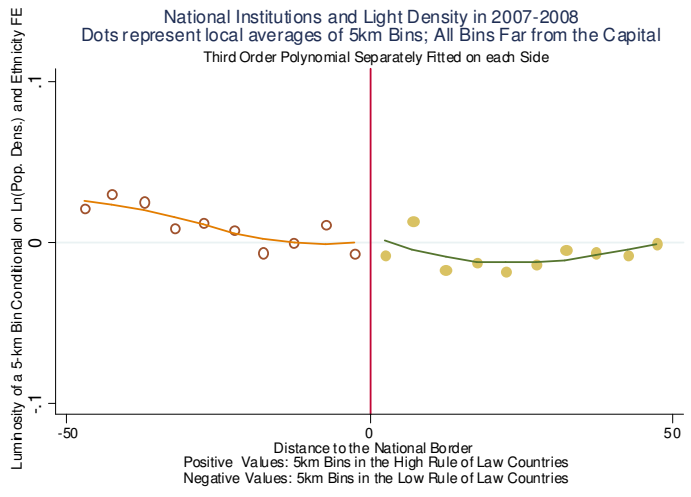

Figure $\mathbf{7 b}$

The Figures plot the average likelihood that pixels within 5 kilometer bins are lit, conditional on log population density and log land area; the Figures also plot predicted luminosity using cubic $\mathrm{RD}$ polynomials on distance to the border. When we focus on pixels of partitioned ethnicities that are relatively close to the respective capitals on both sides of the border (Figure $7 a$ ), pixel-level luminosity at the side of the border with the better-functioning national institutions is significantly higher. In contrast, when we zoom in on pixels that are relatively far from the respective capital cities (Figure $7 b$ ), there are no differences in luminosity, in spite of differences in national institutions.

Robustness In the Supplementary Appendix (in Section 5) we report several sensitivity checks showing that regional development is significantly higher in the part of split 
homelands falling in the country with better functioning institutions, but only for pixels that are (relatively) close the capital. Specifically, this pattern obtains when: (1) we use information from all split groups by pooling all pixels (40,209 observations) and interact the national institutions measures (as well as all controls) with a dummy variable indicating pixels that are close (or relatively close) to the respective capital; (2) we drop iteratively each of the five main African regions; (3) we proxy national institutions with the alternative composite measures of World Bank's Governance Database; (4) following Acemoglu and Johnson (2005) we proxy "property rights" institutions with Polity's Project executive constraints measure or we proxy "contractual" institutions with the legal formalism indicators of Djankov, La Porta, Lopez-deSilanes, and Shleifer (2003); and (5) we use proxies of "early" political institutions (at African independence).

\subsection{Evidence from All Groups}

In principle, the conjecture of the African historiography that the role of national institutions dissipates as one moves further from the capital regards the universe of ethnic homelands. In Table 9 we augment the baseline model (equation (2)) with the (absolute or relative) distance of each pixel to the capital city and an interaction term between distance to the capital and national institutions.

In columns (1) and (4) we report cross-sectional specifications. Due to omitted variables, reverse causation, and other forms of endogeneity, these specifications do not identify casual relationships; yet these models are useful to quantify the correlation between institutional and economic development at the capital; the estimate in column (4) suggests that a one-pointincrease in the rule of law index increases the likelihood that a pixel at the capital city is lit by approximately 18\%; for comparability the analogous cross-sectional estimate in table 3 was approximately half, 0.095. Moreover, the negative and significant coefficients on both absolute and relative distance to the capital indicate that subnational development declines as one moves further from the capital. Yet the most interesting finding is the significantly negative coefficient on the interaction term between distance to the capital and rule of law; this implies that the correlation between national institutions and regional development declines for regions further from the capital centers.

In columns (2) and (5) we include a vector of country-specific constants as this allows us to account for time-invariant country-level characteristics. The coefficient on distance to the capital and most importantly the coefficient on the interaction term between distance to the capital and the rule of law index remain significant at conventional levels. 


\section{Figure 8a Figure 8b}

Column (3) and (6) report our preferred country-ethnicity fixed effect specifications; estimating these quite restrictive models -that include a vector of 1209 ethnic constants- is feasible as proximity to the capital changes not only across but also within ethnic homelands. As in our baseline estimates in the sample of partitioned ethnic groups (in Tables $4-8$ ), by exploiting solely within ethnic homeland variation, we account for ethnic-specific features, related to either geography or culture; moreover the inclusion of ethnicity fixed effects also account for any relation between pre-colonial ethnic features and the location of the capital by colonizers. ${ }^{18}$ The coefficient on the interaction term between national institutions and regional development continues to enter with a negative sign; moreover, the coefficient is statistically significant at standard confidence levels. Thus, the within-ethnicity results in the full sample of African ethnic homelands are quite similar to the pattern obtained within split ethnicities (shown in Table 8). The statistically negative estimate on the interaction in columns (3) and (6) implies that the decaying role of countrywide institutional structures far from the capitals is a general phenomenon and not an artefact of country-specific and more importantly ethnicspecific differences within countries. Figures $8 a-b$ provide a graphical illustration of how (relative) distance to the capital mediates the within-ethnicity correlation between rule of law and subnational development in the African continent. ${ }^{19}$

\subsection{The Reach of the Law beyond the Capital Cities}

The pattern uncovered in Tables $8-9$ points out that the influence of national institutions on subnational development diminishes in areas further from the capital cities. These findings are consistent with the view of the African historiography that both the colonial and the national state is becoming increasingly absent in remote areas with a concomitant decline in law enforcement. In an attempt to provide direct evidence of the differential state presence in areas far and close to the capital, we used individual-level data from the third round of the Afrobarometer Surveys, conducted in 2005 across a representative sample of either 1,200 or

\footnotetext{
${ }^{18}$ Most African capitals were imposed by the colonial powers with little worry on the post-independence needs of African states (Herbst (2000)). Nevertheless, it is plausible that colonizers or early state-builders may have decided on the location of the capital taking into account pre-existing differences across ethnic groups, placing, for example, the capital closer to groups that cooperated or were more developed. The inclusion of ethnicity fixed-effects, thus, also accounts for this potentiality.

${ }^{19}$ Our finding that the positive correlation between national institutions and regional development weakens as one moves further from the capital cities is also related to the literature on optimal country size (Alesina and Spolaore (2003)) and recent works studying the implications of the location of the capitals on institutional and economic development (Campante and Do (2013) and Campante, Do, and Guimaraes (2013)).
} 


\section{2, 400 respondents in 17 Sub-Saharan countries. ${ }^{20}$}

The Afrobarometer Surveys include two questions closely related to law enforcement. The first question regards law enforcement of a serious crime and reads: "How likely do you think it would be that the authorities could enforce the law if a person like you committed a serious crime?" The second question regards tax evasion and reads: "How likely do you think it would be that the authorities could enforce the law if a person like you did not pay a tax on some of the income you earned?" Both measures range from 1 to 4, with higher scores indicating that law enforcement is more likely.

To examine whether perceived law enforcement decays in remote areas, we regressed these two proxies on (absolute and relative) distance to the capital. In columns (1)-(8) in Table 10 we report the results. In all specifications we exploit within-country variation including a vector of country fixed effects. Odd-numbered columns report unconditional estimates, while in evennumbered columns we include a rich set of individual controls. ${ }^{21}$ The coefficient on absolute distance to the capital (in (1), (2), (5), and (6)) is negative and significant, suggesting that the likelihood of law enforcement declines for respondents residing further from the capital city. The same pattern applies when we use relative distance to the capital (in columns (3), (4), (7), and (8)). Individuals located in enumeration areas (villages/towns/cities) relatively further from the respective capitals answer that it is less likely for the law to be enforced. These results clearly indicate a declining presence of authorities in the hinterland.

The specifications reported in columns (9)-(12) provide auxiliary evidence on the declining presence of the state in areas far from the capital using survey data on individual's selfidentification. In these linear probability models the dependent variable is a dummy equal to one if the respondent identifies either exclusively or predominantly with the nation rather than his/her ethnic group. Across all specifications both absolute and relative distance enter negatively implying that in areas far from the capital people are more likely to identify with their ethnicity, as compared to the state. ${ }^{22}$

It should be acknowledged that systematic measurement error in the institutional quality proxies may also explain the weakening correlation between rule of law and regional development in areas far from the capital. Since most institutional variables are measured in the

\footnotetext{
${ }^{20}$ These countries are: Benin, Botswana, Ghana, Kenya, Lesotho, Madagascar, Malawi, Mali, Mozambique, Namibia, Nigeria, Senegal, South Africa, Tanzania, Uganda, Zambia and Zimbabwe. The question on national versus ethnic identification was not asked in Zimbabwe. The 3rd round of the Afrobarometer Surveys were also conducted in Cape Verde; yet we do not have answers to these questions.

${ }^{21}$ Following Nunn and Wantchekon (2011) in even numbered columns we control for the respondent's age and age squared, a gender indicator, a dummy variable for urban households, 22 religion fixed effects, 25 occupational fixed effects, 5 living conditions fixed effects, and 9 education constants.

${ }^{22}$ In Supplementary Appendix 23 we show that a similar pattern emerges when we use as outcomes an index capturing how easy it is to obtain identity documents or basic household services (like electrification, piped water, and sewage system) from the government.
} 
capital cities capturing the rules governing activities of the formal economy, they might not reflect accurately the institutional features in rural areas (Pande and Udry (2006)). Yet the evidence uncovered in Table 10 clearly indicates that law enforcement and state presence more generally decline with distance to the capital centers.

\section{Conclusion}

We study the role of national institutions in shaping regional development captured by satellite images on light density at night by employing a novel approach that accounts both for (un)observed geographical-ecological features and ethnic-specific (cultural, historical) factors. We take advantage of the fact that the arbitrarily drawn colonial borders that endured after African independence partitioned several ethnic groups in different countries, subjecting identical cultures residing in geographically homogeneous territories to different country-level institutions.

We present four sets of results. First, our analysis documents that -in contrast to previous cross-sectional works- differences in economic performance within ethnicities partitioned between neighboring countries cannot be explained by differences in national institutions. The lack of within-ethnicity association between formal institutions and subnational development casts doubt on the causal interpretation of the cross-sectional strong correlation, for Africa at least. This finding, nevertheless, is in line with studies of the African historiography that downplays the role of national institutional structures stressing instead the key role of ethnic-specific traits, related to the role of chiefs, culture, and pre-colonial organization (see Michalopoulos and Papaioannou (2013b) for a literature review). Moreover, our results are in accord with a growing body of research that emphasizes the persistent effect of geographical features, cultural and ethnic norms, epidemiological traits as well as history on long-run comparative development (see Spolaore and Wacziarg (2013) and Nunn (2013) for reviews).

Second, we move beyond average effects by examining the association between national institutions and regional development for each partitioned group in Africa. The analysis reveals considerable heterogeneity. Third, in an effort to shed light on the factors shaping heterogeneity and motivated by studies in the African historiography that emphasize the inability of many African governments to broadcast power outside the capitals (Herbst (2000)), we find that unlike split groups in the hinterland, differences in national institutions map into within-ethnicity differences in luminosity for those located close to the respective capitals. This phenomenon is not specific to split groups. In fact, it reflects a generalized pattern. Looking at the universe of African groups reveals that the explanatory power of national institutions monotonically declines with distance to the capital city. Fourth, we use individual-level data from the 
Afrobarometer Surveys and show that law enforcement decays with distance to the capital. Moreover, ethnic (as opposed to national) identification becomes stronger for individuals in the hinterland.

These correlations vividly illustrate the limited penetration of the state in remote areas, suggesting -that at least within Africa- treating countries as homogeneous entities where nationwide characteristics, in our case the quality of national institutions, exert a uniform influence across regions may be quite misleading. In fact, the uncovered patterns are supportive to an old idea among development scholars (e.g., Lewis (1954)) on the coexistence in Africa (and other parts of the developing world) of a "dual" economic-institutional framework with customary rules being dominant in the countryside and colonial-national institutions becoming relevant for regions closer to the capitals (see also Herbst (2000)).

Our paper calls for future research. One could employ our methodology that compares well-being in border areas using high resolution proxies of development (such as satellite light density) to shed light on the debate regarding the determinants (correlates) of comparative economic development; examining, for example, the effect of financial development, public policies, foreign aid, fragmentation, etc. Moreover, subsequent works could build on our analysis regarding the declining role of national institutions in areas far from the capital and explore the impact of other geographic, cultural, national or ethnic-specific features that may attenuate or strengthen the importance of national policies in promoting subnational development. Finally, our evidence suggests that research on the role of institutions on development should move beyond average effects and examine the delicate interplay between formal institutions, state capacity, and ethnic traits. 


\section{Data Appendix}

Light Density at Night: Light Density is calculated averaging light density observations across pixels that fall within the unit of analysis. We use the average of the values in 2007 and 2008. In the regressions at the ethnic homeland we use Log (0.01 + Average Luminosity). In the Supplementary Appendix we also use the level of luminosity as the dependent variable. In the regressions at the pixel level we use as the dependent variable a dummy variable that takes on the value of one if the area is lit and zero otherwise.

Source: Available at http://www.ngdc.noaa.gov/dmsp/global_composites_v2.html.

Population Density: Log (population density per sq. km. in 2000). Source: Nelson, Andy, 2004. African Population Database Documentation, UNEP GRID Sioux Falls. Available at: http://na.unep.net/siouxfalls/datasets/datalist.php

Area: Log (land area) at the country-ethnic homeland level or at the pixel level. Please note that while most pixels are of the same surface area (2.5x2.5 degrees), pixels intersected by the coastline, borders, and lakes are smaller.

Water Area: In the regressions at the country-ethnicity level we use the Log $(1+$ total area covered by rivers or lakes in sq. $\mathrm{km}$.). In the regressions at the pixel level we use a dummy variable that takes on the value of one when some water body (river, lake, or other stream) falls in each pixel and zero otherwise. Source: Constructed using the "Inland water area features" dataset from Global Mapping International, Colorado Springs, CO, USA. Global Ministry Mapping System.

Elevation: Average elevation in $\mathrm{km}$ of each ethnicity-country or each pixel. Source: National Oceanic and Atmospheric Administration (NOAA) and U.S. National Geophysical Data Center, TerrainBase, release 1.0 (CD-ROM), Boulder, Colorado. http://www.sage.wisc.edu/atlas/data.php?incdataset=Topography

Land Suitability for Agriculture: Average land quality for cultivation within each country-ethnicity homeland or within each pixel. The index is the product of two components capturing the climatic and soil suitability for farming. Source: Michalopoulos (2012); Original Source: Atlas of the Biosphere.

Available at http://www.sage.wisc.edu/iamdata/grid_data_sel.php.

Malaria Stability Index: Average prevalence of malaria within each ethnicity-country or within each pixel. The index takes into account the prevalence and type of mosquitoes indigenous to a region, their human biting rate, their daily survival rate, and their incubation period. Source: Kiszewski, Mellinger, Spielman, Malaney, Sachs, and Sachs (2004)

Distance to the Capital City: The geodesic distance from the centroid of each ethnicity-country/pixel to the capital city of the country it belongs to, measured in $1000 \mathrm{~s}$ 
of km's. Source: Calculated using the Haversine formula.

Relative Distance to the Capital City: Distance to the Capital City divided by the maximum distance to the capital in the same country.

Distance to the Sea Coast: The geodesic distance to the nearest coastline from the centroid of each ethnicity-country/pixel, measured in 1000s of km's. Source: Global Mapping International, Colorado Springs, Colorado, USA. Series name: Global Ministry Mapping System. Series issue: Version 3.0

Distance to the National Border: The geodesic distance to the nearest national border from the centroid of each ethnicity-country/pixel, measured in 1000s of km's. Source: Calculated using ArcGis.

Petroleum: Indicator variable that equals one if an oil field is found in the region (or pixel) of ethnic group $i$ in country c. Source: The Petroleum Dataset v.1.1 contains information on all known on-shore oil and gas deposits throughout the world.

http://www.prio.no/CSCW/Datasets/Geographical-and-Resource/Petroleum-Dataset/PetroleumDataset-v11/

Diamond: Indicator variable that takes on the value of one if a diamond mine is found in the region (or pixel) of ethnic group $i$ in country c. Source: Map of Diamond Resources. www.prio.no/CSCW/Datasets/Geographical-and-Resource/Diamond-Resources/

Rule of Law: The index is "capturing perceptions of the extent to which agents have confidence in and abide by the rules of society, and in particular the quality of contract enforcement, property rights, the police, and the courts, as well as the likelihood of crime and violence." The standardized index ranges from -2.5 to +2.5 with higher values indicating better functioning institutions. We use the average value over the period $1996-2006$. In the regression discontinuity $(\mathrm{RD})$ analysis we also define a dummy (indicator) variable that takes on the value one pixels falling in the country with the higher level of the rule of law index. Source: World Bank Governance Matters Indicators Database (Kaufmann, Kraay, and Mastruzzi (2008)). available at: http://info.worldbank.org/governance/wgi/index.asp.

Control of Corruption: Index on the control of corruption "capturing perceptions of the extent to which public power is exercised for private gain, including both petty and grand forms of corruption, as well as capture of the state by elites and private interests." The standardized index ranges from -2.5 to +2.5 with lower values indicating a higher degree of corruption. We use the average value over the period 1996-2006. In the regression discontinuity (RD) analysis we also define a dummy (indicator) variable that takes on the value one for pixels falling in the country with the higher level of the control of corruption index. Source: World 
Bank Governance Matters Indicators Database (Kaufmann, Kraay, and Mastruzzi (2008)). available at:

http://info.worldbank.org/governance/wgi/index.asp.

Law Enforcement 1: Ordered (range 1-4) variable capturing law enforcement regarding committing a serious crime based on individuals' responses to the following question: "How likely do you think it would be that the authorities could enforce the law if a person like you committed a serious crime?" A score of 1 indicates "not at all likely"; a score of 2 suggests "not very likely"; a score of 3 indicates "likely"; and a score of 4 indicates "very likely". Source: Afrobarometer Surveys. 3rd Round. Question Number: Q70B. available at: http://www.afrobarometer.org/data/round-3-merged

Law Enforcement 2: Ordered (range 1-4) variable capturing law enforcement regarding tax evasion based on individuals' responses to the following question: "How likely do you think it would be that the authorities could enforce the law if a person like you did not pay a tax on some of the income you earned?" A score of 1 indicates "not at all likely"; a score of 2 suggests "not very likely"; a score of 3 indicates "likely"; and a score of 4 indicates "very likely". Source: Afrobarometer Surveys. 3rd Round. Question Number: Q70D. available at: http://www.afrobarometer.org/data/round-3-merged

National Identification: Dummy variable that takes on the value of one if the respondent replies that he or she identifies more strongly with the nation rather than his/her ethnicity. The question reads: "Let us suppose that you had to choose between being a [Ghanaian/Kenyan/etc.] and being $\ldots_{\ldots} \ldots \ldots \ldots \ldots \ldots$ [respondent's identity group]. Which of these two groups do you feel most strongly attached to?" The variable equals one if the respondent replies that he identifies solely or predominantly with his nation and zero otherwise. Source: Afrobarometer Surveys. 3rd Round. Question Q82. available at: http://www.afrobarometer.org/data/round-3-merged 


\section{References}

Acemoglu, D., and S. Johnson (2005): "Unbundling Institutions," Journal of Political Economy, 113(5), 949-995.

Acemoglu, D., S. Johnson, And J. A. Robinson (2001): "The Colonial Origins of Comparative Development: An Empirical Investigation," American Economic Review, 91(5), $1369-1401$.

- (2002): "Reversal of Fortune: Geography and Institutions in the Making of the Modern World Income Distribution," Quarterly Journal of Economics, 107(4), 1231-1294.

- (2005): "Institutions as a Fundamental Cause of Long-Run Growth," in Handbook of Economic Growth, ed. by P. Aghion, and S. N. Durlauf, pp. 109-139. Elsevier North-Holland, Amsterdam, The Netherlands.

Alesina, A., A. Devleeschauwer, W. Easterly, S. Kurlat, and R. Wacziarg (2003): "Fractionalization," Journal of Economic Growth, 8(2), 155-194.

Alesina, A., W. Easterly, and J. Matuszeski (2011): "Artificial States," Journal of the European Economic Association, 9(2), 246-277.

Alesina, A., and P. Giuliano (2013): "Family Ties," in Handbook of Economic Growth, Volume 2, ed. by P. Aghion, and S. Durlauf, vol. 2. Elsevier, Amsterdam, Netherlands.

Alesina, A., S. Michalopoulos, and E. Papaionnnou (2013): "Ethnic Inequality," Working Paper, NBER No. 18512.

Alesina, A., and E. Spolaore (2003): The Size of Nations. MIT Press.

Algan, Y., And P. Cahuc (2013): "Trust, Institutions and Economic Development," in Handbook of Economic Growth, Volume 2, ed. by P. Aghion, and S. Durlauf, vol. 2. Elsevier, Amsterdam, Netherlands.

Alsan, M. M. (2012): "The Effect of the TseTse Fly on African Developmen," manuscript, Harvard University.

Angrist, J., and V. C. Lavy (2002): "New Evidence on Classroom Computers and Pupil Learning," Economic Journal, 112(482), 735-765.

Angrist, J., And J.-S. Pischke (2008): Mostly Harmless Econometrics. Princeton University Press, Princeton, NJ. 
Ashraf, Q., and O. Galor (2013): "The Out of Africa Hypothesis, Human Genetic Diversity, and Comparative Economic Development," American Economic Review, 103(1), 1-46.

Asiwaju, A. (1985): "The Conceptual Framework," in Partitioned Africans, pp. 1-18. St. Martin Press, New York.

Banerjee, A., and L. Iyer (2005): "History, Institutions, and Economic Performance: The Legacy of Colonial Land Tenure Systems in India," American Economic Review, 95, 11901213.

Bates, R. H. (1983): "Modernization, Ethnic Competition, and the Rationality of Politics in Contemporary Africa," in State versus Ethnic Claims: African Policy Dilemmas, ed. by D. Rothchild, and V. A. Olunsorola. Westview Press, Boulder, CO.

- (2008): When Things Fell Apart. State Failure in Late-Century Africa. Cambridge University Press, New York, NY.

Bubb, R. (2012): "States, Law, and Property Rights in West Africa," Working Paper, New York University School of Law.

Cameron, C. A., J. Gelbach, and D. Miller (2011): "Robust Inference with Multi-Way Clustering," Journal of Business and Economic Statistics, 28(2), 238-249.

Campante, F., and Q.-A. Do (2013): "Isolated Capital Cities, Accountability, and Corruption: Evidence from US States," mimeo, Harvard Kennedy School.

Campante, F., Q.-A. Do, and B. Guimaraes (2013): "Isolated Capital Cities and Misgovernance: Theory and Evidence," mimeo, Harvard Kennedy School.

Chen, X., and W. D. Nordhaus (2011): "Using Luminosity Data as a Proxy for Economic Statistics," Proceeedings of the National Academy of Sciences, 108(21), 8589-8594.

Cogneau, D., S. Mesplé-Somps, and G. Spielvogel (2012): "Development at the Border: A Study of National Integration in Post-colonial West Africa," mimeo, Paris Scool of Economics.

Cogneau, D., and A. Moradi (2011): "Borders that Divide: Education and Religion in Ghana and Togo since Colonial Times," Department of Economics, University of Sussex Working Paper 2911.

Conley, T. G. (1999): "GMM Estimation with Cross Sectional Dependence," Journal of Econometrics, 92(1), 1-45. 
Davidson, B. (1992): The Black Man's Burden. Africa and the Curse of the Nation-State. James Currey, Oxford, United Kingdom.

De Long, B., And A. Shleifer (1993): "Princes or Merchants? City Growth before the Industrial Revolution," Journal of Law and Economics, 36(2), 671-702.

Dell, M. (2010): “The Persistent Effects of Peru's Mining Mita," Econometrica, 78(6), 839857.

Diamond, J. (1997): Guns, Germs, and Steel. The Fates of Human Societies. W.W. Norton and Co, New York, NY.

Djankov, S., R. La Porta, F. Lopez-De-Silanes, and A. Shleifer (2003): "Courts," Quarterly Journal of Economics, 118(2), 453-517.

Doll, C. N., J.-P. Muller, and J. G. Morley (2006): "Mapping Regional Economic Activity from Night-Time Light Satellite Imagery," Ecological Economics, 57(1), 75-92.

Dowden, R. (2008): Africa: Altered States, Ordinary Miracles. Portobello Books Ltd, London, UK.

Easterly, W., and R. Levine (1997): "Africa's Growth Tragedy: Policies and Ethnic Divisions," Quarterly Journal of Economics, 112(4), 1203-1250.

Elvidge, C., K. Baugh, E. Kinn, H. Kroenl, and E. Davis (1997): "Mapping of City Lights Using DMSP Operational Linescan System data," Photogrammetric Engineering and Remote Sensing, 63, 727-734.

Englebert, P. (2009): Africa, Unity, Sovereignty and Sorrow. Lynne Rienner Publishers, Inc., Boulder, Colorado.

Englebert, P., S. Tarango, and M. Carter (2002): "Dismemberment and Suffocation: A Contribution to the Debate on African Boundaries," Comparative Political Studies, 35(10), 1093-1118.

Gallup, J. L., And J. D. Sachs (2001): "The Economic Burden of Malaria," The American Journal of Tropical Medicine and Hygiene, 64(1), 85-96.

Gennaioli, N., R. La Porta, F. Lopez-De-Silanes, and A. Shleifer (2013): "Human Capital and Regional Development," Quarterly Journal of Economics, 128(1), 105-164. 
Gennaioli, N., and I. Rainer (2006): "Precolonial Centralization and Institutional Quality in Africa," in Institutions and Norms in Economic Development, ed. by M. Gradstein, and K. Konrad. MIT Press.

(2007): "The Modern Impact of Precolonial Centralization in Africa," Journal of Economic Growth, 12(3), 185-234.

Glaeser, E. L., R. La Porta, F. L. De Silanes, and A. Shleifer (2004): "Do Institutions Cause Growth?," Journal of Economic Growth, 9(3), 271-303.

Glennerster, R., E. Miguel, and A. Rothenberg (2013): "Collective Action in Diverse Sierra Leone Communities," Economic Journal, 123(568), 285-316.

Grosjean, P. (2011): "Long Term Institutional Persistence: Ottoman Rule and Financial Development in the Regions of Europe," Journal of Comparative Economics, 39(2), 1-16.

Guiso, L., P. Sapienza, and L. Zingales (2006): "Does Culture Affect Economic Outcomes?," Journal of Economic Perspectives, 20(2), 23-48.

Henderson, V. J., A. Storeygard, and D. N. Weil (2012): "Measuring Economic Growth from Outer Space," American Economic Review, 102(2), 994-1028.

Herbst, J. (2000): States and Power in Africa. Princeton University Press, Princeton, NJ.

Huillery, E. (2009): "History Matters: The Long Term Impact of Colonial Public Investments in French West Africa," American Economic Journal - Applied Economics, 1(2), 176-215.

Imbens, G. W., and T. Lemieux (2008): "Regression Discontinuity Designs: A Guide to Practice," Journal of Econometrics, 142(2), 615-635.

IYER, L. (2010): "Direct versus Indirect Colonial Rule in India: Long-term Consequences," Review of Economics and Statistics, 92(4), 693-713.

Jedwab, R., And A. Moradi (2012): "Colonial Investments and Long-Term Development in Africa: Evidence from Ghanaian Railways," mimeo George Washington University and Sussex University.

Jerven, M. (2013): Poor Numbers: How We Are Misled by African Development Statistics and What to Do about It. Cornell University Press, Ithaca, NY.

Kaufmann, D., A. Kraay, and M. Mastruzzi (2008): "Governance Matters VIII: Aggregate and Individual Governance Indicators, 1996-2007," Policy Research Working Paper Series 4654, The World Bank. 
Kiszewski, A., A. Mellinger, A. Spielman, P. Malaney, S. E. Sachs, and J. Sachs (2004): "A Global Index of the Stability of Malaria Transmission," American Journal of Tropical Medicine and Hygiene, 70(5), 486-498.

La Porta, R., F. Lopez-De-Silanes, and A. Shleifer (2008): "The Economic Consequences of Legal Origins," Journal of Economic Literature, 46(2), 285-332.

La Porta, R., F. Lopez-de-Silanes, A. Shleifer, and R. Vishny (1997): "Legal Determinants of External Finance," Journal of Finance, 52(3), 1131-1150.

_ (1998): "Law and Finance," Journal of Political Economy, 106(6), 1113-1155.

Laeven, L., and C. Woodruff (2007): "The Quality of the Legal System, Firm Ownership, and Firm Size," Review of Economics and Statistics, 89(4), 601-614.

Landes, D. S. (1998): The Wealth and Poverty of Nations: Why Some Are So Rich and Some So Poor. W.W. Norton, New York, NY.

Lee, D. S., And T. Lemieux (2010): "Regression Discontinuity Designs in Economics," Journal of Economic Literature, 48(2), 281-355.

Lee, D. S., E. Moretti, And M. J. Butler (2004): "Do Voters Affect Or Elect Policies? Evidence from the U. S. House," The Quarterly Journal of Economics, 119(3), 807-859.

Lewis, A. W. (1954): "Economic Development with Unlimited Supplies of Labour," The Manchester School, 22(1), 139-191.

Mamdani, M. (1996): Citizen and Subject. James Currey, London, UK.

Michalopoulos, S. (2012): "The Origins of Ethnolinguistic Diversity," American Economic Review, 102(4), 1508-1539.

Michalopoulos, S., A. Naghavi, and G. Prarolo (2012): "Trade and Geography in the Origins and Spread of Islam," NBER Working Paper No. 18438.

Michalopoulos, S., and E. Papaioannou (2011): "Divide and Rule or the Rule of the Divided? Evidence from Africa," NBER Working Paper No. 17184.

(2013a): "The Long-Run Effects of the Scramble for Africa," NBER Working Paper No. 17620 .

(2013b): "On the Ethnic Origins of African Development: Traditional Chiefs and Precolonial Political Centralization," mimeo Brown University and London Business School. 
(2013c): "Pre-colonial Ethnic Institutions and Contemporary African Development," Econometrica, 81(1), 113-152.

Migdal, J. S. (1988): Strong Societies and Weak States: State-Society Relations and State Capabilities in the Third World. Princeton University Press, Pinceton, NJ.

Miguel, E. (2004): "Tribe or Nation? Nation-Building and Public Goods in Kenya versus Tanzania," World Politics, 56(3), 327-362.

Miles, W. F. (1994): Hausaland Divided: Colonialism and Independence in Nigeria and Niger. Cornell University Press, Ithaca and London.

Moulton, B. R. (1990): "An Illustration of a Pitfall in Estimating the Effects of Aggregate Variables in Micro Units," Review of Economics and Statistics, 72(2), 334-338.

Murdock, G. P. (1959): Africa: Its Peoples and their Culture History. McGraw-Hill, New York, NY. (1967): Ethnographic Atlas: A Summary. The University of Pittsburgh Press, Pittsburgh, PA.

Nunn, N. (2012): "Culture and the Historical Process," Economic History of Developing Regions, 27(S1), 108-126.

(2013): "Historical Development," in Handbook of Economic Growth, Volume 2, ed. by P. Aghion, and S. Durlauf, vol. 2. Elsevier, Amsterdam, Netherlands.

Nunn, N., And D. PugA (2012): "Ruggedness: The Blessing of Bad Geography in Africa," Review of Economics and Statistics, 94(1), 20-36.

Nunn, N., And L. Wantchekon (2011): "The Slave Trade and the Origins of Mistrust in Africa," American Economic Review, 101(7), 3221-3252.

Pande, R., And C. UdRY (2006): "Institutions and Development: A View from Below," in Proceedings of the 9th World Congress of the Econometric Society, ed. by R. Blundell, W. Newey, and T. Persson. Cambridge University Press.

Pinkovskiy, M. (2013): "Economic Discontinuities at Borders: Evidence from Satellite Data on Lights at Night," mimeo MIT.

Putterman, L., and D. N. Weil (2010): "Post-1500 Population Flows and the Long-Run Determinants of Economic Growth and Inequality," Quarterly Journal of Economics, 125(4), $1627-1682$. 
Ross, M. L. (2012): The Oil Curse: How Petroleum Wealth Shapes the Development of Nations. Princeton University Press, Princeton, NJ.

Silva, J. M. S., and S. Tenreyro (2006): "The Log of Gravity," Review o Economics and Statistics, 88(4), 641-658.

Spolaore, E., and R. Wacziarg (2009): "The Diffusion of Development," Quarterly Journal of Economics, 124(2), 469-529.

(2013): "How Deep Are the Roots of Economic Development?, Journal of Economic Literature, $51(2)$.

Tabellini, G. (2010): "Culture and Institutions: Economic Development in the Regions of Europe," Journal of the European Economic Association, 8(4), 677-716.

WeIL, D. N. (2008): Economic Growth. Prentice Hall.

Wesseling, H. L. (1996): Divide and Rule: The Partition of Africa, 1880-1914. Praeger, Amsterdam, Netherlands. 
Table 1: Summary Statistics

\begin{tabular}{|c|c|c|c|c|c|c|c|c|}
\hline variable & Obs. & mean & st. dev. & p25 & median & p75 & $\min$ & $\max$ \\
\hline & \multicolumn{8}{|c|}{ Panel A: Partitioned Ethnic Homelands Sample } \\
\hline Light Density & 507 & 0.228 & 0.768 & 0.000 & 0.015 & 0.095 & 0.000 & 8.561 \\
\hline Ln (0.01 + Light Density) & 507 & -3.168 & 1.586 & -4.605 & -3.696 & -2.258 & -4.605 & 2.148 \\
\hline Ln (0.01 + Population Density) & 507 & 2.650 & 1.929 & 1.647 & 2.936 & 3.945 & -5.069 & 6.386 \\
\hline Ln (1 + Water Area) & 507 & 0.242 & 0.407 & 0.000 & 0.075 & 0.264 & 0.000 & 2.464 \\
\hline Ln (Area) & 507 & 1.876 & 1.490 & 0.798 & 1.906 & 2.963 & -2.170 & 5.665 \\
\hline Mean Elevation & 507 & 0.605 & 0.434 & 0.281 & 0.469 & 0.938 & 0.000 & 2.181 \\
\hline Land Suitability For Agriculture & 507 & 0.415 & 0.224 & 0.273 & 0.439 & 0.573 & 0.002 & 0.959 \\
\hline Malaria Stability Index & 507 & 0.747 & 0.323 & 0.548 & 0.905 & 1.000 & 0.000 & 1.000 \\
\hline Oil Deposit Indicator & 507 & 0.063 & 0.243 & 0.000 & 0.000 & 0.000 & 0.000 & 1.000 \\
\hline Diamond Mine Indicator & 507 & 0.101 & 0.301 & 0.000 & 0.000 & 0.000 & 0.000 & 1.000 \\
\hline Distance to the Capital City & 507 & 0.524 & 0.371 & 0.280 & 0.429 & 0.685 & 0.013 & 1.882 \\
\hline Distance to the Sea Coast & 507 & 0.591 & 0.425 & 0.225 & 0.552 & 0.931 & 0.000 & 1.739 \\
\hline Distance to the Border & 507 & 0.039 & 0.039 & 0.012 & 0.029 & 0.052 & 0.000 & 0.250 \\
\hline Rule of Law & 507 & -0.914 & 0.573 & -1.355 & -1.021 & -0.543 & -2.198 & 0.615 \\
\hline \multirow[t]{2}{*}{ Control of Corruption } & 507 & -0.797 & 0.501 & -1.091 & -0.864 & -0.651 & -1.664 & 0.814 \\
\hline & \multicolumn{8}{|c|}{ Panel B: Pixel-level. Partitioned Ethnic Homelands Sample } \\
\hline Light Density & 42710 & 0.312 & 2.335 & 0.000 & 0.000 & 0.000 & 0.000 & 62.857 \\
\hline Ln (0.01 + Light Density) & 42710 & -4.111 & 1.465 & -4.605 & -4.605 & -4.605 & -4.605 & 4.141 \\
\hline Light Density 0-1 & 42710 & 0.124 & 0.329 & 0.000 & 0.000 & 0.000 & 0.000 & 1.000 \\
\hline Ln (0.01 + Population Density) & 42710 & 2.074 & 1.771 & 0.734 & 2.143 & 3.328 & -5.094 & 9.121 \\
\hline Water Area Indicator & 42710 & 0.129 & 0.335 & 0.000 & 0.000 & 0.000 & 0.000 & 1.000 \\
\hline Ln (Area) & 42710 & 4.885 & 0.650 & 4.857 & 5.211 & 5.243 & 2.303 & 5.259 \\
\hline Mean Elevation & 42566 & 641.612 & 470.408 & 292.111 & 526.048 & 969.556 & -406.000 & 4623.750 \\
\hline Land Suitability For Agriculture & 41149 & 0.341 & 0.259 & 0.103 & 0.325 & 0.511 & 0.001 & 0.999 \\
\hline Malaria Stability Index & 42710 & 0.710 & 0.395 & 0.365 & 0.989 & 1.000 & 0.000 & 1.000 \\
\hline Oil Deposit Indicator & 42710 & 0.018 & 0.135 & 0.000 & 0.000 & 0.000 & 0.000 & 1.000 \\
\hline Diamond Mine Indicator & 42710 & 0.004 & 0.062 & 0.000 & 0.000 & 0.000 & 0.000 & 1.000 \\
\hline Distance to the Capital City & 42710 & 0.532 & 0.369 & 0.271 & 0.439 & 0.707 & 0.001 & 1.933 \\
\hline Distance to the Sea Coast & 42710 & 581.363 & 414.433 & 233.430 & 507.473 & 896.488 & 0.286 & 1735.680 \\
\hline Distance to the Border & 42710 & 65.938 & 68.091 & 15.754 & 44.255 & 93.799 & 0.000 & 448.539 \\
\hline Rule of Law & 42710 & -0.909 & 0.606 & -1.355 & -0.820 & -0.506 & -2.198 & 0.615 \\
\hline Control of Corruption & 42710 & -0.779 & 0.534 & -1.141 & -0.864 & -0.651 & -1.664 & 0.814 \\
\hline
\end{tabular}

The table reports descriptive statistics for all variables employed in the empirical analysis for the sample of partitioned ethnic homelands in Africa. Panel A reports summary statistics at the country-ethnicity level. Panel B reports summary statistics at the pixel level. The Data Appendix gives detailed variable definitions and data sources. 
Table 2: Validity of Identification Design at the Country-Ethnicity Homeland Level

\begin{tabular}{|c|c|c|c|c|c|c|c|c|c|c|}
\hline & \multicolumn{10}{|c|}{ Dependent Variable is: } \\
\hline & $\begin{array}{l}\text { Ln (Land } \\
\text { Area) }\end{array}$ & $\begin{array}{c}\text { Ln (Area } \\
\text { under } \\
\text { Water) }\end{array}$ & $\begin{array}{l}\text { Mean } \\
\text { Elevation }\end{array}$ & $\begin{array}{c}\text { Land } \\
\text { Suitability }\end{array}$ & $\begin{array}{l}\text { Malaria } \\
\text { Stability }\end{array}$ & $\begin{array}{c}\text { Oil } \\
\text { Indicator }\end{array}$ & $\begin{array}{l}\text { Diamond } \\
\text { Indicator }\end{array}$ & $\begin{array}{l}\text { Distance to } \\
\text { the Capital }\end{array}$ & $\begin{array}{c}\text { Distance to } \\
\text { the Sea } \\
\text { Coast }\end{array}$ & $\begin{array}{c}\text { Distance } \\
\text { to the } \\
\text { Border }\end{array}$ \\
\hline & (1) & (2) & (3) & (4) & (5) & (6) & (7) & (8) & (9) & $(10)$ \\
\hline & \multicolumn{10}{|c|}{ Panel A: Rule of Law } \\
\hline $\begin{array}{l}\text { Rule of Law } \\
\text { Double-clustered s.e. }\end{array}$ & $\begin{array}{l}-0.0474 \\
(0.2058)\end{array}$ & $\begin{array}{c}0.0480 \\
(0.0453)\end{array}$ & $\begin{array}{c}0.0041 \\
(0.0217)\end{array}$ & $\begin{array}{l}0.0091 \\
(0.0184)\end{array}$ & $\begin{array}{l}-0.015 \\
(0.0230)\end{array}$ & $\begin{array}{l}0.0365^{*} \\
(0.0199)\end{array}$ & $\begin{array}{l}-0.0161 \\
(0.0433)\end{array}$ & $\begin{array}{l}-0.1887 \\
(0.1233)\end{array}$ & $\begin{array}{l}0.0001 \\
(0.0178)\end{array}$ & $\begin{array}{l}-0.0037 \\
(0.0049)\end{array}$ \\
\hline Adjusted R-squared & 0.682 & 0.796 & 0.964 & 0.935 & 0.941 & 0.753 & 0.547 & 0.582 & 0.986 & 0.639 \\
\hline \multirow[t]{2}{*}{ Observations } & 507 & 507 & 507 & 507 & 507 & 507 & 507 & 507 & 507 & 507 \\
\hline & \multicolumn{10}{|c|}{ Panel B: Control of Corruption } \\
\hline $\begin{array}{l}\text { Control of Corruption } \\
\text { Double-clustered s.e. }\end{array}$ & $\begin{array}{l}-0.0686 \\
(0.2229)\end{array}$ & $\begin{array}{c}0.037 \\
(0.0610)\end{array}$ & $\begin{array}{c}0.0119 \\
(0.0222)\end{array}$ & $\begin{array}{l}-0.0052 \\
(0.0243)\end{array}$ & $\begin{array}{l}-0.0324 \\
(0.0233)\end{array}$ & $\begin{array}{c}0.0431 \\
(0.0294)\end{array}$ & $\begin{array}{l}-0.0199 \\
(0.0612)\end{array}$ & $\begin{array}{l}-0.1753 \\
(0.1490)\end{array}$ & $\begin{array}{c}0.0037 \\
(0.0176)\end{array}$ & $\begin{array}{c}-0.007 \\
(0.0077)\end{array}$ \\
\hline Adjusted R-squared & 0.683 & 0.795 & 0.964 & 0.935 & 0.941 & 0.753 & 0.547 & 0.565 & 0.986 & 0.551 \\
\hline \multirow[t]{2}{*}{ Observations } & 507 & 507 & 507 & 507 & 507 & 507 & 507 & 507 & 507 & 507 \\
\hline & \multicolumn{10}{|c|}{ Panel C: High Rule of Law - Two Major Partitioned Ethnic Areas } \\
\hline $\begin{array}{l}\text { High Rule of Law } \\
\text { Double-clustered s.e. }\end{array}$ & $\begin{array}{c}0.0696 \\
(0.1111)\end{array}$ & $\begin{array}{c}0.0475 \\
(0.0346)\end{array}$ & $\begin{array}{l}-0.0013 \\
(0.0171)\end{array}$ & $\begin{array}{l}0.0129 \\
(0.0132)\end{array}$ & $\begin{array}{l}-0.0103 \\
(0.0195)\end{array}$ & $\begin{array}{c}0.0409 \\
(0.0271)\end{array}$ & $\begin{array}{l}-0.0273 \\
(0.0414)\end{array}$ & $\begin{array}{l}-0.1584 \\
(0.1029)\end{array}$ & $\begin{array}{c}0.0036 \\
(0.0111)\end{array}$ & $\begin{array}{c}0.0031 \\
(0.0049)\end{array}$ \\
\hline Adjusted R-squared & 0.818 & 0.866 & 0.972 & 0.952 & 0.953 & 0.804 & 0.629 & 0.612 & 0.991 & 0.639 \\
\hline Observations & 440 & 440 & 440 & 440 & 440 & 440 & 440 & 440 & 440 & \\
\hline & \multicolumn{10}{|c|}{ Panel C: High Control for Corruption - Two Major Partitioned Ethnic Areas } \\
\hline $\begin{array}{l}\text { High Control of Corruption } \\
\text { Double-clustered s.e. }\end{array}$ & $\begin{array}{c}0.0262 \\
(0.1259)\end{array}$ & $\begin{array}{c}0.0547 \\
(0.0351)\end{array}$ & $\begin{array}{l}-0.0074 \\
(0.0185)\end{array}$ & $\begin{array}{l}0.0105 \\
(0.0160)\end{array}$ & $\begin{array}{l}-0.0025 \\
(0.0217)\end{array}$ & $\begin{array}{l}0.0318 \\
(0.0262)\end{array}$ & $\begin{array}{l}-0.0091 \\
(0.0455)\end{array}$ & $\begin{array}{l}-0.0304 \\
(0.1182)\end{array}$ & $\begin{array}{l}-0.0032 \\
(0.0103)\end{array}$ & $\begin{array}{l}-0.0002 \\
(0.0058)\end{array}$ \\
\hline Adjusted R-squared & 0.817 & 0.867 & 0.972 & 0.952 & 0.953 & 0.802 & 0.627 & 0.569 & 0.991 & 0.638 \\
\hline Observations & 440 & 440 & 440 & 440 & 440 & 440 & 440 & 440 & 440 & 440 \\
\hline Ethnicities & 220 & 220 & 220 & 220 & 220 & 220 & 220 & 220 & 220 & 220 \\
\hline Ethnicity Fixed Effects & Yes & Yes & Yes & Yes & Yes & Yes & Yes & Yes & Yes & Yes \\
\hline
\end{tabular}


The table reports within-ethnicity OLS estimates associating various geographical, ecological, and other characteristics with contemporary national institutions, as reflected in World Bank's Governance Matters rule of law index (in Panel A) and control of corruption index (in Panel B) in areas of partitioned ethnicities. In Panels C and D we focus on the two major partitions of an ethnic group (in total 440 ethnic areas of 220 partitioned ethnicities). The high institutional quality indicator takes on the value one for the areas falling in the country with the higher value in the rule of law index (in Panel C) or in the control for corruption index (in Panel D).

The dependent variable in column (1) is the log (land area); in column (2) is the log (1 + land area under water (lakes, rivers, and other streams)); in column (3) is mean elevation; in column (4) is an index of land suitability for agriculture; in column (5) is the average of a malaria stability index; in column (6) is an indicator for country-ethnic areas with an oil field; in column (7) is an indicator for country-ethnic areas with a diamond mine. In columns (8)-(10) the dependent variable is the distance of the centroid of each country-ethnic area from the capital city, the sea coast, and the national border, respectively. The Data Appendix gives detailed variable definitions and data sources. Below the estimates we report in parentheses double-clustered standard errors at the country and the ethno-linguistic family dimensions. ***, **, and * indicate statistical significance at the $1 \%, 5 \%$, and $10 \%$ level, respectively. 
Table 3 - Cross-Sectional Analysis

National Institutions and Regional Development

\begin{tabular}{|c|c|c|c|c|c|c|c|c|}
\hline & \multicolumn{4}{|c|}{ Rule of Law } & \multicolumn{4}{|c|}{ Control of Corruption } \\
\hline & (1) & $(2)$ & (3) & (4) & (5) & (6) & (7) & (8) \\
\hline \multicolumn{9}{|c|}{ Panel A: Country-Ethnic Homeland Level } \\
\hline $\begin{array}{l}\text { Institutional Quality } \\
\text { Double-clustered s.e. }\end{array}$ & $\begin{array}{l}0.8229 * * * \\
(0.2839)\end{array}$ & $\begin{array}{l}0.8017 * * * \\
(0.2451)\end{array}$ & $\begin{array}{l}0.7646 * * * \\
(0.2507)\end{array}$ & $\begin{array}{l}0.6513^{* * *} \\
(0.1962)\end{array}$ & $\begin{array}{l}1.0328 * * * \\
(0.3421)\end{array}$ & $\begin{array}{l}1.0351 * * * \\
(0.2517)\end{array}$ & $\begin{array}{c}0.9945^{* * *} \\
(0.2334)\end{array}$ & $\begin{array}{r}0.8218 * * * \\
(0.2158)\end{array}$ \\
\hline Adjusted R-squared & 0.080 & 0.314 & 0.379 & 0.468 & 0.0950 & 0.3340 & 0.3950 & 0.475 \\
\hline Observations & 1209 & 1209 & 1209 & 1209 & 1209 & 1209 & 1209 & 1209 \\
\hline \multicolumn{9}{|c|}{ Panel B: Pixel Level } \\
\hline $\begin{array}{l}\text { Institutional Quality } \\
\text { Double-clustered s.e. }\end{array}$ & $\begin{array}{l}0.1248 * * * \\
(0.0443)\end{array}$ & $\begin{array}{l}0.1199 * * * \\
(0.0415)\end{array}$ & $\begin{array}{l}0.0988 * * * \\
(0.0380)\end{array}$ & $\begin{array}{l}0.0765^{* *} \\
(0.0334)\end{array}$ & $\begin{array}{l}0.1470 * * * \\
(0.0478)\end{array}$ & $\begin{array}{l}0.1467 * * * \\
(0.0431)\end{array}$ & $\begin{array}{c}0.1223 * * * \\
(0.0404)\end{array}$ & $\begin{array}{r}0.0968 * * \\
(0.0409)\end{array}$ \\
\hline Adjusted R-squared & 0.049 & 0.175 & 0.192 & 0.256 & 0.056 & 0.185 & 0.198 & 0.260 \\
\hline Observations & 120501 & 120501 & 120501 & 116412 & 120501 & 120501 & 120501 & 116412 \\
\hline Pop. Dens. \& Area & No & Yes & Yes & Yes & No & Yes & Yes & Yes \\
\hline Location Controls & No & No & Yes & Yes & No & No & Yes & Yes \\
\hline Geographic Controls & No & No & No & Yes & No & No & No & Yes \\
\hline
\end{tabular}

The table reports OLS estimates associating regional development with contemporary national institutions, as reflected in World Bank's Governance Matters rule of law index (in columns (1)-(4)) and control of corruption index (in columns (5)-(8)) at the country-ethnicity level (in Panel A) and at the pixel level (in Panel B). In Panel A the dependent variable is log (0.01 + light density at night from satellite) at the ethnicity-country level. In Panel B the dependent variable is an indicator that takes on the value of one if the pixel (of $0.125 \times 0.125$ decimal degrees) is lit and zero otherwise.

In the specifications in columns (2)-(4) and (6)-(8) we control for log (population density in 2000) and log land area at the countryethnicity level (in Panel A) or at the pixel-level (in Panel B). In columns (3), (4), (7), and (8) we control for location characteristics augmenting the specification with distance of the centroid of each ethnicity-country area or each pixel from the capital city of each country, distance from the closest sea coast, and distance from the national border. The set of geographic controls in columns (4) and (8) includes log (1 + area under water (lakes, rivers, and other streams)) for the models in Panel A and an indicator that takes on the value one if there is some water body in the pixel for the models in Panel B, land suitability for agriculture, elevation, a malaria stability index, a diamond mine indicator, and an oil field indicator. The Data Appendix gives detailed variable definitions and data sources. Below the estimates we report in parentheses double-clustered standard errors at the country and at the ethno-linguistic family dimensions. ***, **, and * indicate statistical significance at the $1 \%, 5 \%$, and $10 \%$ level, respectively. 


\section{Table 4: National Institutions and Regional Development across and within Partitioned Ethnic Groups}

\begin{tabular}{|c|c|c|c|c|c|c|c|c|}
\hline & \multicolumn{4}{|c|}{ Rule of Law } & \multicolumn{4}{|c|}{ Control of Corruption } \\
\hline & (1) & (2) & (3) & (4) & (5) & (6) & (7) & (8) \\
\hline & \multicolumn{8}{|c|}{ Panel A: Country-Ethnic Homeland Level } \\
\hline $\begin{array}{l}\text { Institutional Quality } \\
\text { Double-clustered s.e. }\end{array}$ & $\begin{array}{l}0.6510 * * * \\
(0.1951)\end{array}$ & $\begin{array}{c}0.1943 \\
(0.1898)\end{array}$ & $\begin{array}{l}0.5150^{* *} \\
(0.2024)\end{array}$ & $\begin{array}{c}0.2159 \\
(0.2135)\end{array}$ & $\begin{array}{l}0.7904 * * * \\
(0.2268)\end{array}$ & $\begin{array}{c}0.2566 \\
(0.2197)\end{array}$ & $\begin{array}{l}0.6019 * * * \\
(0.2329)\end{array}$ & $\begin{array}{c}0.2675 \\
(0.2439)\end{array}$ \\
\hline Adjusted R-squared & 0.292 & 0.792 & 0.392 & 0.798 & 0.298 & 0.792 & 0.393 & 0.798 \\
\hline Within R-squared & - & 0.061 & - & 0.067 & - & 0.062 & - & 0.067 \\
\hline \multirow[t]{2}{*}{ Observations } & 507 & 507 & 507 & 507 & 507 & 507 & 507 & 507 \\
\hline & \multicolumn{8}{|c|}{ Panel B: Pixel Level } \\
\hline $\begin{array}{l}\text { Institutional Quality } \\
\text { Double-clustered s.e. }\end{array}$ & $\begin{array}{l}0.1072 * * * \\
(0.0400)\end{array}$ & $\begin{array}{c}0.0246 \\
(0.0165)\end{array}$ & $\begin{array}{l}0.0834 * * \\
(0.0324)\end{array}$ & $\begin{array}{r}0.0278 \\
(0.0181)\end{array}$ & $\begin{array}{l}0.1371 * * * \\
(0.0464)\end{array}$ & $\begin{array}{c}0.0370 \\
(0.0273)\end{array}$ & $\begin{array}{l}0.1097 * * * \\
(0.0415)\end{array}$ & $\begin{array}{r}0.0403 \\
(0.0290)\end{array}$ \\
\hline Adjusted R-squared & 0.149 & 0.331 & 0.202 & 0.340 & 0.160 & 0.331 & 0.209 & 0.340 \\
\hline Within R-squared & - & 0.059 & - & 0.066 & - & 0.059 & - & 0.066 \\
\hline Observations & 42710 & 42710 & 41025 & 41025 & 42710 & 42710 & 41025 & 41025 \\
\hline Ethnicity Fixed Effects & No & Yes & No & Yes & No & Yes & No & Yes \\
\hline Pop. Dens. \& Area & Yes & Yes & Yes & Yes & Yes & Yes & Yes & Yes \\
\hline Location Controls & No & No & Yes & Yes & No & No & Yes & Yes \\
\hline Geographic Controls & No & No & Yes & Yes & No & No & Yes & Yes \\
\hline
\end{tabular}

The table reports cross-sectional and within-ethnicity OLS estimates associating regional development with contemporary national institutions, as reflected in World Bank's Governance Matters rule of law index (in columns (1)-(4)) and control of corruption index (in columns (5)-(8)) in areas of partitioned ethnicities at the country-ethnicity level (in Panel A) and at the pixel level (in Panel B). In Panel A the dependent variable is $\log (0.01+$ light density at night from satellite) at the ethnicity-country level. In Panel B the dependent variable is an indicator that takes on the value of one if the pixel (of $0.125 \times 0.125$ decimal degrees) is lit and zero otherwise. Odd-numbered columns report cross-sectional specifications. Even-numbered columns report within-ethnicity estimates, where we include a vector of ethnicity fixed effects (constants not reported).

In all specifications we control for log (population density in 2000) and log land area at the country-ethnicity level (in Panel A) or at the pixel level (in Panel B). In columns (3), (4), (7), and (8) we control for location and geography, augmenting the specification with distance of the centroid of each ethnicity-country (in Panel A) or each pixel (in Panel B) from the capital city of each country, distance from the closest sea coast, and distance from the national border. The set of geographic controls includes $\log (1+$ area under water (lakes, rivers, and other streams)) for the models in Panel A and an indicator that takes on the value one if there is some water body in the pixel for the models in Panel B, land suitability for agriculture, elevation, a malaria stability index, a diamond mine indicator, and an oil field indicator. Besides the adjusted R-squared, the table also reports the within R-squared (defined as the difference of the overall R-squared minus the overall R-squared of a model simply with ethnicity fixed effects).

The Data Appendix gives detailed variable definitions and data sources. Below the estimates we report in parentheses doubleclustered standard errors at the country and ethno-linguistic family dimensions. ${ }^{* *},{ }^{* *}$, and $*$ indicate statistical significance at the $1 \%, 5 \%$, and $10 \%$ level, respectively. 
Table 5: National Institutions and Regional Development across and within Partitioned Ethnic Groups in Areas Close to the Border. Local Regressions

\begin{tabular}{|c|c|c|c|c|c|c|c|c|}
\hline \multirow{3}{*}{ Bandwidth } & \multicolumn{4}{|c|}{ Rule of Law } & \multicolumn{4}{|c|}{ Control of Corruption } \\
\hline & \multicolumn{2}{|c|}{$100 \mathrm{~km}$} & \multicolumn{2}{|c|}{$50 \mathrm{~km}$} & \multicolumn{2}{|c|}{$100 \mathrm{~km}$} & \multicolumn{2}{|c|}{$50 \mathrm{~km}$} \\
\hline & (1) & $(2)$ & (3) & (4) & (5) & (6) & (7) & (8) \\
\hline
\end{tabular}

Panel A: Country-Ethnic Homeland Level

$\begin{array}{lcccccccc}\text { Institutional Quality } & 0.6788^{* * *} & 0.0827 & 0.5975^{* * *} & 0.1503 & 0.8585^{* * *} & 0.0866 & 0.7458^{* * *} & 0.1765 \\ \text { Double-clustered s.e. } & (0.2116) & (0.2318) & (0.2098) & (0.2480) & (0.2465) & (0.2602) & (0.2591) & (0.2951) \\ & & & & & & & & \\ \text { Adjusted R-squared } & 0.311 & 0.842 & 0.285 & 0.848 & 0.324 & 0.842 & 0.293 & 0.848 \\ \text { Within R-squared } & - & 0.027 & - & 0.033 & - & 0.027 & - & 0.033 \\ \text { Observations } & 432 & 432 & 432 & 432 & 432 & 432 & 432 & 432\end{array}$

Panel B: Pixel Level

\begin{tabular}{|c|c|c|c|c|c|c|c|c|}
\hline $\begin{array}{l}\text { Institutional Quality } \\
\text { Double-clustered s.e. }\end{array}$ & $\begin{array}{l}0.0994^{* * *} \\
(0.0384)\end{array}$ & $\begin{array}{r}0.0168 \\
(0.0181)\end{array}$ & $\begin{array}{l}0.1031^{* *} \\
(0.0407)\end{array}$ & $\begin{array}{r}0.0159 \\
(0.0163)\end{array}$ & $\begin{array}{l}0.1292 * * * \\
(0.0471)\end{array}$ & $\begin{array}{r}0.0269 \\
(0.0259)\end{array}$ & $\begin{array}{l}0.1346 * * * \\
(0.0492)\end{array}$ & $\begin{array}{r}0.0197 \\
(0.0210)\end{array}$ \\
\hline Adjusted R-squared & 0.134 & 0.319 & 0.137 & 0.345 & 0.144 & 0.319 & 0.149 & 0.345 \\
\hline Within R-squared & - & 0.051 & ـ & 0.046 & - & 0.051 & - & 0.046 \\
\hline Observations & 21289 & 21289 & 13408 & 13408 & 21289 & 21289 & 13408 & 13408 \\
\hline Ethnicity Fixed Effects & No & Yes & No & Yes & No & Yes & No & Yes \\
\hline Pop. Dens. \& Area & Yes & Yes & Yes & Yes & Yes & Yes & Yes & Yes \\
\hline
\end{tabular}

The table reports cross-sectional and within-ethnicity OLS estimates associating regional development with contemporary national institutions, as reflected in World Bank's Governance Matters rule of law index (in columns (1)-(4)) and control of corruption index (in columns (5)-(8)) in areas of partitioned ethnicities at the country-ethnicity level (in Panel A) and at the pixel level (in Panel B). In Panel A the dependent variable is $\log (0.01+$ light density at night from satellite) at the ethnicity-country level. In Panel B the dependent variable is an indicator that takes on the value of one if the pixel (of $0.125 \times 0.125$ decimal degrees) is lit and zero otherwise.

In columns (1), (2), (5), and (6) we focus on ethnic areas within 50 kilometers of each side of the national border (total 100 kilometers). In columns (3), (4), (7), and (8) we focus on ethnic areas within 25 kilometers of each side of the national border (total 50 kilometers). Odd-numbered columns report cross-sectional specifications. Even-numbered columns report within-ethnicity estimates, where we include a vector of ethnicity fixed effects (constants not reported). In all specifications we control for log (population density in 2000) and log land area at the country-ethnic homeland level (in Panel A) and in the pixel-level (in Panel B). Besides the adjusted R-squared, the table also reports the within R-squared (defined as the difference of the overall R-squared minus the overall R-squared of a model simply with ethnicity fixed effects).

The Data Appendix gives detailed variable definitions and data sources. Below the estimates we report in parentheses double-clustered standard errors at the country and ethno-linguistic family dimensions. ***, **, and * indicate statistical significance at the $1 \%, 5 \%$, and $10 \%$ level, respectively. 

Table 6: National Institutions and Regional Development at the Border
Regression Discontinuity (RD) Estimates

\begin{tabular}{|c|c|c|c|c|c|c|c|c|c|c|c|c|}
\hline \multirow{3}{*}{$\begin{array}{l}\text { Bandwidth } \\
\text { RD Polynomial }\end{array}$} & \multicolumn{6}{|c|}{ Rule of Law } & \multicolumn{6}{|c|}{ Control of Corruption } \\
\hline & \multicolumn{2}{|c|}{ All Pixels } & \multicolumn{2}{|c|}{$100 \mathrm{~km}$} & \multicolumn{2}{|c|}{$50 \mathrm{~km}$} & \multicolumn{2}{|c|}{ All Observations } & \multicolumn{2}{|c|}{$100 \mathrm{~km}$} & \multicolumn{2}{|c|}{$50 \mathrm{~km}$} \\
\hline & 3rd-order & 4th-order & 3rd-order & 4th-order & 3rd-order & 4th-order & 3rd-order & 4th-order & 3rd-order & 4th-order & 3rd-order & 4th-order \\
\hline & (1) & (2) & (3) & (4) & (5) & (6) & (7) & (8) & (9) & $(10)$ & (11) & $(12)$ \\
\hline & \multicolumn{12}{|c|}{ Panel A: Global Regression Discontinuity (RD) Polynomial } \\
\hline $\begin{array}{l}\text { Institutional Quality } \\
\text { Double-clustered s.e. }\end{array}$ & $\begin{array}{c}0.0166 \\
(0.0138)\end{array}$ & $\begin{array}{c}0.0058 \\
(0.0135)\end{array}$ & $\begin{array}{c}0.0123 \\
(0.0165)\end{array}$ & $\begin{array}{c}0.0050 \\
(0.0185)\end{array}$ & $\begin{array}{l}-0.0010 \\
(0.0240)\end{array}$ & $\begin{array}{c}0.0122 \\
(0.0272)\end{array}$ & $\begin{array}{c}0.0038 \\
(0.0154)\end{array}$ & $\begin{array}{l}-0.0086 \\
(0.0137)\end{array}$ & $\begin{array}{c}0.0116 \\
(0.0166)\end{array}$ & $\begin{array}{c}0.0123 \\
(0.0176)\end{array}$ & $\begin{array}{l}-0.0030 \\
(0.0223)\end{array}$ & $\begin{array}{c}0.0079 \\
(0.0276)\end{array}$ \\
\hline $\begin{array}{l}\text { Adjusted R-squared } \\
\text { within R-squared }\end{array}$ & $\begin{array}{l}0.342 \\
0.059\end{array}$ & $\begin{array}{l}0.342 \\
0.059\end{array}$ & $\begin{array}{l}0.320 \\
0.037\end{array}$ & $\begin{array}{l}0.320 \\
0.037\end{array}$ & $\begin{array}{l}0.347 \\
0.064\end{array}$ & $\begin{array}{l}0.347 \\
0.064\end{array}$ & $\begin{array}{l}0.342 \\
0.059\end{array}$ & $\begin{array}{l}0.343 \\
0.060\end{array}$ & $\begin{array}{l}0.320 \\
0.037\end{array}$ & $\begin{array}{l}0.320 \\
0.037\end{array}$ & $\begin{array}{l}0.347 \\
0.064\end{array}$ & $\begin{array}{l}0.347 \\
0.064\end{array}$ \\
\hline & \multicolumn{12}{|c|}{ Panel B: Ethnic-Specific Regression Discontinuity (RD) Polynomial } \\
\hline $\begin{array}{l}\text { Adjusted R-squared } \\
\text { within R-squared }\end{array}$ & $\begin{array}{l}0.416 \\
0.133\end{array}$ & $\begin{array}{l}0.427 \\
0.144\end{array}$ & $\begin{array}{l}0.412 \\
0.129\end{array}$ & $\begin{array}{l}0.423 \\
0.140\end{array}$ & $\begin{array}{l}0.441 \\
0.158\end{array}$ & $\begin{array}{l}0.459 \\
0.176\end{array}$ & $\begin{array}{l}0.416 \\
0.133\end{array}$ & $\begin{array}{l}0.427 \\
0.144\end{array}$ & $\begin{array}{l}0.412 \\
0.129\end{array}$ & $\begin{array}{l}0.423 \\
0.140\end{array}$ & $\begin{array}{l}0.441 \\
0.158\end{array}$ & $\begin{array}{l}0.459 \\
0.176\end{array}$ \\
\hline $\begin{array}{l}\text { Observations } \\
\text { Ethnicity Fixed Effects } \\
\text { Pixel Area \& Pop. Dens. }\end{array}$ & $\begin{array}{c}40209 \\
\text { Yes } \\
\text { Yes }\end{array}$ & $\begin{array}{c}40209 \\
\text { Yes } \\
\text { Yes }\end{array}$ & $\begin{array}{c}21289 \\
\text { Yes } \\
\text { Yes }\end{array}$ & $\begin{array}{c}21289 \\
\text { Yes } \\
\text { Yes }\end{array}$ & $\begin{array}{c}13408 \\
\text { Yes } \\
\text { Yes }\end{array}$ & $\begin{array}{c}13408 \\
\text { Yes } \\
\text { Yes }\end{array}$ & $\begin{array}{c}40209 \\
\text { Yes } \\
\text { Yes }\end{array}$ & $\begin{array}{c}40209 \\
\text { Yes } \\
\text { Yes }\end{array}$ & $\begin{array}{c}21289 \\
\text { Yes } \\
\text { Yes }\end{array}$ & $\begin{array}{c}21289 \\
\text { Yes } \\
\text { Yes }\end{array}$ & $\begin{array}{c}13408 \\
\text { Yes } \\
\text { Yes }\end{array}$ & $\begin{array}{c}13408 \\
\text { Yes } \\
\text { Yes }\end{array}$ \\
\hline
\end{tabular}

The table reports regression discontinuity (RD) estimates. Estimation is performed across the two major partitions of split ethnic group. In Panel A we include a global (common to all partitioned ethnicities) RD polynomial in distance of the centroid of each pixel to the national border, allowing the polynomial terms to differ on the two sides of the border. In Panel B we include ethnic-specific RD polynomials in distance of the centroid of each pixel to the national border, allowing the polynomial terms to differ on the two sides of the border. In odd-numbered columns we include a third-order RD polynomial, while in even-numbered columns we include a fourth-order RD polynomial. In columns (3)-(6) and (9)(12) we restrict estimation to pixels close to the national border using two different bandwidths. In columns (3), (4), (9), and (10) we focus on pixels within 50 kilometers on each side of the national border (total 100 kilometers). In columns (5), (6), (11), and (12) we focus on pixels within 25 kilometers of each side of the national border (total 50

kilometers). The high institutional quality indicator takes on the value of one for pixels falling in the country with the higher value in the rule of law index (in columns (1)-(6)) or in the control of corruption index (in columns (7)-(12)). All specifications include ethnicity fixed effects (constants not reported), the log of pixel-level population density and the log of pixel surface area. Besides the adjusted R-squared, the table also reports the within R-squared (defined as the difference of the overall R-squared minus the overall R-squared of a model simply with ethnicity fixed effects).The Data Appendix gives detailed variable definitions and data sources. Below the estimates we report in parentheses double-clustered standard errors at the country and at the ethnolinguistic level dimensions. ***, **, and * indicate statistical significance at the $1 \%, 5 \%$, and $10 \%$ level, respectively. 
Table 7: National Institutions and Regional Development at the Border Regression Discontinuity (RD) Estimates. Large Discontinuities

\begin{tabular}{|c|c|c|c|c|c|c|c|c|c|c|c|c|}
\hline \multirow{3}{*}{$\begin{array}{l}\text { Cutt-off } \\
\text { Global RD Polynomial }\end{array}$} & \multicolumn{6}{|c|}{ Rule of Law } & \multicolumn{6}{|c|}{ Control of Corruption } \\
\hline & \multicolumn{3}{|c|}{ median } & \multicolumn{3}{|c|}{ 75th percentile } & \multicolumn{3}{|c|}{ median } & \multicolumn{3}{|c|}{ 75th percentile } \\
\hline & No & 3rd-order & 4th-order & No & 3rd-order & 4th-order & No & 3rd-order & 4th-order & No & 3rd-order & 4th-order \\
\hline & (1) & $(2)$ & (3) & (4) & (5) & (6) & (7) & (8) & (9) & $(10)$ & (11) & (12) \\
\hline Institutional Quality & $\begin{array}{c}0.0159 \\
(0.0186)\end{array}$ & $\begin{array}{c}0.0116 \\
(0.0199)\end{array}$ & $\begin{array}{l}-0.0027 \\
(0.0212)\end{array}$ & $\begin{array}{c}0.0134 \\
(0.0311)\end{array}$ & $\begin{array}{c}0.0049 \\
(0.0376)\end{array}$ & $\begin{array}{l}-0.0207 \\
(0.0330)\end{array}$ & $\begin{array}{c}0.009 \\
(0.0204)\end{array}$ & $\begin{array}{c}0.0133 \\
(0.0215)\end{array}$ & $\begin{array}{c}-0.003 \\
(0.0201)\end{array}$ & $\begin{array}{c}0.041 \\
(0.0346)\end{array}$ & $\begin{array}{c}0.0367 \\
(0.0336)\end{array}$ & $\begin{array}{c}0.0024 \\
(0.0251)\end{array}$ \\
\hline Adjusted R-squared & 0.398 & 0.400 & 0.400 & 0.458 & 0.461 & 0.462 & 0.399 & 0.399 & 0.400 & 0.457 & 0.460 & 0.461 \\
\hline within R-squared & 0.072 & 0.074 & 0.075 & 0.075 & 0.078 & 0.080 & 0.064 & 0.065 & 0.065 & 0.078 & 0.080 & 0.082 \\
\hline Observations & 19349 & 19349 & 19349 & 10031 & 10031 & 10031 & 19814 & 19814 & 19814 & 10353 & 10353 & 10353 \\
\hline Ethnicities & 110 & 110 & 110 & 51 & 51 & 51 & 108 & 108 & 108 & 46 & 46 & 46 \\
\hline Ethnicity Fixed Effects & Yes & Yes & Yes & Yes & Yes & Yes & Yes & Yes & Yes & Yes & Yes & Yes \\
\hline Pixel Area \& Pop. Dens. & Yes & Yes & Yes & Yes & Yes & Yes & Yes & Yes & Yes & Yes & Yes & Yes \\
\hline
\end{tabular}

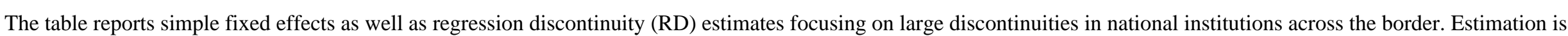

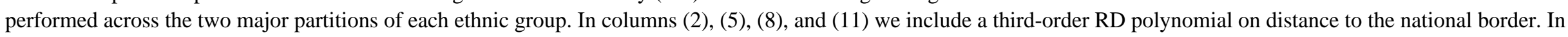

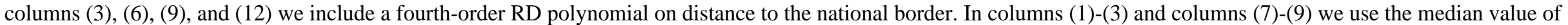

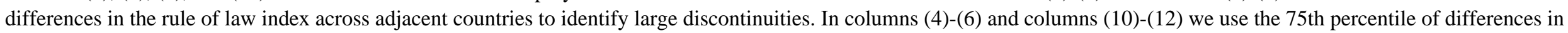

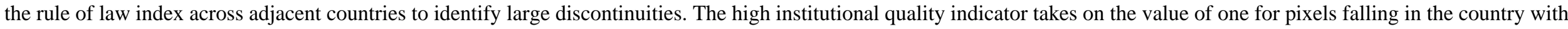

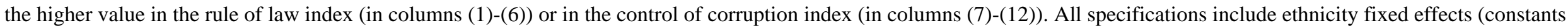

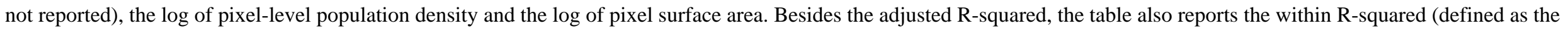
difference of the overall R-squared minus the overall R-squared of a model simply with ethnicity fixed effects).

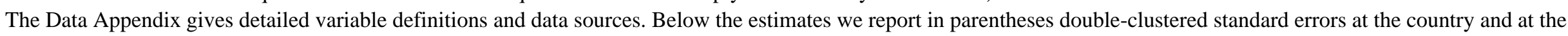
ethnolinguistic level dimensions. ${ }^{* * *}, * *$, and $*$ indicate statistical significance at the $1 \%, 5 \%$, and $10 \%$ level, respectively. 


\section{Table 8 - Heterogeneity: National Institutions and Regional Development within Partitioned Ethnicities Close and Far from the Capital Cities}

\begin{tabular}{|c|c|c|c|c|c|c|c|}
\hline \multicolumn{2}{|c|}{ Rule of Law } & \multicolumn{2}{|c|}{ Control of Corruption } & \multicolumn{2}{|c|}{ Rule of Law } & \multicolumn{2}{|c|}{ Control of Corruption } \\
\hline \multicolumn{4}{|c|}{ Absolute Distance to the Capital } & \multicolumn{4}{|c|}{ Relative Distance to the Capital } \\
\hline$\frac{\text { Close }}{(1)}$ & $\underline{\mathrm{Far}}$ & $\frac{\text { Close }}{\text { (3) }}$ & $\frac{\text { Far }}{(4)}$ & $\frac{\text { Close }}{(5)}$ & Far & $\frac{\text { Close }}{(7)}$ & $\frac{\text { Far }}{(8)}$ \\
\hline
\end{tabular}

Panel A: All Observations/Pixels

$\begin{array}{lcccccccc}\text { Institutional Quality } & 0.0675 & 0.0206 & 0.1220^{* *} & 0.0330 & 0.1064 * & 0.0127 & 0.1455^{* *} & 0.0218 \\ \text { Double-clustered s.e. } & (0.0438) & (0.0233) & (0.0581) & (0.0258) & (0.0585) & (0.0225) & (0.0675) & (0.0237) \\ & & & & & & & & \\ \text { Adjusted R-squared } & 0.421 & 0.210 & 0.423 & 0.211 & 0.451 & 0.245 & 0.452 & 0.246 \\ \text { within R-squared } & 0.089 & 0.062 & 0.091 & 0.063 & 0.084 & 0.046 & 0.085 & 0.047 \\ \text { Observations } & 12546 & 15225 & 12546 & 15225 & 10612 & 19385 & 10612 & 19385 \\ \text { Number of Ethnicities } & 85 & 95 & 85 & 95 & 66 & 139 & 66 & 139\end{array}$

Panel B: Local Regressions (100km bandwidth)

\begin{tabular}{lccccccccc} 
Institutional Quality & 0.0450 & 0.0040 & $0.1111^{*}$ & 0.0153 & $0.1140 *$ & -0.0005 & $0.1564 * *$ & 0.0112 \\
Double-clustered s.e. & $(0.0618)$ & $(0.0239)$ & $(0.0651)$ & $(0.0269)$ & $(0.0641)$ & $(0.0235)$ & $(0.0620)$ & $(0.0258)$ \\
& & & & & & & & \\
Adjusted R-squared & 0.407 & 0.195 & 0.410 & 0.196 & 0.445 & 0.225 & 0.447 & 0.225 \\
within R-squared & 0.085 & 0.044 & 0.087 & 0.044 & 0.090 & 0.036 & 0.092 & 0.036 \\
Observations & 6129 & 8120 & 6129 & 8120 & 4655 & 10987 & 4655 & 10987 \\
Number of Ethnicities & 81 & 94 & 81 & 94 & 60 & 137 & 60 & 137 \\
Ethnicity Fixed Effects & Yes & Yes & Yes & Yes & Yes & Yes & Yes & Yes \\
Pop. Dens. \& Area & Yes & Yes & Yes & Yes & Yes & Yes & Yes & Yes \\
Location \& Geography & Yes & Yes & Yes & Yes & Yes & Yes & Yes & Yes \\
\hline
\end{tabular}

The table reports within-ethnicity OLS estimates associating regional development with contemporary national institutions, as reflected in World Bank's Governance Matters rule of law index (in columns (1), (2), (5), and (6)) and control of corruption index (in columns (3), (4), (7), and (8)) in areas of partitioned ethnicities. The unit of analysis is a pixel of 0.125 x 0.125 decimal degrees (around 12 x 12 kilometers) within partitioned ethnicities. The dependent variable is a dummy variable that takes the value one if the pixel is lit and zero otherwise. In odd-numbered columns we restrict estimation to pixels of partitioned ethnic areas that are close to the capital city. In evennumbered columns we restrict estimation to pixels of partitioned ethnic areas that are far from the capital city. In columns (1)-(4) we use as a cut-off the median value of absolute distance to the capital across all African pixels, while in columns (5)-(8) we use as a cut-off the median value of the within-country distance to the respective capital city.

In Panel A we use all pixels of partitioned ethnicities. In Panel B we report local linear regressions restricting estimation to pixels of partitioned ethnicities within 50 kilometers from each side of the national border (total 100 kilometers). All specifications include a vector of ethnicity fixed effects (constants not reported). In all specifications we control for log population density, log land area, distance of the centroid of each pixel from the capital city of each country (in columns (5)-(8) we use relative distance to the capital city of each country), distance from the closest sea coast, distance from the national border, an indicator for pixels with a water body (lakes, rivers, and other streams)), land suitability for agriculture, elevation, a malaria stability index, a diamond mine indicator, and an oil field indicator. Besides the adjusted R-squared, the table also reports the within R-squared (defined as the difference of the overall R-squared minus the overall R-squared of a model simply with ethnicity fixed effects). The Data Appendix gives detailed variable definitions and data sources. Below the estimates we report in parentheses double-clustered standard errors at the country and ethno-linguistic family dimensions. ${ }^{* *}, * *$, and * indicate statistical significance at the $1 \%, 5 \%$, and $10 \%$ level, respectively. 


\section{Table 9: National Institutions, Distance to the Capital, and Regional Development Pixel-Level Estimates in the Full Sample}

Absolute Distance to the Capital

Double-clustered s.e.

Distance to the Capital

Double-clustered s.e.

Rule of Law X
Distance to the Capital

Adjusted R-squared

Observations

Pixel Area \& Pop. Dens.

Location Controls

Geographic Controls

Country Fixed Effects

Country-Ethnicity FE
(1)

(2)

$0.1434 * * *$

(0.0426)

$$
\begin{gathered}
-0.1352 * * * \\
(0.0511) \\
-0.1243 * * *
\end{gathered}
$$

(0.0363)

0.261

116412
$-0.2103 * * *$
(0.0404)
$-0.1097 * *$
(0.0534)

$-0.1513 * * *$

$-0.0850 * *$

(0.0315)

(0.0352)

0.362

116412

0.429

116412

$-0.1457 * * *$

(4) (5)

(5)

(6)
0.267
116412
$-0.3098 * * *$
(0.0846)
$-0.2530 * * *$
(0.0502)

(0.0499)

$0.1790 * * *$
$(0.0472)$

$-0.2297 * * *$

$-0.1850 * * *$

$-0.1042 * *$

(0.0624)

(0.0461)

(0.0439)

0.429

116412

The table reports OLS estimates associating regional development with distance to the capital city and contemporary national institutions, as reflected in World Bank's Governance Matters rule of law index across the full sample of country-ethnic homelands in Africa. The unit of analysis is pixels of 0.125 x 0.125 decimal degrees (around 12 x 12 kilometers). The dependent variable is a dummy variable that takes the value one if the pixel is lit and zero otherwise.

Columns (1) and (5) give unconditional estimates. In columns (2)-(4) and (6)-(8) we control for log (population density), log land area, distance of the centroid of each pixel from the capital city of each country, distance from the closest sea coast, distance from the national border, an indicator for pixels with a water body (lakes, rivers, and other streams)), land suitability for agriculture, elevation, a malaria stability index, a diamond mine indicator, and an oil field indicator. The specifications in columns (3) and (7) include a vector of country fixed effects (constants not reported). The specifications in columns (4) and (8) include a vector of country-ethnicity fixed effects (constants not reported). The Data Appendix gives detailed variable definitions and data sources. Below the estimates we report in parentheses double-clustered standard errors at the country and ethno-linguistic family dimensions. $* * *, * *$, and * indicate statistical significance at the $1 \%, 5 \%$, and $10 \%$ level, respectively. 
Table 10: Law Enforcement and Ethnic Identification as Function of Distance to the Capital Afrobarometer Sample. Country-Fixed-Effects Estimates

\begin{tabular}{|c|c|c|c|c|c|c|c|c|c|c|c|c|}
\hline & \multicolumn{4}{|c|}{ Law Enforcement 1: Serious Crime } & \multicolumn{4}{|c|}{ Law Enforcement 2: Tax Evasion } & \multicolumn{4}{|c|}{ National versus Ethnic Identification } \\
\hline & (1) & $(2)$ & (3) & (4) & (5) & (6) & (7) & (8) & (9) & (10) & $(11)$ & $(12)$ \\
\hline $\begin{array}{l}\text { Absolute Distance } \\
\text { Double-clustered s.e. }\end{array}$ & $\begin{array}{c}-0.1238 * * * \\
(0.0446)\end{array}$ & $\begin{array}{c}-0.1027 * * \\
(0.0408)\end{array}$ & & & $\begin{array}{c}-0.1118^{* * * *} \\
(0.0410)\end{array}$ & $\begin{array}{c}-0.1006 * * * \\
(0.0386)\end{array}$ & & & $\begin{array}{c}-0.0850 * * \\
(0.0414)\end{array}$ & $\begin{array}{r}-0.0740 * \\
(0.0382)\end{array}$ & & \\
\hline $\begin{array}{l}\text { Relative Distance } \\
\text { Double-clustered s.e. }\end{array}$ & & & $\begin{array}{c}-0.0860 * * \\
(0.0375)\end{array}$ & $\begin{array}{l}-0.0665 * \\
(0.0354)\end{array}$ & & & $\begin{array}{r}-0.0655^{*} \\
(0.0341)\end{array}$ & $\begin{array}{r}-0.0563 * \\
(0.0326)\end{array}$ & & & $\begin{array}{c}-0.0949 * * \\
(0.0411)\end{array}$ & $\begin{array}{r}-0.0819 * * \\
(0.0379)\end{array}$ \\
\hline $\begin{array}{l}\text { Adjusted R-squared } \\
\text { Observations }\end{array}$ & $\begin{array}{r}0.069 \\
20466\end{array}$ & $\begin{array}{l}0.075 \\
19862\end{array}$ & $\begin{array}{l}0.068 \\
20466\end{array}$ & $\begin{array}{l}0.075 \\
19862\end{array}$ & $\begin{array}{l}0.053 \\
20842\end{array}$ & $\begin{array}{l}0.062 \\
20230\end{array}$ & $\begin{array}{l}0.052 \\
20842\end{array}$ & $\begin{array}{l}0.062 \\
20230\end{array}$ & $\begin{array}{l}0.096 \\
20125\end{array}$ & $\begin{array}{l}0.108 \\
19503\end{array}$ & $\begin{array}{l}0.097 \\
20125\end{array}$ & $\begin{array}{l}0.109 \\
19503\end{array}$ \\
\hline $\begin{array}{l}\text { Individual Controls } \\
\text { Country FE }\end{array}$ & $\begin{array}{l}\text { No } \\
\text { Yes }\end{array}$ & $\begin{array}{l}\text { Yes } \\
\text { Yes }\end{array}$ & $\begin{array}{l}\text { No } \\
\text { Yes }\end{array}$ & $\begin{array}{l}\text { Yes } \\
\text { Yes }\end{array}$ & $\begin{array}{l}\text { No } \\
\text { Yes }\end{array}$ & $\begin{array}{l}\text { Yes } \\
\text { Yes }\end{array}$ & $\begin{array}{l}\text { No } \\
\text { Yes }\end{array}$ & $\begin{array}{l}\text { Yes } \\
\text { Yes }\end{array}$ & $\begin{array}{l}\text { No } \\
\text { Yes }\end{array}$ & $\begin{array}{l}\text { Yes } \\
\text { Yes }\end{array}$ & $\begin{array}{l}\text { No } \\
\text { Yes }\end{array}$ & $\begin{array}{l}\text { Yes } \\
\text { Yes }\end{array}$ \\
\hline
\end{tabular}

The table reports country fixed effects OLS estimates, associating legal enforcement (in columns (1)-(8)) and ethnic identification (in columns (9)-(12)) as reflected by individual responses in the Afrobarometer Surveys (3rd round) at the individual level with distance to the capital.

The dependent variable is columns (1)-(4) is an ordered index (range from 1 to 4) based on individual responses on how likely it is that authorities will enforce the law if a person like the respondent committed a serious crime. The dependent variable is columns (5)-(8) is an ordered index (range from 1 to 4 ) based on individual responses on how likely it is that authorities will enforce the law if a person like the respondent did not pay taxes on income earned. For both measures a score of 1 indicates "not at all likely", a score of 2 indicates "not very likely", a score of 3 indicates "likely" and a score of 4 indicates "very likely". The dependent variable in columns (9)-(12) is a dummy variable that takes on the value of one if the respondent replies that she identifies more strongly with her nation than the ethnicity she belongs to.

Even-numbered columns include a rich set of individual controls. The individual-level conditioning set includes age, age squared, a gender indicator variable, an urban indicator, 22 religion fixed effects, 25 occupation fixed effects, 5 living conditions fixed effects, and 9 education fixed effects. All specifications include a set of country fixed effects (constants not reported).

The Data Appendix gives detailed variable definitions and data sources. Below the estimates we report in parentheses double-clustered standard errors at the enumeration area and at the ethnicity level. ${ }^{* * *}, * *$, and $*$ indicate statistical significance at the $1 \%, 5 \%$, and $10 \%$ level, respectively. 


\title{
On-line Supplementary Appendix (not for publication)
}

\section{National Institutions and Subnational Development in Africa*}

\author{
Stelios Michalopoulos \\ Brown University and NBER
}

\author{
Elias Papaioannou \\ London Business School, NBER and CEPR
}

August 10, 2013

\begin{abstract}
The Supplementary Appendix is split into five sections. Section 1 reports the results from a cross-validation analysis of the luminosity data that we use to proxy economic development at the regional level within African ethnic homelands. Section 2 gives descriptive statistics and provides further evidence on the validity of our identification strategy that compares economic development within the historical homeland of partitioned groups. Section 3 provides some guidance as to what the ethnicity fixed effects reflect. Section 4 reports numerous sensitivity checks of the qualitatively and quantitatively weak association between national institutions and economic performance within partitioned ethnic homelands. Section 5 reports various sensitivity checks illustrating the heterogeneous relationship between national institutions and subnational development in areas far and close from the capital cities.
\end{abstract}

\footnotetext{
${ }^{*}$ We thank 7 anonymous referees for proposing many of the sensitivity checks reported in this Supplementary Appendix. This paper draws on material from Michalopoulos and Papaioannou ("Divide and Rule or the Rule of the Divided?" 2011). All errors are our sole responsibility. All errors are our sole responsibility.
} 


\section{Cross-Validation Analysis}

While a plethora of recent works shows that luminosity is a significant correlate of economic development both across and within countries (Henderson, Storeygard, and Weil (2012), Elvidge, Baugh, Kihn, Kroehl, and Davis (1997), Doll, Muller, and Morley (2006), Michalopoulos and Papaioannou (2013b), and Pinkovskiy (2013)), we performed several additional cross-validation exercises investigating the relationship between luminosity and various economic indicators both across countries and within ethnic homelands in our sample of countries.

Cross-country Analysis We first examined whether luminosity correlates with development across African states. Appendix Figure $1 a$ illustrates the unconditional correlation between log light density and log real GDP per capita in 2000. There is a strong positive association. The $R^{2}$ of the regression is 0.35 and the estimate on luminosity is more than 6 standard errors larger than zero. Besides economic well-being, light density also reflects urbanization. Appendix Figure $1 b$ shows the relationship between log real GDP per capita and log light density partialling out log population density (in 2000). The conditional on urbanization relationship between log light density and log GDP p.c. is even stronger; the coefficient on log light density increases from 0.31 to 0.47 and the $t$-statistic jumps to 10 .

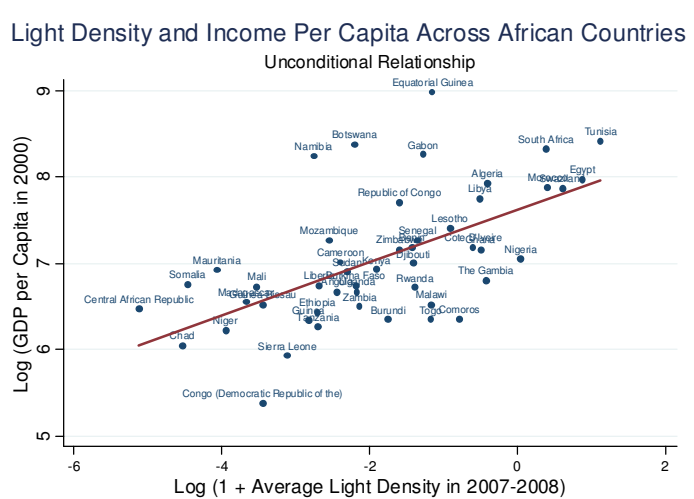

Appendix Figure 1a

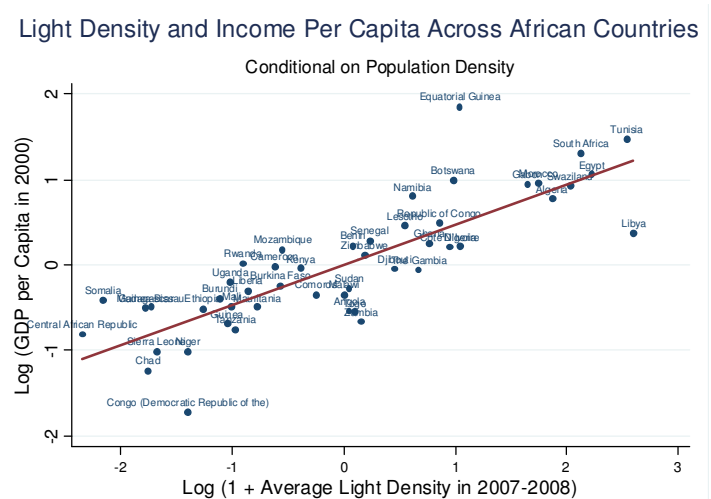

Appendix Figure 1b

Within-Group Analysis We further cross-validated the luminosity data using comparable across countries survey-level data from the 2005 Afrobarometer Surveys on household's access to electrification, access to piped water, presence of a sewage system, and respondents' years of schooling. The Afrobarometer surveys are based on interviews conducted in a random sample of either 1, 200 or 2, 400 individuals of voting age in 17 Sub-Saharan African countries. ${ }^{1}$

\footnotetext{
${ }^{1}$ These countries are: Benin, Botswana, Ghana, Kenya, Lesotho, Madagascar, Malawi, Mali, Mozambique, Namibia, Nigeria, Senegal, South Africa, Tanzania, Uganda, Zambia, and Zimbabwe.
} 
We assign each respondent's current location (Afrobarometer's enumeration area) to one of the 826 homelands in Murdock's (1959) ethnolinguistic map and we then examine the association with luminosity.

Appendix Table 1 reports in a regression framework the within-ethnicity correlation between the four proxy measures of development and log light density. Besides the inclusion of ethnicity fixed effects, in all specifications we condition on log population density to account for differences in urbanization (as we do in most of our empirical specifications in the main part of the paper). The specifications in columns (1), (4), (7), and (10) show that there is a strong and highly significant association (at the $99 \%$ confidence level) between luminosity and all proxies of subnational development. We also estimate specifications using variation across enumeration areas within split groups (in (2), (5), and (8), and (11)) and within non-split ethnicities (in (3), (6), (9), and (12)), respectively. The positive correlation between luminosity and development is strong in both samples suggesting that luminosity is a reliable proxy of economic performance within both split and non-split homelands.

We also explored how differences in luminosity across the national border within the historical homeland of the same ethnicity reflect differences in economic performance averaging the individual responses at the level of each ethnic partition. There are 32 ethnic groups split in adjacent countries whose individual partitions have at least one enumeration area in the Afrobarometer Surveys. We then examined the within-ethnicity across-the-national-border association between log light density and each of the four development proxies. Appendix Figures $2 a-2 d$ depict the respective scatter-plots partialling out differences in log population density. Ethnic partitions with higher light density are populated by individuals enjoying better access to public goods (electrification, sewage system, and piped water) and are on average more educated.

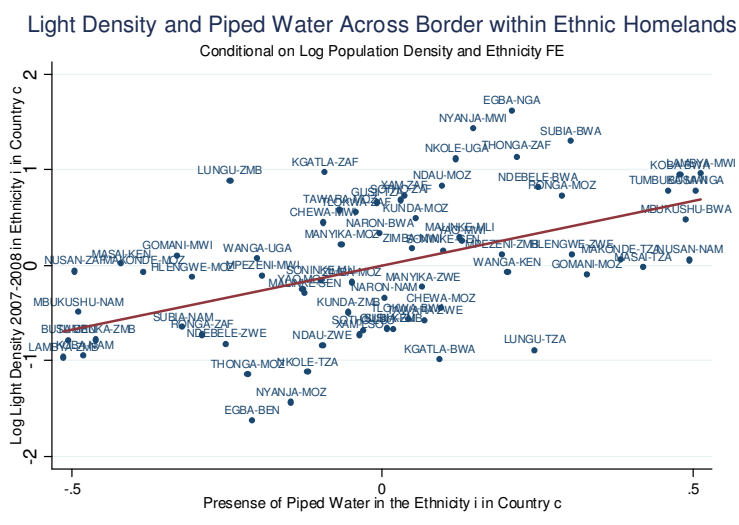

Appendix Figure 2a

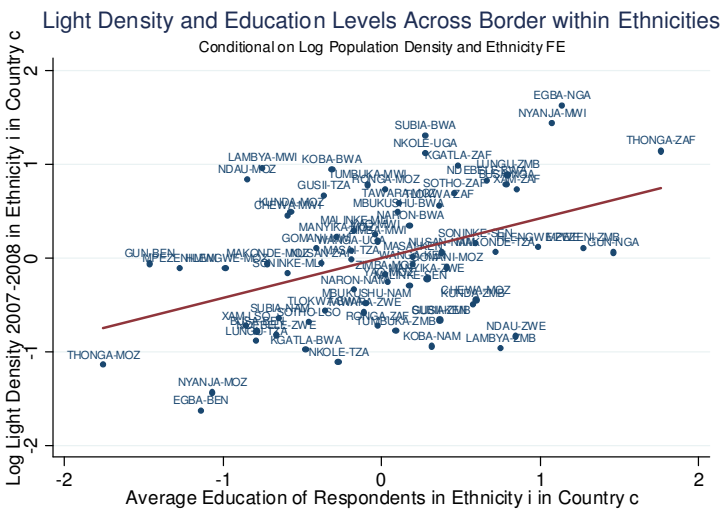

Appendix Figure 2b 


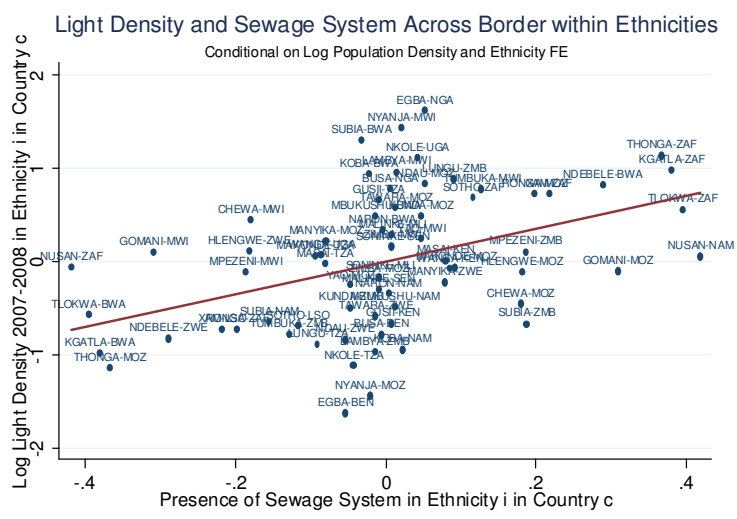

Appendix Figure 2c

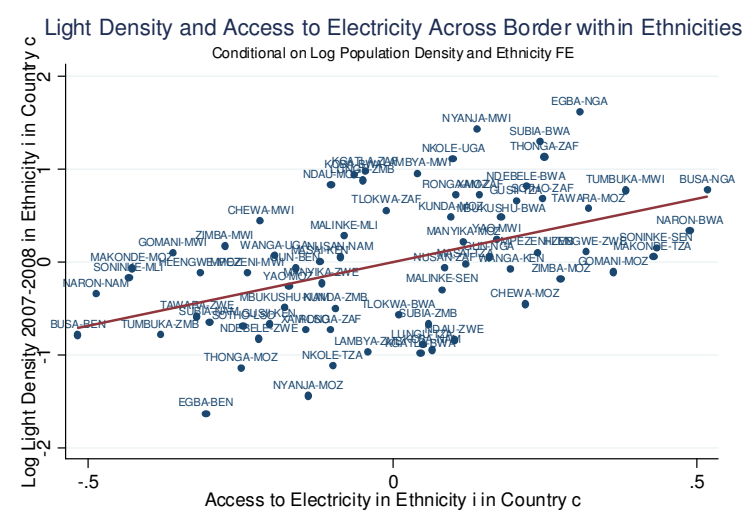

Appendix Figure 2d

\section{Summary Statistics and Further Evidence on the Identifica- tion Strategy}

\subsection{Descriptive Statistics}

Appendix Figure $3 a$ reports the distribution of satellite light density at night across partitioned ethnic homelands (220 ethnicities; 507 country-ethnicity observations). Appendix Figure $3 b$ plots the distribution of the log of light density adding a small number $\left(y_{i, c} \equiv \ln (0.01+\right.$ Light Density $y_{i, c}$ ). This transformation assures that $(i)$ we use all (country-ethnic homeland) observations and $(i i)$ we minimize the problem of outliers. This is the main dependent variable in our estimates at the country-ethnic homeland level (e.g., Table 4-Panel $A$ ).

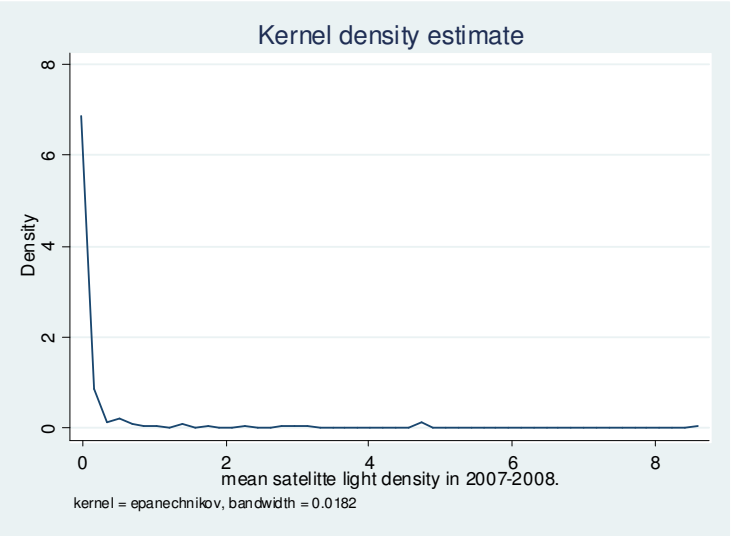

Appendix Figure 3a

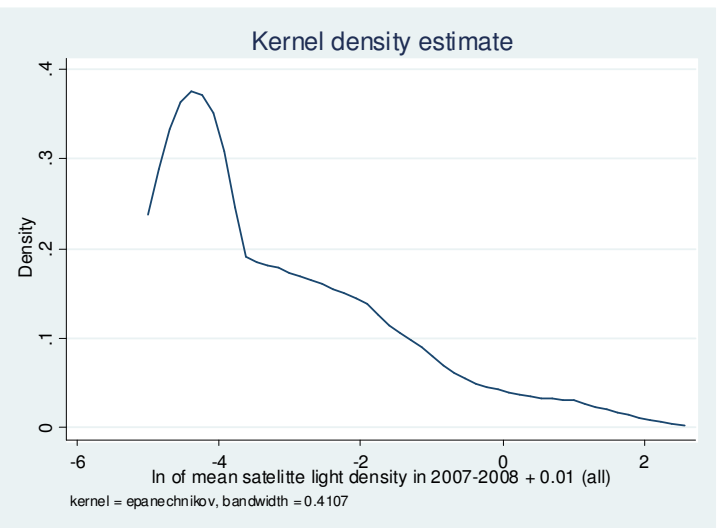

Appendix Figure 3b

Appendix Table 2 Panel $A$ reports summary statistics for all variables at the ethniccountry homeland level in the full sample (1,209 observations) that includes both partitioned (e.g., Ewe in Togo and Ewe in Ghana) and non-split ethnic regions (e.g., Ndebele in Botswana 
or the Luo in Kenya). Appendix Table 2 - Panel $B$ reports summary statistics for all variables in the full sample at the pixel level (120,501 observations). [Table 1 gives summary statistics for the sample of partitioned ethnic homelands].

\subsection{Further Evidence on the Identification Strategy}

In Appendix Table 3 we investigate whether differences in institutional quality across the border correlate with differences in various geographic, ecological, and natural resource characteristics at the pixel-level. The results (of these "similarity regressions") are thus similar to those reported in Table 2, where we performed the analysis at the partitioned-ethnic homeland level. With the exception of distance to the capital, within partitioned ethnicities differences in geography, ecology, location, and natural resources are small and not systematically linked to differences in national institutions.

In Figures $4 a-4 g$ we investigate whether observable characteristics jump discontinuously within partitioned ethnicities as one crosses the border towards the relatively more institutionally developed country. As in our baseline RD analysis (Figures $5 a-b$, Figures $7 a-b$ ), the figures plot the average value of the geographic, location, ecological and natural resource attribute for intervals (bins) of 5 kilometer width (the vertical line marks the national boundary). We look within 50 kilometers from each side of the boundary (total $100 \mathrm{~km}$ around the national border). The figures also plot the predicted value of the pixel-level geographic trait from a $3^{\text {rd }}$ order RD polynomial (on distance to the national border) fitted separately for pixels in the partitions that fall in the relatively high institutional quality country (where distance to the national border takes on positive values) and pixels falling in the relatively low institutional quality country (where distance takes on negative values). In line with the within-ethnicity estimates in Table 2 and the complementary (at the pixel-level) results reported in Supplementary Appendix Table 3 there are no discontinuities in geographic attributes crossing the national boundary towards the more institutionally developed country. 


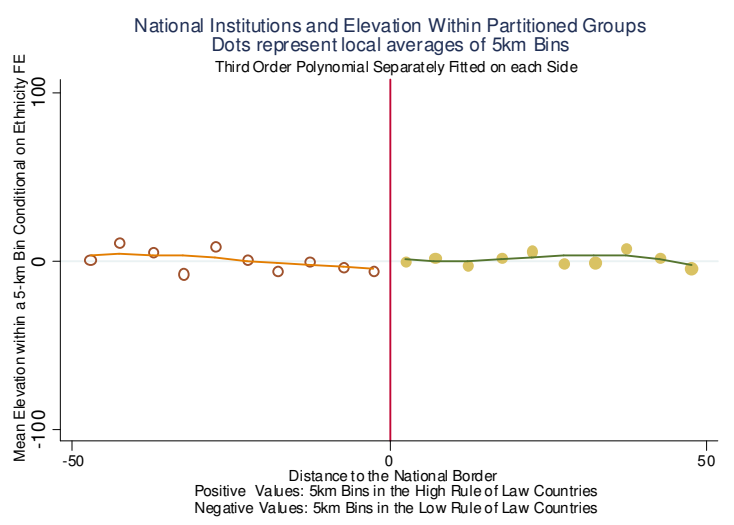

Appendix Figure 4a

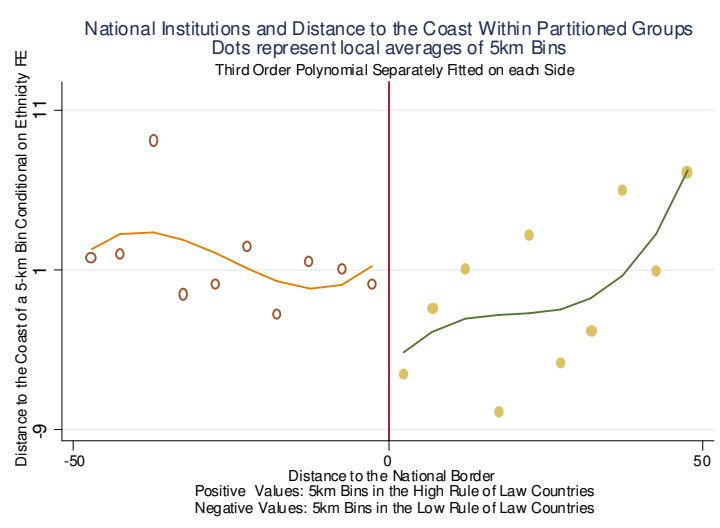

Appendix Figure 4c

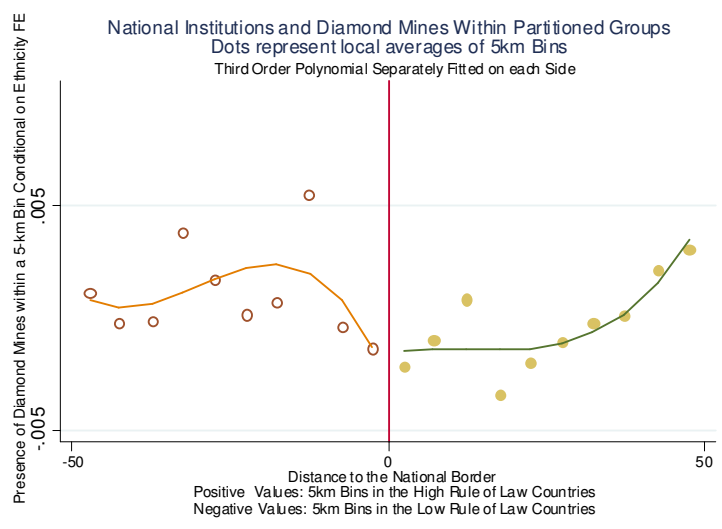

Appendix Figure 4e

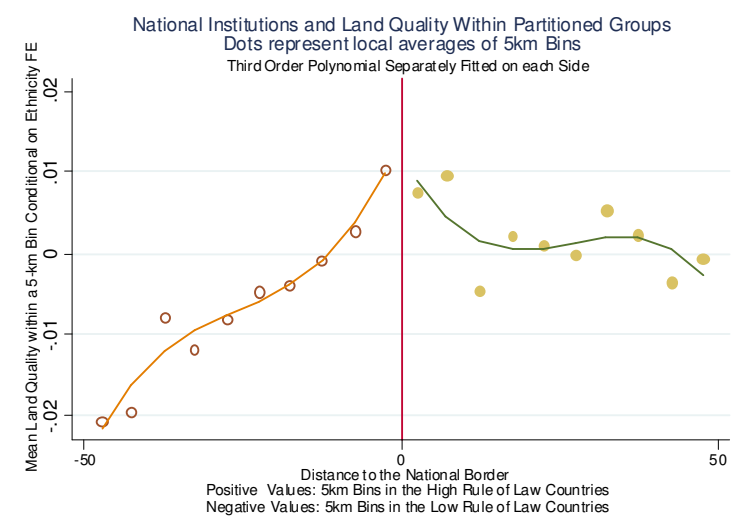

Appendix Figure 4b

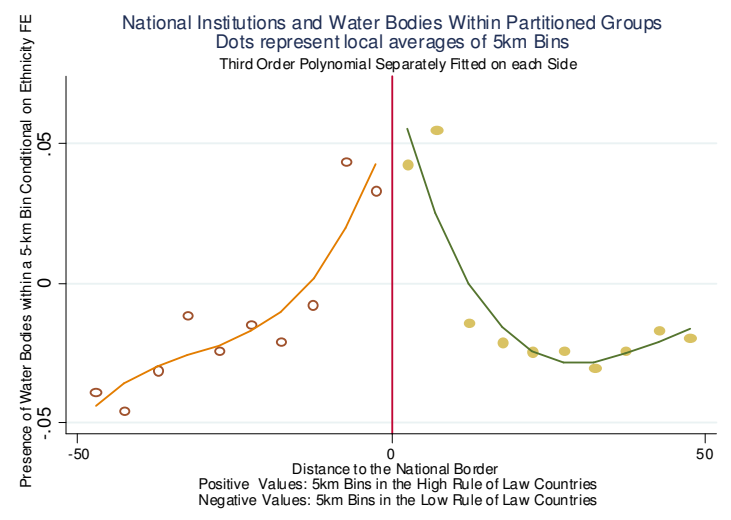

Appendix Figure 4d

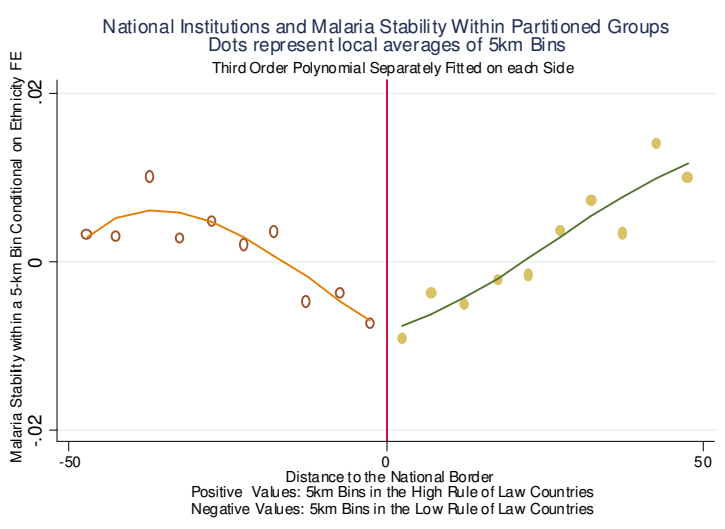

Appendix Figure 4f 


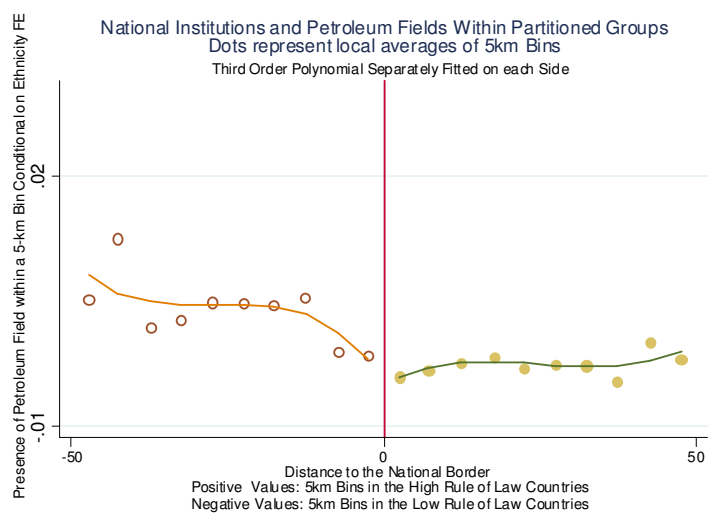

Appendix Figure 4g

\section{A Preliminary Analysis on What the Ethnicity Fixed Effects Capture}

We also conducted a preliminary investigation of the features that are behind the sizable drop of the cross-sectional estimates when we add the ethnicity constants (e.g., Tables 4-5) focusing on the role of geographic characteristics and ethnic-specific pre-colonial economic and institutional traits.

Observable Geographic Features First, in Appendix Table 4 we investigate how differences in geographical traits across border regions change with the inclusion of ethnicityspecific constants. Panel $A$ reports within-group estimates, whereas Panel $B$ reports the analogous cross-sectional estimates (i.e., without the ethnicity constants). Across all specifications, the cross-sectional differences are quantitatively larger than the within-ethnicity ones. For example, the cross-sectional estimates reveal a significant negative correlation between national institutions and the malaria stability index. Similarly, there is a positive and significant correlation between water areas and national institutions. However, these differences disappear, once we focus on adjacent border regions within the same ethnic homeland. This implies that by looking within neighboring border areas populated by the same group, we neutralize among other biases those driven by systematic differences in the geography.

Pre-colonial Ethnic Traits Second, in an attempt to identify ethnic-specific characteristics that weaken the role of national institutions in Appendix Table 5 we focused on the subset of partitioned ethnicities for which we have information on various economic, cultural, institutional, and anthropological pre-colonial traits from Murdock (1967). ${ }^{2}$ Out of the 826

\footnotetext{
${ }^{2}$ Murdock's (1967) data have been used recently by several authors (e.g., Fenske (2012), Gennaioli and Rainer (2007), Alsan (2012), Michalopoulos and Papaioannou (2013b), Michalopoulos, Naghavi, and Prarolo (2012),
} 
groups (shown in Figure 1) 534 may be linked to Murdock's (1967) Ethnographic Atlas. So the sample drops from 42,710 (see Table 4 - Panel $B$ ) to 27,661 pixels. In column (1) we regress luminosity on the rule of law index, simply conditioning on pixel-level (log) population density and $(\log )$ pixel area. ${ }^{3}$ The coefficient on the rule of law index is 0.115 and the estimate is statistically significant at $5 \%$. The coefficient is almost identical to the one found in the pixel-sample of all split ethnic homelands (Table 4-Panel $B$, column (1)).

In column (2) we include the full set of geographic and location controls, namely distance to the coast, distance to the capital city, distance to the national border, mean elevation, an indicator that takes on the value one for pixels with a water body, an index of malaria suitability, an index of land quality for agriculture, and indicators for the presence of diamond mines and petroleum fields. These geographic controls enter with significant point estimates in most specifications. The inclusion of this detailed set of environmental and ecological controls makes the estimate on national institutions drop considerably (by 40\%) to 0.0676; the coefficient retains significance though the $p$-value falls.

In column (3) we control for the complexity of pre-colonial political organization, using Murdock's jurisdictional hierarchy beyond the local community index. The index ranges from 0 to 4 and reflects the number of jurisdictional levels in each society above the local (usually village) level. A score of 0 indicates acephalous societies, scores of 1 and 2 indicate petty and large paramount chiefdoms, while a score of 3 and 4 indicate large states. The coefficient on the jurisdictional hierarchy index enters with a positive and highly significant coefficient; in line with the cross-ethnicity results of Michalopoulos and Papaioannou (2013b) pre-colonial political centralization correlates strongly with ethnic development. Most importantly given our focus, the introduction of this proxy of ethnic-specific pre-colonial political complexity makes the coefficient on the rule of law index decline (by approximately 20\%) to 0.059 and become statistically insignificant. This implies that the significant cross-sectional correlation between national institutions and economic development was partly driven by differences in pre-colonial political centralization across groups. ${ }^{4}$

In column (4) we add decile dummies reflecting ethnic-specific pre-colonial subsistence on agriculture and animal husbandry, respectively. Compared to the specification with the

Nunn (2008), Alesina, Giuliano, and Nunn (2013), Giuliano and Nunn (2013)) to study the role of various ethnic attributes, such as indigenous slavery, pre-colonial political centralization, local electoral norms, polygyny, use of plough, etc.

${ }^{3}$ Although most pixels are of the same size (2.5 x 2.5 decimal degrees), pixels intersected by the coast line, the national and ethnic boundaries are smaller.

${ }^{4}$ This result is also in line with the cross-country results of Gennaioli and Rainer $(2006,2007)$ who present cross-country regression evidence that pre-colonial ethnic-specific political centralization (averaged in each country) correlates with both institutional and economic development (as reflected in the rule of law index and log of per capita GDP in 2000, respectively). 
set of geographic controls in column (2), exploiting variation in current economic performance within groups of comparable pre-colonial economic organization makes the estimate on rule of law decline by half (from 0.0676 to 0.033 ) and become statistically insignificant. This result suggests that part of association between national institutions and ethnic development was driven by deeply-rooted ethnic differences in the organization of the local economy.

In column (5) we jointly control for the structure of the subsistence economy and the degree of political centralization at the time of colonization; the coefficient on the rule of law remains both quantitatively and statistically insignificant; in contrast the ethnic-specific index of pre-colonial political centralization retains its economic and statistical significance. In columns (6)-(10) we show that a similar pattern obtains when we proxy national institutions with the control of corruption index.

Summary Overall, the results in Appendix Tables 4 and 5 imply that the ethnicityspecific constants capture (among other traits) both variation in observable geographic features as well as differences in the pre-colonial structure of the economy and the political organization of each group.

\section{Sensitivity Analysis on the Average Effect of National Insti- tutions on Ethnic Development}

We have performed numerous sensitivity checks to explore the robustness of our finding in the first part of the paper (Section 4) showing the lack of a systematic association between national institutions and regional development within partitioned ethnic homelands. Specifically.

Luminosity in Levels In Supplementary Appendix Table 6 we report estimates expressing luminosity in levels. To account for the non-linear nature of the data (see Appendix Figure $3 a$ above), on top of the simple LS estimates (given in Panel $A$ ) we also report Poisson pseudo-maximum likelihood estimates (in Panel $B$ ), that are better suited to account for extreme values and the large number of zeros (Wooldridge (2002), Silva and Tenreyro (2006)). In line with our baseline estimates (Tables $4-5$ ), the coefficient on the national institutions measures in the ethnicity fixed effects models is small and statistically indistinguishable from zero.

Other Measures of Institutional Quality from the Governance Matters Database In Supplementary Appendix Table 7 we report results associating light density at the country-ethnicity level with other aspects of governance, using data from World Bank's Gov- 
ernance Database (Kaufmann, Kraay, and Mastruzzi (2008)). Besides the rule of law and the control of corruption measures that we use in the main paper, this database gives proxies of national institutional quality along four other dimensions, government effectiveness (in (1)$(2)$ ), regulatory quality (in (3)-(4)), voice and accountability (in (5)-(6)), and political stability (in (7)-(8)). These indexes also range from -2.5 to 2.5 with higher values reflecting better functioning national institutions. The coefficient on the cross-sectional estimates (reported in odd-numbered columns) is positive and statistically significant with the government effectiveness and the political stability indicators. The coefficients on the regulatory quality and voice and accountability are also sizable, though not significant. Yet once we add ethnicity fixed effects to explore variation across the national border within partitioned ethnic groups, all coefficients drop sizably and they are all statistically insignificant. This shows that on average differences in national institutions do not correlate with differences in development -as reflected in satellite images on light density at night.

Institutional Quality in 2007 By averaging the national institutions measures across all years that we have data before 2007, we account for yearly fluctuations and hence decrease measurement error; we also investigated whether the lack of within-ethnicity correlation between national institutions and subnational development is driven by the averaging of the national institutions measures over the period of 1996 - 2006. In particular, we experimented using the values of these measures in specific years. We continue finding weak and insignificant correlations between national institutions and within-group economic performance. In Supplementary Appendix Table 8 we report estimates using the 2007 values of national institutional quality. Panel $A$ gives results at the country-ethnic homeland level, while Panel $B$ gives analogous results at the pixel-level. The pattern is unchanged. While in the cross-section there is a significantly positive association between national institutions and subnational development, once we introduce ethnicity fixed effects the coefficients on national institutions drop considerably (by more than $50 \%$ at the country-ethnicity level and by $75 \%$ at the pixel level) and become statistically insignificant.

Artificial Borders A merit of our approach to study the role of national institutions in shaping subnational development within partitioned ethnic homelands is that there is wide agreement that border design in Africa was to a great extent arbitrary (see Asiwaju (1985) and Englebert (2009) for references). As the British prime minister at the time of Africa colonization, Lord Salisbury summarized "we have been engaged in drawing lines upon maps where no white man's feet have ever tord; we have been giving away mountains and rivers and lakes to each other, only hindered by the small impediment that we never knew exactly where the 
mountains and rivers and lakes were." Moreover, in Michalopoulos and Papaioannou (2013a) we establish formally that apart from the land mass and water area of an ethnicity's historical homeland, no other geographic, economic, and historical trait predicts ethnic partitioning by the national borders.

Nevertheless, in an attempt to further mitigate concerns regarding the endogeneity of border drawing and motivated by the work of Alesina, Easterly, and Matuszeski (2011) we constructed the fractal dimension of each bilateral border segment using the box-count method that aims at identifying straight versus squiggly borders. The intuition behind this measure is that more straight-line like borders are more likely to be arbitrary compared to more squiggly ones.

The fractal dimension is constructed in the following manner: First, we generate grids of various dimensions. The smallest box size we use is 0.001 by 0.001 decimal degrees (normalized to 1). We also construct grids with box sizes of $2,3,4,6,8,16,32,64$, and 128. Second, we project each of these grids onto a country's border and we count the number of boxes that each bilateral border segment intersects. Third, using all ten data points (for each border) we regress In(boxcount) on In(boxsize); finally, we take the negative of the regression slope as the fractal dimension for the border segment.

Values of the fractal measure of African bilateral borders range between 1 and 1.0794, with lower values corresponding to more straight-line like borders. Consider Botswana, for example, which shares borders with Namibia, South Africa and Zimbabwe. The western border (with Namibia) has a fractal measure is 1.0139 (as the border largely follows longitudinal lines), while the eastern border with Zimbabwe has a higher fractal measure of 1.0154, as only parts of it follow straight lines; the southern border with South Africa has a fractal dimension of 1.0281, as it is much more squiggly (see Appendix Figure 5). The median fractal dimension across bilateral borders in Africa is 1.01825 and the standard deviation is 0.01394 .

After constructing the measures of border artificiality we re-estimated the empirical specification focusing on partitioned ethnic groups separated by relatively straight borders (fractal measure below the median). Appendix Tables $9 A$ and $9 B$ report the results. In Appendix Table $9 A$ the unit of analysis is the ethnicity-country (see Figure $2 a$ in the main part of the paper), whereas Appendix Table $9 B$ gives the results at the pixel level (see Figure $2 b$ in the main part of the paper. Focusing on partitioned ethnic homelands in this subset of African borders that are more likely to be artificial produces similar results. Across all specifications with ethnicity fixed effects the coefficient on the two proxies of national institutions is very 
small and always statistically insignificant.

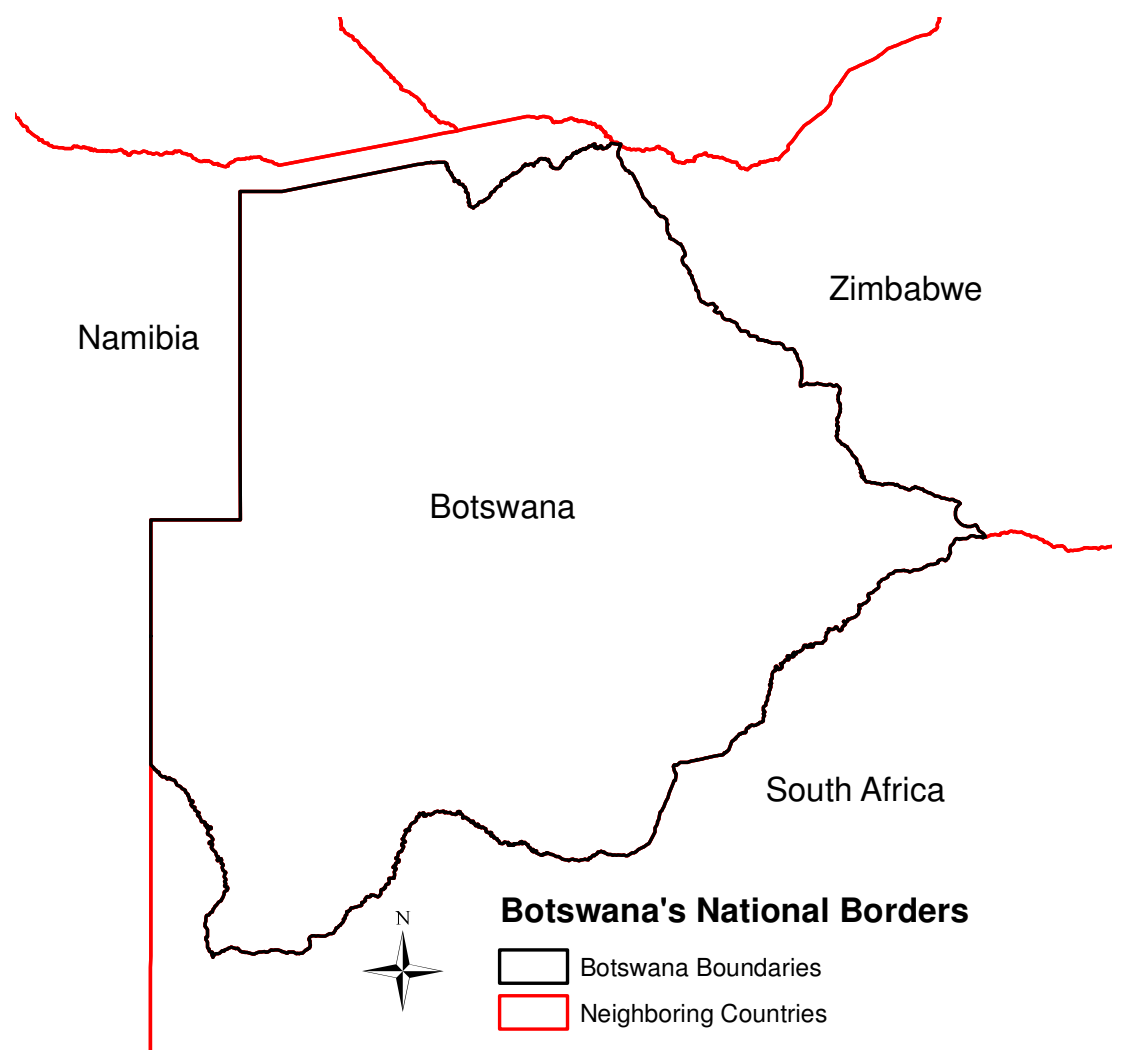

Appendix Figure 5

Migration Anecdotal evidence suggests that national boundaries across Africa are poorly enforced due to the lack of border patrolling, poor demarcation, and geographic conditions (desert areas in the North, rainforest in Central Africa). Hence, if people migrate to take advantage of higher incomes in regions with better national institutions, mobility across national boundaries may attenuate income differences on the two sides of the border. In this case, however, population density should differ systematically between partitions as a result of migration towards those located in the countries with relatively better institutions. Alternatively, it may be the case that population in the low institutional quality country clusters near the border to migrate daily on the other side to work. ${ }^{5}$ We explore in detail the issue of migration with two alternative approaches.

In Supplementary Appendix Table 10 we directly examine the effect of national institutions on population density; for completeness we use two different sources of population density

\footnotetext{
${ }^{5}$ Note that the ease of migration might not necessarily lead to attenuation bias. In fact, migration might accentuate the importance of institutions if firms relocate to take advantage of the better institutional environment on the other side of the border. Hence, as a result of migration of firms and people this would imply that aggregate economic activity, captured by luminosity and/or population density, would be magnified in the partition enjoying better national institutions. The results below suggest that this is not the case.
} 
estimates at the grid level: the United Nations Environmental Program (results reported in Panel $A$ ) and the Gridded Population of the World Database (in Panel $B$ ). There is no systematic association between the quality of national institutions and log population density in border areas where partitioned ethnicities reside; the coefficient is small and even changes sign across specifications. This suggests that the insignificant within-ethnicity relationship between national institutions and regional development is not likely to be driven by migration.

Moreover, to the extent that population density reflects regional development (as in Malthusian models), the insignificant coefficients of rule of law and control of corruption provide additional evidence that national institutions are not systematically linked to ethnic development.

To further account for cross-border migration we excluded areas close to the border. Doing so, we account for potential temporary migration and for local trade. By excluding areas close to the national border we also mitigate concerns related to lights' stealing and bleeding (and/or blooming) in the luminosity data. Supplementary Appendix Table 11 reports crosssectional (in odd-numbered columns) and within-ethnicity specifications (in even-numbered columns). For completeness we report results both at the country-ethnicity homeland level (in Panel $A$ ) and at the pixel level (in Panel $B$ ). In columns (1), (2), (5), and (6) we exclude areas within 25 kilometers from each side of the national border (total 50 kilometers), while in columns (3), (4), (7), and (8) we exclude regions within 50 kilometers of each side of the border (total 100 kilometers). The results are similar to the baseline estimates (in Tables 4 and 5). In the cross section there is a strong positive correlation between institutional quality and luminosity; however, the coefficient drops sizably and becomes statistically indistinguishable from zero when we add ethnicity fixed effects.

Regional Variation Supplementary Appendix Table 12 reports ethnicity fixed effects estimates at the ethnic homeland level (in Panel $A$ ) and at the pixel level (in Panel $B$ ), excluding each time a different African region (using the classification of Nunn (2008)). The coefficient on the national institutions is small and in all but two specifications statistically indistinguishable from zero.

Border-Fixed-Effects Estimates Our analysis focuses on border areas populated by split groups. Due to the arbitrary drawing of African borders the majority of national boundaries have resulted in partitioned ethnic homelands. For example, a segment of the Kenyan-Tanzanian border splits the Maasai, the Uganda-Congo border straddles the homeland of the Konjo, whereas the Tonga is the only group whose homeland is intersected by a segment of the national boundary separating Zimbabwe from Zambia. So, for border segments that 
generate partitioned groups, border fixed effects are likely to capture variation roughly similar to the one captured by ethnicity constants. This is shown to be the case in Supplementary Appendix Table 13 where we introduce in the sample of the two-major partitions border fixed effects instead of group-specific constants.

Afrobarometer Data We repeated our analysis using data from the 2005 Afrobarometer household surveys on public goods provision and education as the dependent variable. Due to limited coverage, the sample reduces to 32 partitioned ethnic groups with at least one enumeration area in each of the partitions across the countries that the Afrobarometer surveys cover. In spite of the reduction in sample size, it is useful repeating the analysis with survey data both for cross-validation of the luminosity data and because one of the primary channels associating national institutions with development is the provision of public goods. Our specification reads:

$$
y_{e, i, c}=\gamma I Q L_{c}+\lambda P D_{e, i, c}+a_{i}+\varepsilon_{e, i, c} .
$$

The dependent variable, $y_{e, i, c}$, reflects average household's access to an electricity grid, access to piped water, access to a sewage system, and average years of schooling in Afrobarometer's enumeration area, $e$, that falls in the historical homeland of partitioned ethnicity $i$ in country $c$. In each enumeration area (town, village) we use the average value of public goods provision measures across surveyed households.

Supplementary Appendix Table 14 reports the results. We start our analysis using luminosity as the dependent variable. Columns (1)-(2) report estimates associating national institutions and luminosity across Afrobarometer's enumeration areas (luminosity is calculated within a $10 \mathrm{~km}$ radius from each enumeration area's centroid). Column (1) shows that there is a significant positive association between rule of law (or the control of corruption index) and luminosity across cities/villages. Yet the correlation weakens considerably and changes sign when we include ethnicity fixed effects (in (2)). ${ }^{6}$

In columns (3)-(4) we use as the dependent variable household's access to an electricity grid (the average is $53.5 \%$ ). The cross-sectional estimates show that electrification is greater in towns/villages falling in countries with better institutions. Yet once we focus within the same historical ethnic homeland to examine whether households' access to an electricity grid is higher in countries with more developed national institutions, the correlation weakens considerably and loses significance. In columns (5)-(6) we associate national institutions with household

\footnotetext{
${ }^{6}$ We cannot estimate local (close to the national border) regressions with the Afrobarometer data because the sample size of Afrobarometer enumeration areas drops considerably when limiting attention to areas close to the national border.
} 
access to piped water across Afrobarometer's enumeration areas (the mean is 0.49). While the cross-sectional correlation is positive, adding ethnicity fixed effects to exploit across-the-border variation in villages/towns of the same ethnic group, makes the coefficient insignificant. In columns (7)-(8) we examine whether access to a sewage system is systematically associated with national institutions (on average access to a sewage system is 0.24 ) whereas in columns (9)-(10) we use as the dependent variable average years of schooling across respondents within each enumeration area (on average household heads have 3 years of education). The estimates, albeit less precisely estimated, echo our previous findings. Across all permutations the within-ethnicity coefficients on rule of law and control of corruption are small and statistically indistinguishable from zero.

Two-Dimensional RD Given the spatial dimension of our data, following Dell (2010) we also experimented with two-dimensional RD polynomials in latitude and longitude. Supplementary Appendix Table 15 reports these results. Across all model permutations, the RD estimates on the high national institutions index are very small (usually less than 0.01) and statistically indistinguishable from zero.

\section{Sensitivity Analysis on the Heterogeneous Role of National Institutions}

We estimated various specifications $(a)$ illustrating the heterogeneous relationship between national institutions and subnational development (that is graphically shown in Figures $6 a-6 b$ ) and (b) linking this heterogeneity to distance to the capital. In this section we present the main robustness checks.

\subsection{Heterogeneity across and within African Regions}

Heterogeneity across African Regions As a first pass of exploring potential heterogeneity of the within-ethnicity association between national institutions and regional development, we estimated separate models for each of the five main African regions (using the classification of Nunn (2008)). Supplementary Appendix Table 16 reports LS estimates in the two major partitions of split groups examining whether ethnic development is higher in the country with the relatively better institutional quality. The estimates reveal that for groups split across countries in Eastern and Western Africa, local economic activity is not systematically linked to the quality of national institutions. In contrast, a positive correlation between luminosity and institutional quality emerges when we focus on Southern Africa. A positive association between institutional quality and regional development emerges also for Central 
African countries (though the estimate is much smaller and not always significant). In contrast, when we look within split groups in North Africa a negative correlation emerges (though the number of split groups is very small). These findings suggest that the overall weak relationship between national institutions and subnational development masks considerable regional heterogeneity.

A Closer Look at Regional Heterogeneity Supplementary Appendix Table 17 reports specifications similar to those in Appendix Table 16, but we now estimate separately the relationship between national institutions and luminosity for pixels close to and pixels far from the capital cities, respectively. To distinguish between pixels far and close to the capitals we use the median of the within-country distance to the respective capital city as the cutoff. A couple of interesting patterns emerge -that are in line with the baseline estimates (in Table 8).

Across all five African regions the estimate on the high rule of law indicator is larger when we focus on pixels of split groups close to the capital cities. This is consistent with the findings of Table 8. In Central Africa, Eastern Africa and Western Africa the high rule of law indicator is positive and large (though not always significant) when we restrict estimation to areas close to the respective capitals; in contrast, the coefficient is zero for split groups that are far from the capital. The results from Northern Africa are also in line with our baseline estimates. Within North Africa, where the overall association between institutional quality and development was found to be negative (Appendix Table 16) a significantly positive association emerges for split groups that are close to the respective capitals. Though there are only two groups, the pattern is in line with the estimates in the full sample of split ethnicities. ${ }^{7}$ Unlike the rest of the African regions, in Southern Africa a positive and significant association between national institutions and regional development obtains also for groups whose partitions are far from the respective capital cities.

\subsection{Heterogeneity and Proximity to the Capital Cities}

\section{Proximity to the Capital and National Institution Using All Pixels within}

Split Groups In Table 8 we focused separately on split groups that have pixels on both sides of the border either close to or far from the respective capital city. The reason for splitting the sample was to illustrate the pattern on the differential importance of national institutions in areas far and close from the capital in the most transparent manner and motivate the ensuing $\mathrm{RD}$ graphs accordingly (Figures $7 A-7 b$ ). However, a limitation of this approach is that we

\footnotetext{
${ }^{7}$ These groups are the Hamama and the Tunisians which are split between Algeria and Tunisia. Luminosity for these two groups that are close to the respective capitals is much higher in Tunisia, where the rule of law index equals 0.294 compared to Algeria's rule of law index which is two standard deviations lower, -0.712 .
} 
do not use information from the entire sample of split groups (that also includes split groups where pixels on the one side of the border are close to the capital, while pixels at the other side of the border are far from the capital).

In Supplementary Appendix 18 we report estimates pooling all observations (pixels) from split groups allowing the coefficient on national institutions (and all other controls) to differ for pixels close to the capital city. We use two different thresholds to define the close (proximity to the capital) indicator (dummy variable). In columns (1)-(4) we use as a cutoff the median of capital distance computed across all pixels in Africa, whereas in columns (5)-(8) we calculate the within-country median distance to the capital and use the latter to classify pixels accordingly. The evidence suggests that the coefficient on national institutions is zero and insignificant for pixels far from the capital; in contrast the coefficient on the rule of law index for pixels that are close (or relatively close) to the capital is positive and significant, illustrating that institutional and regional development do correlate but only in the vicinity of the capitals.

Dropping Iteratively Each African Region In Supplementary Appendix Table 19 we show that the differential role of national institutions far and close to the capital city is not driven by a specific region of the continent. We follow the format of Appendix Table 18 and pool together all pixels from partitioned groups allowing the coefficient on national institutions (and all control variables) to differ for pixels relatively close to the respective capital city. Iteratively we drop from the estimation partitioned ethnicities that fall into one of the five main African regions. The pattern is similar to the one where we used information from all partitioned African ethnic homelands (reported in Appendix Table 18). The diminishing role of national institutions for regions far from the capital city is a rather general phenomenon of the African landscape and is not driven by one particular region.

In Appendix Table 20 instead of pooling all observations (pixels) from all partitioned ethnic homelands we follow the structure of the baseline results in Table 8 and we estimate separate specifications for split groups that have pixels on both sides of the border that are close (far) from the respective capitals. The results are qualitatively and quantitatively comparable to the ones shown in Appendix Table 19 and Table 8.

Alternative Measures of Institutional Quality For completeness we re-estimated all models using the other four composite measures of national institutions from the Governance Indicators, namely bureaucratic quality, regulatory quality, voice and accountability, and political stability. Supplementary Appendix Table 21 shows that the pattern revealed in Table 8 (and Appendix Table 18) obtains also with these alternative proxies of national insti- 
tutions. The overall association between institutional quality and regional development within the homelands of partitioned ethnicities is weak and often insignificant (see also Supplementary Appendix Table 7). Yet for the part (pixels) of partitioned groups that are close to the respective capitals differences in national institutions across the border do translate into significant differences in regional development. This applies to all institutional quality measures but the political stability index. For example, the estimate on the bureaucratic (regulatory) quality suggests that pixel-level luminosity is 0.109 (0.079) higher in the partitions close to the capital in the country with the better national institutions. In contrast the analogous estimates for pixels of split groups far from the capitals are close to zero and statistically insignificant (one exception is the regulatory quality index which although similarly small remains significance at $10 \%)$.

Unbundling Institutions There is a wealth of measures proxying institutional quality across countries. So far we have employed the most commonly used ones, namely the rule of law and control of corruption indexes from the World Bank Governance Indicators (Kaufmann, Kraay, and Mastruzzi (2008)). This dataset has the advantage that unlike other measures, provides coverage for all African countries assuaging concerns that the results are biased by the exclusion of relatively weak states (like Somalia, Liberia, Libya etc.) which are not covered by other datasets. Moreover, World Bank's Governance Indicators aggregate various institutional quality measures across six dimensions (through principal components), accounting effectively for idiosyncrasies and systematic biases and thus minimizing measurement error. Yet, we also experimented with alternative measures of national institutions finding a similar pattern. In Supplementary Appendix Table 22 we report estimates using Polity's executive constraints index to capture "property rights institutions" and indicators of legal formalism (from the work of Djankov, La Porta, Lopez-de-Silanes, and Shleifer (2003)) to proxy for "contractual" institutions. This approach (and exact measures) follows Acemoglu and Johnson (2005), who in turn attribute it to Douglas North's distinction of state's basic functions, i.e., protect investors from expropriation and facilitate economic activity by establishing a sound legal infrastructure (North (1981)).

In columns (1)-(3) we measure "property rights" institutions using the average of the executive constraints index over the period 1991-2006. The coefficient on executive constraints within all partitioned ethnicities (in column (1)) is small and statistically insignificant. The coefficient on the property rights proxy is larger (though still statistically insignificant) when we restrict estimation to areas of partitioned ethnicities close to the capital. In columns (4)(6), we follow Acemoglu, Johnson, Robinson, and Yared (2008) and proxy "early" property 
rights institutions using the average value of executive constraints in the first decade after independence (so for most countries, we use the mean value in the 1960s). These specifications have the benefit that we use predetermined proxies of national institutions. In line with the evidence so far there is no systematic association between institutional quality at independence and subnational development in the full sample of split ethnicities (in (4)). Nevertheless, the coefficient on executive constraints at independence is seven times larger for regions close to the capitals (0.0711) compared to regions far from the capital centers (0.01), though both estimates are statistically insignificant.

In columns (7)-(12) we report estimates using two legal formalism indicators from World Bank's Doing Business Project, that are based on Djankov, La Porta, Lopez-de-Silanes, and Shleifer (2003) and Djankov, Mc Liesh, and Shleifer (2007); we use the most recent update of the Doing Business Database rather than the original measures to increase the sample size (though still there is no coverage for Somalia, Libya, Ivory Coast, and Liberia). The merit of looking at these measures of legal quality is that they reflect a specific aspect of the institutional environment. In columns (7)-(9) we use the log number of days necessary to resolve through the court system a simple dispute arising from the enforcement of a contract worth twice the country's per capita GDP. In columns (10)-(12) we use the log number of procedures needed to resolve this dispute via courts. The estimate in the full sample of split ethnicities (in columns (7) and (10)) is negative, implying that dysfunctional, slow, and formalistic legal systems are associated with a lower level of development; yet the estimates are small and statistically indistinguishable from zero. However, unlike areas far from the capitals where dysfunctional legal institutions have no bearing on regional development, the relationship between local economic activity and contractual institutions becomes much stronger for partitioned ethnicities close to the capital cities.

Distance to the Capital, State Presence and Public Good Provision In Appendix Table 23 we provide further evidence on the weak penetration of state's basic functions in areas far from the capital cities using micro-level data from the Afrobarometer Surveys covering close to 20,000 individuals from 17 countries. The within-country specifications show that proximity to the capital correlates negatively with the provision of public goods by the state and the easiness of obtaining an identity document. In particular, the estimates in columns (1)-(4) show that respondents residing in enumeration areas (towns/villages) further from the capital find it increasingly difficult to obtain an identity document (such as a birth certificate, driver's license, passport or a voter card). The same pattern applies when we employ as a dependent variable an ordered index reflecting the difficulty obtaining basic household services 
(like piped water, electricity or telephone) from the government in columns (5)-(8). These results corroborate the pattern shown in Table 10 pointing out the declining state presence in areas further from the capital centers. 


\section{Variables' Definitions}

\subsection{Afrobarometer Sample}

Access to an electricity grid: Assessed by the field supervisor "whether in the enumeration area there is an electricity grid that most houses could access". Source: 2005 Afrobarometer Surveys; available at http://www.economics.harvard.edu/faculty/nunn/data_nunn

Access to piped water: Assessed by the field supervisor "whether in the enumeration area there is a piped water system that most houses could access". Source: 2005 Afrobarometer Surveys.

Access to sewage system: Assessed by the field supervisor "whether in the enumeration area there is a sewage system that most houses could access". Source: 2005 Afrobarometer Surveys.

Schooling: Average years of schooling across respondents within Afrobarometer's enumeration areas. Source: 2005 Afrobarometer Surveys.

Difficulty to obtain identity document: Ordered variable based in individual responses to the following question (Question Q71a): "Based on your experience, how easy or difficult is to obtain the following services? Or do you never try and get these services from government: An identity document (such as a birth certificate, driver's license, passport or voter card)? "Value Labels: 1=Very Difficult, 2=Difficult, 3=Easy, 4=Very Easy, 7=Never Try. If the answer is "Never Try" then looked at Question Q73a "Why do you never try to get: An identity document?" if the answer is " $3=$ Govt does not provide it" then we replace those respondents with "1=Very Difficult" for the Q71a. For the rest that have answered "7=Never Try" in Q71a we assign them as missing.

Difficulty to obtain household services: Ordered variable based in individual responses to the following question (Question Q71b): "Based on your experience, how easy or difficult is to obtain the following services? Or do you never try and get these services from government: Household services (like piped water, electricity or telephone)?" Value Labels: $1=$ Very Difficult, $2=$ Difficult, $3=$ Easy, $4=$ Very Easy, $7=$ Never Try. If the answer is "Never Try" then looked at Question Q73b "Why do you never try to get: Household services?" if the answer is " $3=$ Govt does not provide it" then we replace those respondents with " $1=$ Very Difficult" for the Q71b. For the rest that have answered "7=Never Try" in Q71b we assign them as missing. 


\subsection{Country-Level Institutional Quality Measures}

Bureaucratic Quality: The index "captures perceptions of the quality of public services, the quality of the civil service and the degree of its independence from political pressures, the quality of policy formulation and implementation, and the credibility of the government's commitment to such policies." The standardized index ranges from -2.5 to +2.5 with higher values indicating better functioning institutions. We use the average value over the period $1996-2006$. Source: World Bank Governance Matters Indicators Database (Kaufmann, Kraay, and Mastruzzi (2008)). available at: http://info.worldbank.org/governance/wgi/index.asp

Regulatory Quality: The index "captures perceptions of the ability of the government to formulate and implement sound policies and regulations that permit and promote private sector development." The standardized index ranges from -2.5 to +2.5 with higher values indicating better functioning institutions. We use the average value over the period $1996-$ 2006. Source: World Bank Governance Matters Indicators Database (Kaufmann, Kraay, and Mastruzzi (2008)).

Voice and Accountability: The index "captures perceptions of the extent to which a country's citizens are able to participate in selecting their government, as well as freedom of expression, freedom of association, and a free media." The standardized index ranges from -2.5 to +2.5 with higher values indicating better functioning institutions. We use the average value over the period 1996 - 2006. Source: World Bank Governance Matters Indicators Database (Kaufmann, Kraay, and Mastruzzi (2008)).

Political Stability and Absence of Violence: The index "measures perceptions of the likelihood that the government will be destabilized or overthrown by unconstitutional or violent means, including politically-motivated violence and terrorism." The standardized index ranges from -2.5 to +2.5 with higher values indicating better functioning institutions. We use the average value over the period 1996 - 2006. Source: World Bank Governance Matters Indicators Database (Kaufmann, Kraay, and Mastruzzi (2008)).

Executive Constraints: Standardized (to range $0-1$ ) index capturing constraints on the executive. We take the average over the period 1991 - 2006. Source: Polity IV Project. (Marshall, Jaggers, and Gurr (2010).

Available at: http://www.systemicpeace.org/polity/polity4.htm

Executive Constraints at independence: Standardized (to range $0-1$ ) index capturing constraints on the executive in the first ten years after independence. Source: Polity IV Project (Marshall, Jaggers, and Gurr (2010).

Available at: http://www.systemicpeace.org/polity/polity4.htm

Legal Formalism 1 - Days for Contract Enforcement: Log number of days required 
to resolve a commercial lawsuit between two domestic businesses. The dispute involves the breach of a sales contract worth twice the income per capita of the economy. The case study assumes that the court hears arguments on the merits and that an expert provides an opinion on the quality of the goods in dispute. The time is measured from the perspective of an entrepreneur (the plaintiff) pursuing the standardized case through local courts. Source Doing Business Project (based on the methodology developed in Djankov et al. (2003); Djankov et al. (2007)).

Legal Formalism 2 - Procedures for Contract Enforcement: Log number of procedures required to resolve a commercial lawsuit between two domestic business. The dispute involves the breach of a sales contract worth twice the income per capita of the economy. The case study assumes that the court hears arguments on the merits and that an expert provides an opinion on the quality of the goods in dispute. The number of procedures is measured from the perspective of an entrepreneur (the plaintiff) pursuing the standardized case through local courts. Source Doing Business Project (based on the methodology developed in Djankov et al. (2003); Djankov et al. (2007)).

\subsection{Ethnic-Level Variables from Murdock (1967)}

Jurisdictional Hierarchy beyond Local Community: Ordered variable ranging from 0 to 4 indicating the number of jurisdictional levels (political complexity) in each society above the local level. A 0 indicates stateless societies, 1 and 2 indicate petty and large paramount chiefdoms (or their equivalent), 3 and 4 indicate large states. Source: Murdock (1967); variable code in the Ethnolinguistic Atlas v33; Available at:

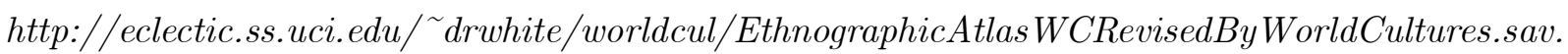

Pastoralism - Animal Husbandry: Set of ten indicators (dummy variables) reflecting the percentage of subsistence coming from animal husbandry for each ethnicity at the time of colonization. 1: 0\%-5\% dependence; 2 : $6 \%$-15\% dependence; $3: 16 \%-25 \%$ dependence; $4: 26 \%$ 35\% dependence; 5: 36\%-45\% dependence; 6: 46\%-55\% dependence; 7: 56\%-65\% dependence; 8: 66\%-75\% dependence; 9: 76\%-85\% dependence; and 10: 86\%-100\% dependence. Source: Murdock (1967); variable code in the Ethnographic Atlas v4.

Agriculture Dependence: Set of ten indicators (dummy variables) reflecting the percentage of subsistence coming from agriculture for each ethnicity at the time of colonization. 1: 0\%-5\% dependence; 2: 6\%-15\% dependence; 3: 16\%-25\% dependence; 4: 26\%-35\% dependence; 5: 36\%-45\% dependence; 6: 46\%-55\% dependence; 7: 56\%-65\% dependence; 8: $66 \%-75 \%$ dependence; 9: 76\%-85\% dependence; and 10: 86\%-100\% dependence. Source: Murdock (1967); variable code in the Ethnographic Atlas v5. 


\section{References}

Acemoglu, D., and S. Johnson (2005): "Unbundling Institutions," Journal of Political Economy, 113(5), 949-995.

Acemoglu, D., S. Johnson, J. A. Robinson, and P. Yared (2008): "Income and Democracy," American Economic Review, 98(3), 808-842.

Alesina, A., W. Easterly, and J. Matuszeski (2011): "Artificial States," Journal of the European Economic Association, 9(2), 246-277.

Alesina, A., P. Giuliano, and N. Nunn (2013): "On the Origins of Gender Roles: Women and the Plough," Quarterly Journal of Economics, 128(2), 169-530.

Alsan, M. M. (2012): "The Effect of the TseTse Fly on African Developmen," manuscript, Harvard University.

Asiwaju, A. (1985): "The Conceptual Framework," in Partitioned Africans, pp. 1-18. St. Martin Press, New York.

Dell, M. (2010): "The Persistent Effects of Peru's Mining Mita," Econometrica, 78(6), 839857.

Djankov, S., R. La Porta, F. Lopez-De-Silanes, and A. Shleifer (2003): "Courts," Quarterly Journal of Economics, 118(2), 453-517.

Djankov, S., C. Mc Liesh, and A. Shleifer (2007): "Private Credit in 129 Countries," Journal of Financial Economics, 84(2), 299-329.

Doll, C. N., J.-P. Muller, and J. G. Morley (2006): "Mapping Regional Economic Activity from Night-Time Light Satellite Imagery," Ecological Economics, 57(1), 75-92.

Elvidge, C., K. Baugh, E. Kinn, H. Kroehl, and E. Davis (1997): "Mapping of City Lights Using DMSP Operational Linescan System data," Photogrammetric Engineering and Remote Sensing, 63, 727-734.

Englebert, P. (2009): Africa, Unity, Sovereignty and Sorrow. Lynne Rienner Publishers, Inc., Boulder, Colorado.

Fenske, J. (2012): "African polygamy: Past and present," mimeo, Oxford University. 
Gennaioli, N., and I. Rainer (2006): "Precolonial Centralization and Institutional Quality in Africa," in Institutions and Norms in Economic Development, ed. by M. Gradstein, and K. Konrad. MIT Press.

(2007): "The Modern Impact of Precolonial Centralization in Africa," Journal of Economic Growth, 12(3), 185-234.

Giuliano, P., and N. Nunn (2013): "The Transmission of Democracy: From the Village to the Nation State," American Economic Review, Papers and Proceedings, 103(3), 86-92.

Henderson, V. J., A. Storeygard, and D. N. Weil (2012): "Measuring Economic Growth from Outer Space," American Economic Review, 102(2), 994-1028.

Kaufmann, D., A. KraAy, and M. Mastruzzi (2008): "Governance Matters VIII: Aggregate and Individual Governance Indicators, 1996-2007," Policy Research Working Paper Series 4654, The World Bank.

Michalopoulos, S., A. Naghavi, and G. Prarolo (2012): "Trade and Geography in the Origins and Spread of Islam," NBER Working Paper No. 18438.

Michalopoulos, S., and E. Papaionnnou (2011): "Divide and Rule or the Rule of the Divided? Evidence from Africa," NBER Working Paper No. 17184.

(2013a): "The Long-Run Effects of the Scramble for Africa," NBER Working Paper No. 17620.

— (2013b): "Pre-colonial Ethnic Institutions and Contemporary African Development," Econometrica, 81(1), 113-152.

Murdock, G. P. (1967): Ethnographic Atlas: A Summary. The University of Pittsburgh Press, Pittsburgh, PA.

North, D. C. (1981): Structure and Change in Economic History. Norton, New York, NY.

Nunn, N. (2008): "The Long Term Effects of Africa's Slave Trades," Quarterly Journal of Economics, 123(1), 139-176.

Pinkovskiy, M. (2013): "Economic Discontinuities at Borders: Evidence from Satellite Data on Lights at Night," mimeo MIT.

Silva, J. M. S., And S. Tenreyro (2006): "The Log of Gravity," Review o Economics and Statistics, 88(4), 641-658. 
Wooldridge, J. M. (2002): Econometric Analysis of Cross Section and Panel Data. MIT Press, Cambridge, MA. 
Appendix Table 1: Satellite Light Density at Night and Proxy Measures of Development within Ethnicities across Afrobarometer Enumeration Areas

\begin{tabular}{|c|c|c|c|c|c|c|c|c|c|c|c|c|}
\hline & \multicolumn{3}{|c|}{ Access to Piped Water } & \multicolumn{3}{|c|}{ Presence of Sewage System } & \multicolumn{3}{|c|}{ Presence of Electricity Grid } & \multicolumn{3}{|c|}{ Schooling Years } \\
\hline & $\frac{\text { All }}{(1)}$ & $\frac{\text { Split }}{(2)}$ & $\frac{\text { Non-Split }}{(3)}$ & $\frac{\text { All }}{(4)}$ & $\frac{\text { Split }}{(5)}$ & $\frac{\text { Non-Split }}{(6)}$ & $\frac{\text { All }}{(7)}$ & $\frac{\text { Split }}{(8)}$ & $\frac{\text { Non-Split }}{(9)}$ & $\frac{\text { All }}{(10)}$ & $\frac{\text { Split }}{(11)}$ & $\frac{\text { Non-Split }}{(12)}$ \\
\hline & \multicolumn{12}{|c|}{ Panel A: Using a $10 \mathrm{~km}$ radius } \\
\hline Log Light Density & $\begin{array}{c}0.0489 * * * \\
(0.0072)\end{array}$ & $\begin{array}{c}0.0436 * * * \\
(0.0135)\end{array}$ & $\begin{array}{l}0.0522 * * * \\
(0.0078)\end{array}$ & $\begin{array}{c}0.0379 * * * \\
(0.0066)\end{array}$ & $\begin{array}{c}0.0416^{* * *} \\
(0.0121)\end{array}$ & $\begin{array}{c}0.0355^{* * *} \\
(0.0111)\end{array}$ & $\begin{array}{c}0.0532 * * * \\
(0.0107)\end{array}$ & $\begin{array}{c}0.0575 * * * \\
(0.0154)\end{array}$ & $\begin{array}{c}0.0504^{* * *} \\
(0.0136)\end{array}$ & $\begin{array}{c}0.1236 * * * \\
(0.0179)\end{array}$ & $\begin{array}{c}0.1177 * * * \\
(0.0436)\end{array}$ & $\begin{array}{c}0.1272 * * * \\
(0.0212)\end{array}$ \\
\hline \multirow[t]{2}{*}{ Adjusted R-squared } & 0.363 & 0.322 & 0.380 & 0.326 & 0.263 & 0.343 & 0.393 & 0.348 & 0.397 & 0.541 & 0.511 & 0.543 \\
\hline & \multicolumn{12}{|c|}{ Panel B: Using a $5 \mathrm{~km}$ radius } \\
\hline Log Light Density & $\begin{array}{c}0.0433^{* * *} \\
(0.0066)\end{array}$ & $\begin{array}{c}0.0367^{* * *} \\
(0.0124)\end{array}$ & $\begin{array}{c}0.0477 * * * \\
(0.0070)\end{array}$ & $\begin{array}{c}0.0356^{* * *} \\
(0.0049)\end{array}$ & $\begin{array}{c}0.0425^{* * *} \\
(0.0085)\end{array}$ & $\begin{array}{c}0.0304^{* * *} \\
(0.0072)\end{array}$ & $\begin{array}{c}0.0491^{* * *} \\
(0.0090)\end{array}$ & $\begin{array}{c}0.0508^{* * *} \\
(0.0135)\end{array}$ & $\begin{array}{c}0.0478^{* * *} \\
(0.0119)\end{array}$ & $\begin{array}{c}0.1028^{* * *} \\
(0.0156)\end{array}$ & $\begin{array}{c}0.0997 * * * \\
(0.0330)\end{array}$ & $\begin{array}{c}0.1045^{* * *} \\
(0.0190)\end{array}$ \\
\hline Ethnicity FE & Yes & Yes & Yes & Yes & Yes & Yes & Yes & Yes & Yes & Yes & Yes & Yes \\
\hline Population Density & Yes & Yes & Yes & Yes & Yes & Yes & Yes & Yes & Yes & Yes & Yes & Yes \\
\hline Ethnicities & 282 & 97 & 185 & 282 & 97 & 185 & 282 & 97 & 185 & 282 & 97 & 185 \\
\hline Enumeration Areas & 2241 & 806 & 1435 & 2221 & 799 & 1422 & 2249 & 805 & 1444 & 2268 & 812 & 1456 \\
\hline Adjusted R-squared & 0.365 & 0.322 & 0.384 & 0.331 & 0.280 & 0.346 & 0.400 & 0.356 & 0.403 & 0.540 & 0.511 & 0.542 \\
\hline
\end{tabular}

The table reports ethnicity-fixed-effects estimates associating four proxy measures of development (using micro-level data from the Afrobarometer) with log satellite light density at night, $\log (0.01+$ light density). The unit of analysis is the enumeration area of the Afrobarometer Surveys. As within each enumeration area there are several households, we average household responses across the enumeration area and use the respective mean values as the dependent variable. In Panel A light density at night is the average light density in a radius of $10 \mathrm{~km}$ from the centroid of Afrobarometer's enumeration area. In Panel B light density at night is the average light density in a radius of $5 \mathrm{~km}$ from the centroid of Afrobarometer's enumeration area. The dependent variable is columns (1)-(3) reflects "whether in the enumeration area there is a piped water system that most houses could access" as assessed by the field supervisor.

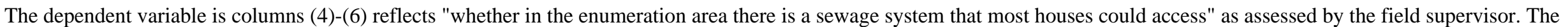

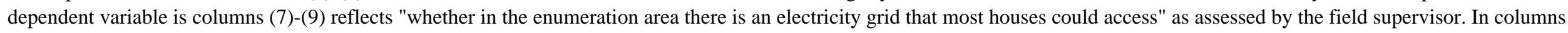

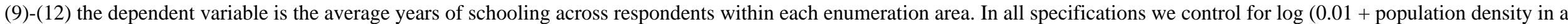

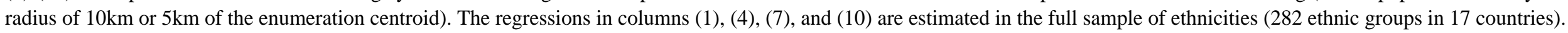

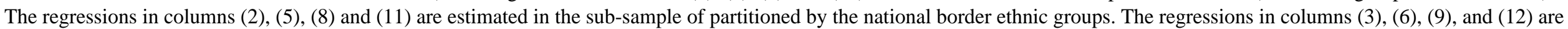

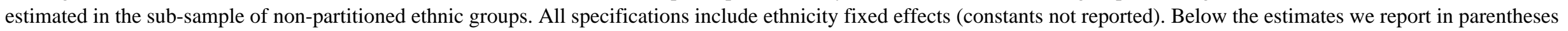
double-clustered standard errors at the country and at the ethnicity dimension. ${ }^{* *}$, ${ }^{* *}$, and * indicate statistical significance at the $1 \%$, $5 \%$, and $10 \%$ level, respectively. 


\section{Appendix Table 2: Summary Statistics in the Full Sample (Partitioned and Non-Partitioned Ethnic Groups)}

\begin{tabular}{|c|c|c|c|c|c|c|c|c|}
\hline variable & Obs. & mean & st. dev. & p25 & median & p75 & $\min$ & $\max$ \\
\hline & \multicolumn{8}{|c|}{ Panel A: All Country-Ethnic Homelands Sample } \\
\hline Light Density & 1209 & 0.368 & 1.567 & 0.000 & 0.018 & 0.136 & 0.000 & 25.140 \\
\hline Ln (0.01 + Light Density) & 1209 & -3.008 & 1.721 & -4.605 & -3.570 & -1.925 & -4.605 & 3.225 \\
\hline Ln (0.01 + Population Density) & 1209 & 2.787 & 1.828 & 1.886 & 3.070 & 4.016 & -6.673 & 7.432 \\
\hline Ln (1 + Water Area) & 1209 & 0.265 & 0.417 & 0.003 & 0.097 & 0.327 & 0.000 & 3.119 \\
\hline Ln (Area) & 1209 & 2.051 & 1.552 & 1.013 & 2.121 & 3.138 & -2.212 & 6.202 \\
\hline Mean Elevation & 1209 & 0.622 & 0.440 & 0.290 & 0.489 & 0.956 & 0.000 & 2.181 \\
\hline Land Suitability for Agriculture & 1209 & 0.410 & 0.238 & 0.255 & 0.424 & 0.572 & 0.001 & 0.979 \\
\hline Malaria Stability Index & 1209 & 0.725 & 0.339 & 0.512 & 0.891 & 1.000 & 0.000 & 1.000 \\
\hline Oil Deposit Indicator & 1209 & 0.084 & 0.278 & 0.000 & 0.000 & 0.000 & 0.000 & 1.000 \\
\hline Diamond Mine Indicator & 1209 & 0.093 & 0.291 & 0.000 & 0.000 & 0.000 & 0.000 & 1.000 \\
\hline Distance to the Capital City & 1209 & 0.508 & 0.367 & 0.263 & 0.414 & 0.639 & 0.010 & 1.882 \\
\hline Distance to the Sea Coast & 1209 & 0.604 & 0.431 & 0.224 & 0.563 & 0.931 & 0.000 & 1.739 \\
\hline Distance to the Border & 1209 & 0.107 & 0.118 & 0.020 & 0.061 & 0.159 & 0.000 & 0.637 \\
\hline Rule of Law & 1209 & -0.962 & 0.587 & -1.395 & -1.060 & -0.543 & -2.198 & 0.615 \\
\hline Control of Corruption & 1209 & -0.841 & 0.512 & -1.164 & -0.879 & -0.685 & -1.664 & 0.814 \\
\hline
\end{tabular}

\section{Panel B: Pixel Level. Full Sample}

\begin{tabular}{lcccccccc} 
Light Density & 120501 & 0.557 & 3.466 & 0.000 & 0.000 & 0.000 & 0.000 & 62.982 \\
Ln (0.01 + Light Density) & 120501 & -3.934 & 1.727 & -4.605 & -4.605 & -4.605 & -4.605 & 4.143 \\
Light Density 0-1 & 120501 & 0.158 & 0.364 & 0.000 & 0.000 & 0.000 & 0.000 & 1.000 \\
Ln (0.01 + Population Density) & 120501 & 2.244 & 1.828 & 0.882 & 2.325 & 3.583 & -5.198 & 10.101 \\
Water Area Indicator & 120501 & 0.132 & 0.338 & 0.000 & 0.000 & 0.000 & 0.000 & 1.000 \\
Ln (Area) & 120501 & 4.925 & 0.610 & 4.994 & 5.211 & 5.246 & 2.303 & 5.259 \\
Mean Elevation & 120501 & 662.516 & 496.491 & 294.000 & 533.111 & 998.444 & -702.000 & 4623.750 \\
Land Suitability for Agriculture & 119947 & 0.355 & 0.276 & 0.100 & 0.329 & 0.536 & 0.001 & 0.999 \\
Malaria Stability Index & 116896 & 0.665 & 0.423 & 0.134 & 0.978 & 1.000 & 0.000 & 1.000 \\
Oil Deposit Indicator & 120501 & 0.029 & 0.168 & 0.000 & 0.000 & 0.000 & 0.000 & 1.000 \\
Diamond Mine Indicator & 120501 & 0.003 & 0.053 & 0.000 & 0.000 & 0.000 & 0.000 & 1.000 \\
Distance to the Capital City & 120501 & 0.525 & 0.367 & 0.260 & 0.428 & 0.700 & 0.001 & 1.933 \\
Distance to the Sea Coast & 120501 & 573.221 & 432.284 & 193.790 & 495.168 & 901.139 & 0.111 & 1735.680 \\
Distance to the Border & 120501 & 190.413 & 226.369 & 51.240 & 124.073 & 243.834 & 0.000 & 1483.292 \\
Rule of Law & 120501 & -0.927 & 0.647 & -1.454 & -0.864 & -0.448 & -2.198 & 0.615 \\
Control of Corruption & 120501 & -0.775 & 0.585 & -1.141 & -0.871 & -0.464 & -1.664 & 0.814 \\
\hline
\end{tabular}

The table reports descriptive statistics for all variables employed in the empirical analysis for all ethnic homelands in Africa. Panel A reports summary statistics at the country-ethnicity level. Panel B reports summary statistics at the pixel level. The Data Appendix gives detailed variable definitions and data sources. 
Appendix Table 3: Validity of the Identification Design at the Pixel Level

\begin{tabular}{|c|c|c|c|c|c|c|c|c|c|}
\hline & \multicolumn{9}{|c|}{ Dependent variable is: } \\
\hline & $\begin{array}{l}\text { Area under } \\
\text { Water } \\
\text { Indicator }\end{array}$ & $\begin{array}{c}\text { Mean } \\
\text { Elevation }\end{array}$ & $\begin{array}{c}\text { Land } \\
\text { Suitability }\end{array}$ & $\begin{array}{l}\text { Malaria } \\
\text { Stability }\end{array}$ & $\begin{array}{c}\text { Oil } \\
\text { Indicator }\end{array}$ & $\begin{array}{l}\text { Diamond } \\
\text { Indicator }\end{array}$ & $\begin{array}{l}\text { Distance to } \\
\text { the Capital }\end{array}$ & $\begin{array}{l}\text { Distance to the } \\
\text { Sea Coast }\end{array}$ & $\begin{array}{l}\text { Distance to } \\
\text { the Border }\end{array}$ \\
\hline & (1) & (2) & (3) & (4) & (5) & (6) & (7) & (8) & (9) \\
\hline & \multicolumn{9}{|c|}{ Panel A: Rule of Law } \\
\hline $\begin{array}{l}\text { Rule of Law } \\
\text { Double-clustered s.e. }\end{array}$ & $\begin{array}{c}0.0136 \\
(0.0172)\end{array}$ & $\begin{array}{c}10.5747 \\
(39.5890)\end{array}$ & $\begin{array}{l}0.0093 \\
(0.0162)\end{array}$ & $\begin{array}{l}-0.0006 \\
(0.0171)\end{array}$ & $\begin{array}{c}0.0054 \\
(0.0033)\end{array}$ & $\begin{array}{l}-0.0005 \\
(0.0010)\end{array}$ & $\begin{array}{l}-0.1919 * \\
(0.1076)\end{array}$ & $\begin{array}{c}4.9043 \\
(25.2232)\end{array}$ & $\begin{array}{c}1.913 \\
(7.5431)\end{array}$ \\
\hline \multirow[t]{2}{*}{ Observations } & $\begin{array}{l}0.150 \\
42710\end{array}$ & $\begin{array}{l}0.760 \\
42710\end{array}$ & $\begin{array}{l}0.751 \\
42566\end{array}$ & $\begin{array}{l}0.871 \\
41149\end{array}$ & $\begin{array}{l}0.378 \\
42710\end{array}$ & $\begin{array}{l}0.025 \\
42710\end{array}$ & $\begin{array}{l}0.607 \\
42710\end{array}$ & $\begin{array}{l}0.950 \\
42710\end{array}$ & $\begin{array}{l}0.338 \\
42710\end{array}$ \\
\hline & \multicolumn{9}{|c|}{ Panel B: Control of Corruption } \\
\hline $\begin{array}{l}\text { Control of Corruption } \\
\text { Double-clustered s.e. }\end{array}$ & $\begin{array}{c}0.0038 \\
(0.0219)\end{array}$ & $\begin{array}{c}6.9204 \\
(45.7242)\end{array}$ & $\begin{array}{l}-0.0086 \\
(0.0202)\end{array}$ & $\begin{array}{l}-0.0135 \\
(0.0209)\end{array}$ & $\begin{array}{l}0.0064 * \\
(0.0038)\end{array}$ & $\begin{array}{l}-0.0007 \\
(0.0016)\end{array}$ & $\begin{array}{l}-0.1419 \\
(0.1263)\end{array}$ & $\begin{array}{c}7.1719 \\
(27.9690)\end{array}$ & $\begin{array}{l}1.7353 \\
(9.4991)\end{array}$ \\
\hline Adjusted R-squared & 0.150 & 0.760 & 0.751 & 0.872 & 0.377 & 0.025 & 0.586 & 0.950 & 0.338 \\
\hline \multirow[t]{2}{*}{ Observations } & 42710 & 42710 & 42566 & 41149 & 42710 & 42710 & 42710 & 42710 & 42710 \\
\hline & \multicolumn{9}{|c|}{ Panel C: High Rule of Law - Two Major Partitions of Split Groups } \\
\hline $\begin{array}{l}\text { High Rule of Law } \\
\text { Double-clustered s.e. }\end{array}$ & $\begin{array}{c}0.0096 \\
(0.0149)\end{array}$ & $\begin{array}{c}7.2195 \\
(30.4552)\end{array}$ & $\begin{array}{c}0.01 \\
(0.0125)\end{array}$ & $\begin{array}{l}0.0008 \\
(0.0171)\end{array}$ & $\begin{array}{l}0.0013 \\
(0.0037)\end{array}$ & $\begin{array}{l}-0.0008 \\
(0.0012)\end{array}$ & $\begin{array}{l}-0.1186 \\
(0.0777)\end{array}$ & $\begin{array}{c}1.5385 \\
(16.5715)\end{array}$ & $\begin{array}{l}7.2374 \\
(6.4173)\end{array}$ \\
\hline Adjusted R-squared & 0.152 & 0.766 & 0.759 & 0.868 & 0.380 & 0.026 & 0.627 & 0.954 & 0.348 \\
\hline \multirow[t]{2}{*}{ Observations } & 40209 & 40209 & 40074 & 38797 & 40209 & 40209 & 40209 & 40209 & 40209 \\
\hline & \multicolumn{9}{|c|}{ Panel D: High Control of Corruption - Two Major Partitions of Split Groups } \\
\hline $\begin{array}{l}\text { High Control of Corruption } \\
\text { Double-clustered s.e. }\end{array}$ & $\begin{array}{c}0.0009 \\
(0.0145)\end{array}$ & $\begin{array}{l}-26.3412 \\
(32.3645)\end{array}$ & $\begin{array}{l}0.0034 \\
(0.0132)\end{array}$ & $\begin{array}{l}0.0087 \\
(0.0178)\end{array}$ & $\begin{array}{c}0.0031 \\
(0.0036)\end{array}$ & $\begin{array}{c}0.0006 \\
(0.0010)\end{array}$ & $\begin{array}{c}0.0327 \\
(0.0889)\end{array}$ & $\begin{array}{l}-12.9125 \\
(16.6480)\end{array}$ & $\begin{array}{c}1.947 \\
(6.4677)\end{array}$ \\
\hline Adjusted R-squared & 0.152 & 0.766 & 0.758 & 0.868 & 0.380 & 0.026 & 0.609 & 0.954 & 0.346 \\
\hline Observations & 40209 & 40209 & 40074 & 38797 & 40209 & 40209 & 40209 & 40209 & \\
\hline Ethnicity Fixed Effects & Yes & Yes & Yes & Yes & Yes & Yes & Yes & Yes & Yes \\
\hline
\end{tabular}


The table reports within-ethnicity OLS estimates associating various geographical, ecological, and other characteristics at the pixel level with contemporary national institutions, as reflected in World Bank's Governance Matters rule of law index (in Panel A) and control of corruption index (in Panel B) in areas of partitioned ethnicities. In Panels C and $\mathrm{D}$ we focus on the two major partitions of an ethic group. The high institutional quality indicator takes on the value of one for pixels falling in the country with the higher value in the rule of law index (in Panel C) or in the control of corruption index (in Panel D).

The dependent variable in column (1) is an indicator that takes on the value of one for pixels with a water body (lakes, rivers, and other streams)); in column (2) is mean elevation; in column (3) is the an index of land suitability for agriculture; in column (4) is the average of a malaria stability index; in column (5) is an indicator for pixels with an oil field; in column (6) is an indicator for pixels with a diamond mine. In columns (7), (8), and (9) the dependent variable is the distance of the centroid of each pixel from the capital city, the sea coast, and the national border, respectively. The Data Appendix gives detailed variable definitions and data sources. Below the estimates we report in parentheses double-clustered standard errors at the country and the ethno-linguistic family dimensions. ***, **, and * indicate statistical significance at the $1 \%$, $5 \%$, and $10 \%$ level, respectively. 


\section{Appendix Table 4: Geographic Features between and within Ethnic Groups at the Country-Ethnicity Homeland Level}

\begin{tabular}{|c|c|c|c|c|c|c|c|c|c|c|}
\hline & \multicolumn{10}{|c|}{ Dependent variable is: } \\
\hline & $\begin{array}{l}\text { Ln (Land } \\
\text { Area) }\end{array}$ & $\begin{array}{c}\text { Ln (Area under } \\
\text { Water) }\end{array}$ & $\begin{array}{c}\text { Mean } \\
\text { Elevation }\end{array}$ & $\begin{array}{c}\text { Land } \\
\text { Suitability }\end{array}$ & $\begin{array}{l}\text { Malaria } \\
\text { Stability }\end{array}$ & $\begin{array}{c}\text { Oil } \\
\text { Indicator }\end{array}$ & $\begin{array}{l}\text { Diamond } \\
\text { Indicator }\end{array}$ & $\begin{array}{c}\text { Distance to the } \\
\text { Capital }\end{array}$ & $\begin{array}{c}\text { Distance to the } \\
\text { Sea Coast }\end{array}$ & $\begin{array}{l}\text { Distance to } \\
\text { the Border }\end{array}$ \\
\hline & (1) & $(2)$ & (3) & (4) & (5) & (6) & (7) & (8) & (9) & (10) \\
\hline & \multicolumn{10}{|c|}{ Panel A: Geographic Features within Groups } \\
\hline Rule of Law & -0.0474 & 0.048 & 0.0041 & 0.0091 & -0.015 & $0.0365^{*}$ & -0.0161 & -0.1887 & 0.0001 & -0.0037 \\
\hline Double-clustered s.e. & $(0.2058)$ & $(0.0453)$ & $(0.0217)$ & $(0.0184)$ & $(0.0230)$ & $(0.0199)$ & $(0.0433)$ & $(0.1233)$ & $(0.0178)$ & $(0.0049)$ \\
\hline Adjusted R-squared & 0.682 & 0.796 & 0.964 & 0.935 & 0.941 & 0.753 & 0.547 & 0.582 & 0.986 & 0.639 \\
\hline \multirow[t]{2}{*}{ Ethnicity Fixed Effects } & Yes & Yes & Yes & Yes & Yes & Yes & Yes & Yes & Yes & Yes \\
\hline & \multicolumn{10}{|c|}{ Panel B: Geographic Features across Groups } \\
\hline Rule of Law & 0.1217 & $0.1011^{*}$ & 0.0431 & -0.0023 & $-0.1216^{*}$ & 0.0066 & -0.0300 & $-0.2110 *$ & -0.1163 & 0.0016 \\
\hline Double-clustered s.e. & $(0.1962)$ & $(0.0524)$ & $(0.0932)$ & $(0.0413)$ & $(0.0676)$ & $(0.0367)$ & $(0.0497)$ & $(0.1132)$ & $(0.1078)$ & $(0.0040)$ \\
\hline Adjusted R-squared & 0.004 & 0.022 & 0.005 & 0.002 & 0.049 & 0.002 & 0.005 & 0.114 & 0.026 & 0.003 \\
\hline Ethnicity Fixed Effects & No & No & No & No & No & No & No & No & No & No \\
\hline Observations & 507 & 507 & 507 & 507 & 507 & 507 & 507 & 507 & 507 & 507 \\
\hline Ethnicities & 220 & 220 & 220 & 220 & 220 & 220 & 220 & 220 & 220 & 220 \\
\hline
\end{tabular}

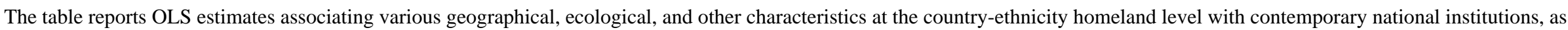

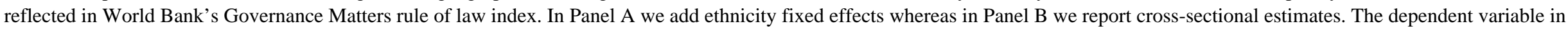

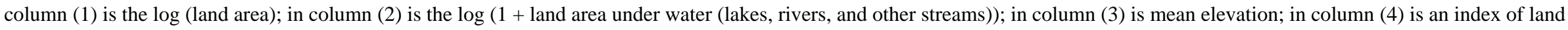

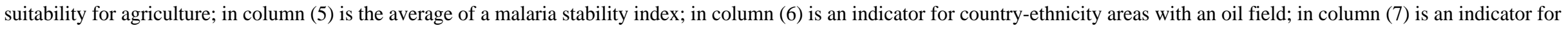

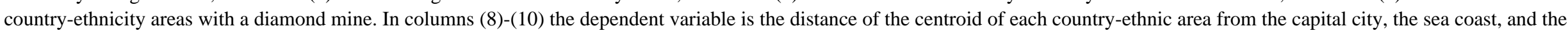

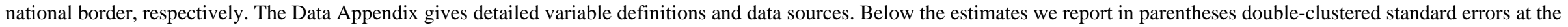
country and the ethno-linguistic family dimensions. ${ }^{* * *}, * *$, and * indicate statistical significance at the $1 \%, 5 \%$, and $10 \%$ level, respectively. 


\section{Appendix Table 5: National Institutions and Regional Development at the Border A Primary Analysis on What the Ethnicity Fixed Effects Capture}

\begin{tabular}{|c|c|c|c|c|c|c|c|c|c|c|}
\hline & \multicolumn{5}{|c|}{ Rule of Law } & \multicolumn{5}{|c|}{ Control of Corruption } \\
\hline & $(1)$ & (2) & (3) & (4) & (5) & (6) & $(7)$ & (8) & (9) & $(10)$ \\
\hline National Institutions & $\begin{array}{c}0.1149 * * \\
(0.0464)\end{array}$ & $\begin{array}{l}0.0676^{*} \\
(0.0350)\end{array}$ & $\begin{array}{c}0.0559 \\
(0.0344)\end{array}$ & $\begin{array}{c}0.0329 \\
(0.0301)\end{array}$ & $\begin{array}{c}0.0361 \\
(0.0318)\end{array}$ & $\begin{array}{c}0.1406 * * * \\
(0.0545)\end{array}$ & $\begin{array}{c}0.0877^{*} \\
(0.0470)\end{array}$ & $\begin{array}{c}0.0703 \\
(0.0445)\end{array}$ & $\begin{array}{c}0.0678 \\
(0.0478)\end{array}$ & $\begin{array}{c}0.0492 \\
(0.0451)\end{array}$ \\
\hline Pre-colonial Political Features & & & & & & & & & & \\
\hline Jurisdictional Hierarchy & & & $\begin{array}{r}0.0428 * * \\
(0.0176)\end{array}$ & & $\begin{array}{r}0.0438 * * \\
(0.0172)\end{array}$ & & & $\begin{array}{r}0.0402 * * \\
(0.0166)\end{array}$ & & $\begin{array}{r}0.0421 * * \\
(0.0164)\end{array}$ \\
\hline $\begin{array}{l}\text { Type of Subsistence Economy } \\
\text { Agriculture \& Pastoral Intensity } \\
p \text {-value of joint significance }\end{array}$ & No & No & No & $\begin{array}{c}\text { Yes } \\
{[0.00]}\end{array}$ & $\begin{array}{c}\text { Yes } \\
{[0.00]}\end{array}$ & No & No & No & $\begin{array}{c}\text { Yes } \\
{[0.00]}\end{array}$ & $\begin{array}{c}\text { Yes } \\
{[0.00]}\end{array}$ \\
\hline Adjusted R-squared & 0.152 & 0.212 & 0.223 & 0.258 & 0.252 & 0.159 & 0.215 & 0.224 & 0.245 & 0.253 \\
\hline Observations & 27661 & 27661 & 27661 & 27661 & 27661 & 27661 & 27661 & 27661 & 27661 & 27661 \\
\hline Ethnicity Fixed Effects & No & No & No & No & No & No & No & No & No & No \\
\hline Pixel Area \& Pop. Dens. & Yes & Yes & Yes & Yes & Yes & Yes & Yes & Yes & Yes & Yes \\
\hline Location \& Geographic Controls & No & Yes & Yes & Yes & Yes & No & Yes & Yes & Yes & Yes \\
\hline
\end{tabular}

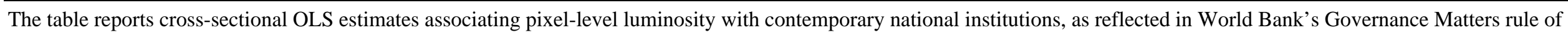

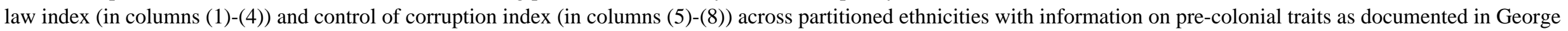

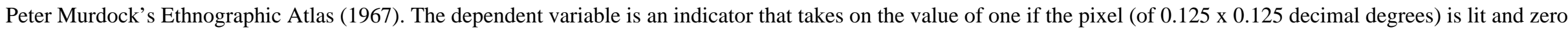
otherwise.

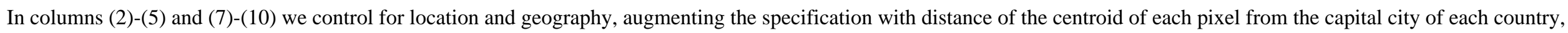

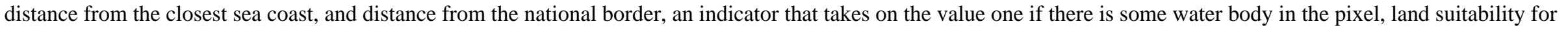
agriculture, elevation, a malaria stability index, a diamond mine indicator, and an oil field indicator.

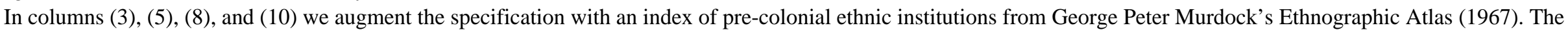

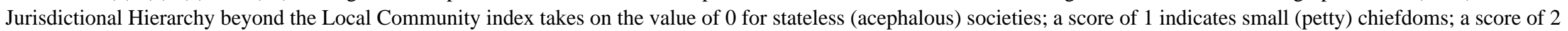
indicates large (paramount) chiefdoms; and a score of 3 indicates large centralized states.

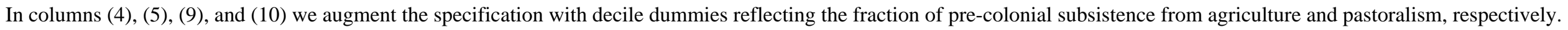
The data are from George Peter Murdock's Ethnographic Atlas (1967).

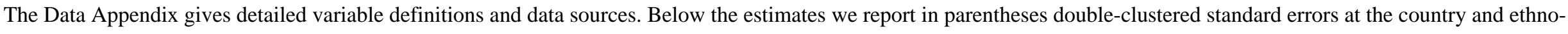
linguistic family dimensions. ***, **, and * indicate statistical significance at the $1 \%$, 5\%, and $10 \%$ level, respectively. 


\section{Appendix Table 6 \\ Sensitivity Analysis. Luminosity Expressed in Levels}

\begin{tabular}{|c|c|c|c|c|c|c|c|c|}
\hline & \multicolumn{4}{|c|}{ Rule of Law } & \multicolumn{4}{|c|}{ Control of Corruption } \\
\hline & (1) & (2) & (3) & (4) & (5) & (6) & (7) & (8) \\
\hline & \multicolumn{8}{|c|}{ Panel A: LS Estimates - Luminosity in Levels } \\
\hline $\begin{array}{l}\text { Institutional Quality } \\
\text { Double-clustered s.e. }\end{array}$ & $\begin{array}{r}0.1799 * * \\
(0.0902)\end{array}$ & $\begin{array}{c}0.0492 \\
(0.0898)\end{array}$ & $\begin{array}{c}0.1365 \\
(0.0931)\end{array}$ & $\begin{array}{c}0.0634 \\
(0.1065)\end{array}$ & $\begin{array}{r}0.2148 * * \\
(0.1065)\end{array}$ & $\begin{array}{c}0.0505 \\
(0.1302)\end{array}$ & $\begin{array}{c}0.1654 \\
(0.1091)\end{array}$ & $\begin{array}{c}0.0835 \\
(0.1476)\end{array}$ \\
\hline Adjusted R-squared & 0.104 & 0.669 & 0.252 & 0.680 & 0.106 & 0.669 & 0.253 & 0.681 \\
\hline within R-squared & - & 0.046 & - & 0.057 & - & 0.046 & - & 0.057 \\
\hline \multirow[t]{2}{*}{ Observations } & 507 & 507 & 507 & 507 & 507 & 507 & 507 & 507 \\
\hline & \multicolumn{8}{|c|}{ Panel B: Poisson ML Estimates - Luminosity in Levels } \\
\hline $\begin{array}{l}\text { Institutional Quality } \\
\text { Double-clustered s.e. }\end{array}$ & $\begin{array}{c}0.8905 * * * \\
(0.2928)\end{array}$ & $\begin{array}{c}0.0958 \\
(0.1380)\end{array}$ & $\begin{array}{r}0.6563^{* *} \\
(0.3155)\end{array}$ & $\begin{array}{c}0.1934 \\
(0.1572)\end{array}$ & $\begin{array}{c}1.0270^{* * *} \\
(0.2451)\end{array}$ & $\begin{array}{c}0.1219 \\
(0.1388)\end{array}$ & $\begin{array}{c}0.7200 * * \\
(0.3506)\end{array}$ & $\begin{array}{c}0.2713 \\
(0.1783)\end{array}$ \\
\hline Log Likelihood & -235.58 & -127.51 & -178.58 & -126.62 & -233.66 & -127.50 & -178.88 & -126.57 \\
\hline Observations & 507 & 507 & 507 & 507 & 507 & 507 & 507 & 507 \\
\hline Ethnicity Fixed Effects & No & Yes & No & Yes & No & Yes & No & Yes \\
\hline Pop. Dens. \& Land Area & Yes & Yes & Yes & Yes & Yes & Yes & Yes & Yes \\
\hline Location \& Geography & No & No & Yes & Yes & No & No & Yes & Yes \\
\hline
\end{tabular}

The table reports estimates associating regional development with contemporary national institutions, as reflected in World Bank's Governance Matters rule of law index (in columns (1)-(4)) and control of corruption index (in columns (5)-(8)) in areas of partitioned ethnicities. In both panels the dependent variable is light density at night at the ethnicity-country level. Panel A reports OLS estimates. Panel B reports Poisson pseudo-maximum likelihood estimates.

Odd-numbered columns report cross-sectional specifications. Even-numbered columns report within-ethnicity estimates, where we include a vector of ethnicity fixed effects (constants not reported). In all specifications we control for log (population density in 2000) and $\log$ land area. In columns (3), (4), (7), and (8) we also control for location and geography, augmenting the specification with distance of the centroid of each ethnicity-country area from the capital city of each country, distance from the closest sea coast, and distance from the national border. The set of geographic controls includes $\log (1+$ area under water (lakes, rivers, and other streams)), land suitability for agriculture, elevation, a malaria stability index, a diamond mine indicator, and an oil field indicator. Besides the overall adjusted R-squared, the table also reports the within R-squared (defined as the difference of the overall R-squared minus the overall R-squared of a model simply with ethnicity fixed effects). The Data Appendix gives detailed variable definitions and data sources. Below the estimates we report in parentheses double-clustered standard errors at the country and ethno-linguistic family dimensions. ${ }^{* *}, * *$, and $*$ indicate statistical significance at the $1 \%, 5 \%$, and $10 \%$ level, respectively. 


\section{Appendix Table 7: Contemporary National Institutions and Regional Development across and within Partitioned Ethnic Groups}

Sensitivity Analysis. Alternative Measures of Institutional Quality from World Bank's Governance Matters Database

Measure of National Institutions (World Bank Governance Matters Database)

\begin{tabular}{|c|c|c|c|c|c|c|c|}
\hline \multicolumn{2}{|c|}{ Bureaucratic Quality } & \multicolumn{2}{|c|}{ Regulatory Quality } & \multicolumn{2}{|c|}{ Voice and Accountability } & \multicolumn{2}{|c|}{ Political Stability } \\
\hline (1) & (2) & (3) & (4) & (5) & (6) & (7) & (8) \\
\hline $\begin{array}{c}0.7789 * * * \\
(0.1883)\end{array}$ & $\begin{array}{c}0.2223 \\
(0.1921)\end{array}$ & $\begin{array}{c}0.4504 * * \\
(0.1898)\end{array}$ & $\begin{array}{c}0.1392 \\
(0.1572)\end{array}$ & $\begin{array}{c}0.3343 \\
(0.2047)\end{array}$ & $\begin{array}{c}0.1468 \\
(0.1370)\end{array}$ & $\begin{array}{c}0.3059 * * \\
(0.1267)\end{array}$ & $\begin{array}{c}0.0346 \\
(0.1341)\end{array}$ \\
\hline 0.310 & 0.792 & 0.268 & 0.791 & 0.255 & 0.792 & 0.262 & 0.790 \\
\hline- & 0.061 & - & 0.060 & - & 0.061 & - & 0.059 \\
\hline 507 & 507 & 507 & 507 & 507 & 507 & 507 & 507 \\
\hline No & Yes & No & Yes & No & Yes & No & Yes \\
\hline Yes & Yes & Yes & Yes & Yes & Yes & Yes & Yes \\
\hline
\end{tabular}

Institutional Quality

Double-clustered s.e.

Adjusted R-squared

Within R-squared

Observations

Ethnicity Fixed Effects

Pop. Dens. \& Land Area

The table reports cross-sectional and within-ethnicity OLS estimates associating regional development with contemporary national institutions, as reflected in World Bank's Governance Matters bureaucratic quality index (in columns (1)-(2)), regulatory quality index (in columns (3)-(4)), voice and accountability index (in columns (5)-(6)), and political stability index (in columns (7)-(8)) in areas of partitioned ethnicities. The dependent variable is the log $(0.01+$ light density at night from satellite) at the ethnicitycountry level.

Odd-numbered columns report cross-sectional specifications. Even-numbered columns report within-ethnicity estimates, where we include a vector of ethnicity fixed effects (constants not reported). In all specifications we control for log (population density in 2000) and log land area. Besides the overall adjusted R-squared, the table also reports the within R-squared (defined as the difference of the overall R-squared minus the overall R-squared of a model simply with ethnicity fixed effects). The Data Appendix gives detailed variable definitions and data sources. Below the estimates we report in parentheses double-clustered standard errors at the country and ethno-linguistic family dimensions. ${ }^{* * *},{ }^{* *}$, and $*$ indicate statistical significance at the $1 \%, 5 \%$, and $10 \%$ level, respectively. 


\section{Appendix Table 8: National Institutions and Regional Development across and within Partitioned Ethnic Groups Sensitivity Analysis. Measures of Institutional Quality in 2007}

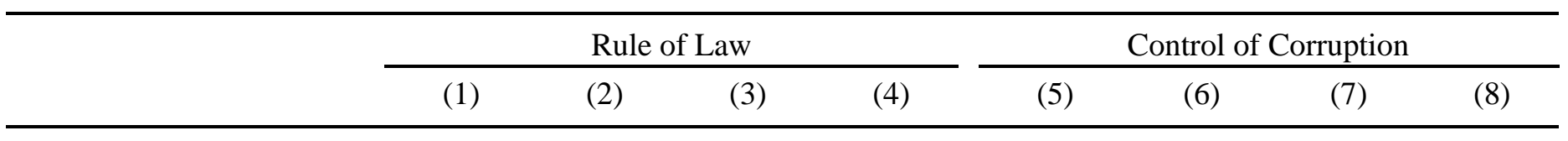

\section{Panel A: Country-Ethnic Homeland Level}

\begin{tabular}{|c|c|c|c|c|c|c|c|c|}
\hline $\begin{array}{l}\text { Institutional Quality in } 2007 \\
\text { Double-clustered s.e. }\end{array}$ & $\begin{array}{l}0.6731^{* * *} \\
(0.1863)\end{array}$ & $\begin{array}{c}0.2331 \\
(0.1525)\end{array}$ & $\begin{array}{l}0.5261^{* * *} \\
(0.1805)\end{array}$ & $\begin{array}{c}0.2420 \\
(0.1689)\end{array}$ & $\begin{array}{l}0.8372 * * * \\
(0.2204)\end{array}$ & $\begin{array}{r}0.2415 \\
(0.1711)\end{array}$ & $\begin{array}{l}0.6857 * * * \\
(0.2100)\end{array}$ & $\begin{array}{c}0.2301 \\
(0.1891)\end{array}$ \\
\hline Adjusted R-squared & 0.298 & 0.794 & 0.395 & 0.799 & 0.298 & 0.792 & 0.399 & 0.798 \\
\hline Within R-squared & - & 0.063 & - & 0.068 & - & 0.062 & - & 0.067 \\
\hline Observations & 507 & 507 & 507 & 507 & 507 & 507 & 507 & 507 \\
\hline
\end{tabular}

\section{Panel B: Pixel Level}

Institutional Quality in $20070.1083 * * *$

Double-clustered s.e.

$(0.0413)$

0.0221

$0.0850 * * * \quad 0.0241$

(0.0160) (0.0287)

(0.0156)

$0.1511^{* * *}$

0.0342

$0.1264 * * *$

0.0385

$(0.0491)$

(0.0232)

(0.0395)

(0.0238)

Adjusted R-squared

0.153

0.331

0.205

0.340

0.066

Within R-squared

Observations

$4 \overline{2710}$

0.059

42710

$4 \overline{1025}$

41025

0.161

0.331

0.059

$4 \overline{2710}$

42710

0.214

0.340

Ethnicity Fixed Effects

Pop. Dens. \& Area

Location Controls

Geographic Controls

$\begin{array}{llll}\text { No } & \text { Yes } & \text { No } & \text { Yes } \\ \text { Yes } & \text { Yes } & \text { Yes } & \text { Yes } \\ \text { No } & \text { No } & \text { Yes } & \text { Yes } \\ \text { No } & \text { No } & \text { Yes } & \text { Yes }\end{array}$

No
Yes
No
No

Yes
Yes
No
No

$\overline{41025}$

0.066

41025

The table reports cross-sectional and within-ethnicity OLS estimates associating regional development with contemporary national institutions, as reflected in World Bank's Governance Matters rule of law index (in columns (1)-(4)) and control of corruption index (in columns (5)-(8)) in areas of partitioned ethnicities at the country-ethnicity level (in Panel A) and at the pixel level (in Panel B). In Panel A the dependent variable is $\log (0.01+$ light density at night from satellite) at the ethnicity-country level. In Panel B the dependent variable is an indicator that takes on the value of one if the pixel (of $0.125 \times 0.125$ decimal degrees) is lit and zero otherwise. Odd-numbered columns report cross-sectional specifications. Even-numbered columns report within-ethnicity estimates, where we include a vector of ethnicity fixed effects (constants not reported).

In all specifications we control for log (population density in 2000) and log land area at the country-ethnicity level (in Panel A) or at the pixel-level (in Panel B). In columns (3), (4), (7), and (8) we control for location and geography, augmenting the specification with distance of the centroid of each ethnicity-country (in Panel A) or each pixel (in Panel B) from the capital city of each country, distance from the closest sea coast, and distance from the national border. The set of geographic controls includes $\log (1+$ area under water (lakes, rivers, and other streams)) for the models in Panel A and an indicator that takes on the value one if there is some water body in the pixel for the models in Panel B, land suitability for agriculture, elevation, a malaria stability index, a diamond mine indicator, and an oil field indicator. Besides the overall adjusted R-squared, the table also reports the within R-squared (defined as the difference of the overall R-squared minus the overall R-squared of a model simply with ethnicity fixed effects). The Data Appendix gives detailed variable definitions and data sources. Below the estimates we report in parentheses doubleclustered standard errors at the country and ethno-linguistic family dimensions. ${ }^{* * *},{ }^{* *}$, and $*$ indicate statistical significance at the $1 \%, 5 \%$, and $10 \%$ level, respectively. 


\section{Appendix Table 9A \\ Sensitivity Analysis. Focusing on Artificial Borders. Country-Ethnic Homeland Analysis}

\begin{tabular}{|c|c|c|c|c|c|c|c|c|}
\hline & \multicolumn{4}{|c|}{ Rule of Law } & \multicolumn{4}{|c|}{ Control of Corruption } \\
\hline & (1) & (2) & (3) & (4) & (5) & (6) & (7) & (8) \\
\hline & \multicolumn{8}{|c|}{ Panel A: All Homelands } \\
\hline $\begin{array}{l}\text { Institutional Quality } \\
\text { Double-clustered s.e. }\end{array}$ & $\begin{array}{c}0.6931^{* * *} \\
(0.1876)\end{array}$ & $\begin{array}{c}0.1390 \\
(0.4018)\end{array}$ & $\begin{array}{l}0.4204^{*} \\
(0.2279)\end{array}$ & $\begin{array}{c}0.0843 \\
(0.2016)\end{array}$ & $\begin{array}{c}0.8440 * * * \\
(0.2578)\end{array}$ & $\begin{array}{c}0.1037 \\
(0.4488)\end{array}$ & $\begin{array}{r}0.5059 * * \\
(0.2415)\end{array}$ & $\begin{array}{l}-0.0103 \\
(0.2241)\end{array}$ \\
\hline Adjusted R-squared & 0.311 & 0.848 & 0.423 & 0.859 & 0.317 & 0.847 & 0.424 & 0.859 \\
\hline within R-squared & - & 0.045 & - & 0.056 & - & 0.044 & - & 0.056 \\
\hline Observations & 220 & 220 & 220 & 220 & 220 & 220 & 220 & 220 \\
\hline \multirow[t]{2}{*}{ Ethnicities } & 110 & 110 & 110 & 110 & 110 & 110 & 110 & 110 \\
\hline & \multicolumn{8}{|c|}{ Panel B: Local Regressions } \\
\hline $\begin{array}{l}\text { Institutional Quality } \\
\text { Double-clustered s.e. }\end{array}$ & $\begin{array}{c}0.6910^{* * * *} \\
(0.1878)\end{array}$ & $\begin{array}{c}0.1410 \\
(0.3643)\end{array}$ & $\begin{array}{c}0.6791 * * * \\
(0.1746)\end{array}$ & $\begin{array}{c}0.1847 \\
(0.3498)\end{array}$ & $\begin{array}{c}0.8608^{* * * *} \\
(0.2680)\end{array}$ & $\begin{array}{c}0.0819 \\
(0.3852)\end{array}$ & $\begin{array}{c}0.8594 * * * \\
(0.2296)\end{array}$ & $\begin{array}{c}0.2472 \\
(0.3349)\end{array}$ \\
\hline Adjusted R-squared & 0.302 & 0.842 & 0.282 & 0.858 & 0.312 & 0.841 & 0.293 & 0.858 \\
\hline within R-squared & - & 0.036 & - & 0.052 & - & 0.035 & - & 0.052 \\
\hline Observations & 216 & 216 & 216 & 216 & 216 & 216 & 216 & 216 \\
\hline Ethnicities & 108 & 108 & 108 & 108 & 108 & 108 & 108 & 108 \\
\hline Ethnicity Fixed Effects & No & Yes & No & Yes & No & Yes & No & Yes \\
\hline Pop. Dens. \& Land Area & Yes & Yes & Yes & Yes & Yes & Yes & Yes & Yes \\
\hline Location \& Geography & No & No & Yes & Yes & No & No & Yes & Yes \\
\hline
\end{tabular}

The table reports estimates associating regional development with contemporary national institutions, as reflected in World Bank's Governance Matters rule of law index (in columns (1)-(4)) and control of corruption index (in columns (5)-(8)) in areas of partitioned ethnicities. Odd-numbered columns report cross-sectional specifications. Even-numbered columns report within-ethnicity estimates, where we include a vector of ethnicity fixed effects (constants not reported). In all specifications we control for log (population density in 2000) and log land area. In columns (3), (4), (7), and (8) we also control for location and geography, augmenting the specification with distance of the centroid of each ethnicity-country area from the capital city of each country, distance from the closest sea coast, and distance from the national border. The set of geographic controls includes $\log (1+$ area under water (lakes, rivers, and other streams)), land suitability for agriculture, elevation, a malaria stability index, a diamond mine indicator, and an oil field indicator. Besides the overall adjusted R-squared, the table also reports the within R-squared (defined as the difference of the overall R-squared minus the overall R-squared of a model simply with ethnicity fixed effects). In Panel B (in local regressions) we lose two ethnicities, namely, the Barabra and the Bideyat because there is zero population density close to the border. The Data Appendix gives detailed variable definitions and data sources. Below the estimates we report in parentheses double-clustered standard errors at the country and ethno-linguistic family dimensions. ***, **, and * indicate statistical significance at the $1 \%, 5 \%$, and $10 \%$ level, respectively. 
Appendix Table 9B: National Institutions and Regional Development Sensitivity Analysis. Focusing on Artificial Borders. Pixel-level Analysis

\begin{tabular}{|c|c|c|c|c|c|c|c|c|c|c|c|c|}
\hline \multirow{3}{*}{ Sample - Bandwidth } & \multicolumn{6}{|c|}{ Rule of Law } & \multicolumn{6}{|c|}{ Control of Corruption } \\
\hline & \multicolumn{2}{|c|}{ All Pixels } & \multicolumn{2}{|c|}{$100 \mathrm{~km}$} & \multicolumn{2}{|c|}{$50 \mathrm{~km}$} & \multicolumn{2}{|c|}{ All Observations } & \multicolumn{2}{|c|}{$100 \mathrm{~km}$} & \multicolumn{2}{|c|}{$50 \mathrm{~km}$} \\
\hline & $(1)$ & $(2)$ & (3) & (4) & (5) & (6) & (7) & (8) & (9) & $(10)$ & $(11)$ & $(12)$ \\
\hline $\begin{array}{c}\text { Institutional Quality } \\
\text { Double-clustered s.e. }\end{array}$ & $\begin{array}{c}0.0979 * * * \\
(0.0380)\end{array}$ & $\begin{array}{c}0.0131 \\
(0.0158)\end{array}$ & $\begin{array}{c}0.0891^{* *} \\
(0.0348)\end{array}$ & $\begin{array}{c}0.0115 \\
(0.0167)\end{array}$ & $\begin{array}{c}0.0909 * * \\
(0.0391)\end{array}$ & $\begin{array}{c}0.0125 \\
(0.0148)\end{array}$ & $\begin{array}{c}0.1303^{* * *} \\
(0.0482)\end{array}$ & $\begin{array}{c}0.0208 \\
(0.0261)\end{array}$ & $\begin{array}{c}0.1171^{* *} \\
(0.0489)\end{array}$ & $\begin{array}{c}0.0154 \\
(0.0214)\end{array}$ & $\begin{array}{r}0.1231^{* *} \\
(0.0528)\end{array}$ & $\begin{array}{c}0.0191 \\
(0.0200)\end{array}$ \\
\hline $\begin{array}{l}\text { Adjusted R-squared } \\
\text { within R-squared }\end{array}$ & 0.172 & $\begin{array}{l}0.373 \\
0.068\end{array}$ & 0.151 & $\begin{array}{l}0.360 \\
0.065\end{array}$ & 0.143 & $\begin{array}{l}0.377 \\
0.056\end{array}$ & 0.182 & $\begin{array}{l}0.374 \\
0.067\end{array}$ & 0.159 & $\begin{array}{l}0.360 \\
0.065\end{array}$ & 0.154 & $\begin{array}{l}0.377 \\
0.056\end{array}$ \\
\hline Observations & $\overline{22967}$ & 22967 & $\overline{11455}$ & 11455 & $\overline{7031}$ & 7031 & $\overline{22967}$ & 22967 & $1 \overline{1455}$ & 11455 & $\overline{7031}$ & 7031 \\
\hline Ethnicities & 108 & 108 & 108 & 108 & 108 & 108 & 108 & 108 & 108 & 108 & 108 & 108 \\
\hline Ethnicity Fixed Effects & Yes & Yes & Yes & Yes & Yes & Yes & Yes & Yes & Yes & Yes & Yes & Yes \\
\hline
\end{tabular}

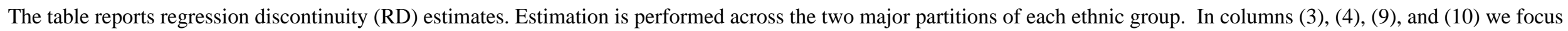

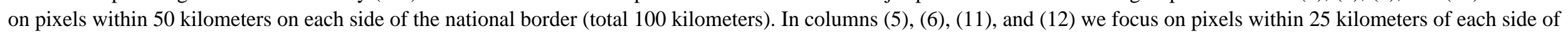

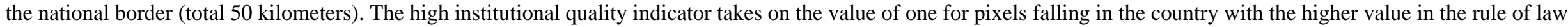

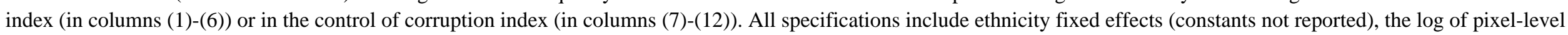

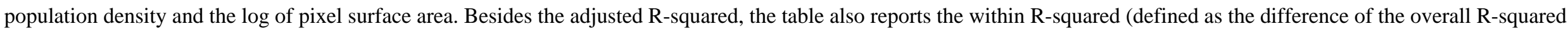

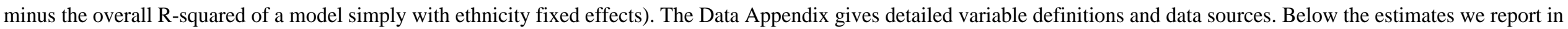

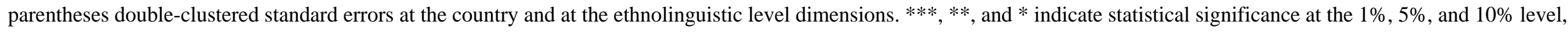
respectively. 


\section{Appendix Table 10: National Institutions and Regional Population Density Sensitivity Analysis. Accounting for Migration}

\begin{tabular}{|c|c|c|c|c|c|c|c|c|}
\hline & \multicolumn{4}{|c|}{ Rule of Law } & \multicolumn{4}{|c|}{ Control of Corruption } \\
\hline & (1) & $(2)$ & (3) & (4) & (5) & (6) & (7) & (8) \\
\hline & \multicolumn{8}{|c|}{ Panel A: Data on Population Density from the United Nations Environmental Program } \\
\hline \multirow[t]{2}{*}{ Institutional Quality } & -0.1226 & -0.0043 & -0.1465 & -0.1647 & -0.2874 & -0.0585 & -0.1656 & -0.1836 \\
\hline & $(0.4572)$ & $(0.2586)$ & $(0.3053)$ & $(0.3097)$ & $(0.5247)$ & $(0.2867)$ & $(0.3411)$ & $(0.3454)$ \\
\hline \multirow{3}{*}{$\begin{array}{l}\text { Adjusted R-squared } \\
\text { within R-squared }\end{array}$} & 0.003 & 0.801 & 0.819 & 0.824 & 0.008 & 0.802 & 0.819 & 0.823 \\
\hline & - & 0.000 & 0.018 & 0.023 & - & 0.000 & 0.018 & 0.022 \\
\hline & \multicolumn{8}{|c|}{ Panel B: Data on Population Density from the Gridded Population of the World Database } \\
\hline \multirow[t]{2}{*}{ Institutional Quality } & -0.1963 & -0.1366 & -0.2815 & -0.3255 & -0.3601 & -0.2159 & -0.3386 & -0.3614 \\
\hline & $(0.3577)$ & $(0.2132)$ & $(0.2331)$ & $(0.2394)$ & $(0.3955)$ & $(0.2311)$ & $(0.2798)$ & $(0.2845)$ \\
\hline \multirow{2}{*}{$\begin{array}{l}\text { Adjusted R-squared } \\
\text { within R-squared }\end{array}$} & 0.007 & 0.826 & 0.844 & 0.854 & 0.016 & 0.827 & 0.844 & 0.852 \\
\hline & - & 0.001 & 0.019 & 0.029 & - & 0.002 & 0.019 & 0.027 \\
\hline Ethnicity Fixed Effects & No & Yes & Yes & Yes & No & Yes & Yes & Yes \\
\hline Location Controls & No & No & Yes & Yes & No & No & Yes & Yes \\
\hline Geographic Controls & No & No & No & Yes & No & No & No & Yes \\
\hline Observations & 507 & 507 & 507 & 507 & 507 & 507 & 507 & 507 \\
\hline
\end{tabular}

The table reports cross-sectional and within-ethnicity OLS estimates associating regional population density with contemporary national institutions, as reflected in World Bank's Governance Matters rule of law index (in columns (1)-(4)) and control of corruption index (in columns (5)-(8)) in areas of partitioned ethnicities. The dependent variable is $\log (0.01+$ population density at the ethnicity-country level). In Panel A we use local population data (estimates) from United Nations Environmental Program (http://na.unep.net/siouxfalls/datasets/datalist.php). In Panel B we use local population data (estimates) from the Gridded Population of the World Database (http://sedac.ciesin.columbia.edu/gpw/).

Columns (1) and (5) report cross-sectional estimates. Columns (2)-(4) and (6)-(8) report within-ethnicity estimates that include a vector of ethnicity fixed effects (constants not reported). Columns (3), (4), (7), and (8) include as controls the distance of the centroid of each ethnicity-country area from the capital city of each country, the distance from the closest sea coast, and the distance from the national border. Columns (4) and (8) also include as controls the $\log (1+$ area under water (lakes, rivers, and other streams)), $\log$ (surface area), land suitability for agriculture, elevation, a malaria stability index, a diamond mine indicator, and an oil field indicator. Besides the overall adjusted R-squared, the table also reports the within R-squared (defined as the difference of the overall R-squared minus the overall R-squared of a model simply with ethnicity fixed effects). The Data Appendix gives detailed variable definitions and data sources. ${ }^{* * *}, * *$, and $*$ indicate statistical significance at the $1 \%, 5 \%$, and $10 \%$ level, respectively. 


\section{Appendix Table 11: National Institutions and Regional Development at the Pixel Level across and within Partitioned Ethnic Groups \\ Sensitivity Analysis. Accounting for Migration and Bleeding in Luminosity by Excluding Areas Close to the National Border}

\begin{tabular}{|c|c|c|c|c|c|c|c|c|}
\hline \multirow{3}{*}{ Excluding pixels within } & \multicolumn{4}{|c|}{ Rule of Law } & \multicolumn{4}{|c|}{ Control of Corruption } \\
\hline & \multicolumn{2}{|c|}{$50 \mathrm{~km}$} & \multicolumn{2}{|c|}{$25 \mathrm{~km}$} & \multicolumn{2}{|c|}{$50 \mathrm{~km}$} & \multicolumn{2}{|c|}{$25 \mathrm{~km}$} \\
\hline & (1) & $(2)$ & (3) & $(4)$ & (5) & (6) & (7) & (8) \\
\hline
\end{tabular}

Panel A: Country-Ethnicity Sample

$\begin{array}{lccccccccc}\text { Institutional Quality } & 0.7159^{* * *} & 0.1346 & 0.8177^{* * *} & 0.2434 & 0.9158^{* * *} & 0.2296 & 0.9155^{* * *} & 0.2923 \\ & (0.2534) & (0.2495) & (0.2163) & (0.4061) & (0.2974) & (0.3215) & (0.2662) & (0.5777) \\ & & & & & & & & \\ \text { Adjusted R-squared } & 0.282 & 0.813 & 0.284 & 0.775 & 0.300 & 0.814 & 0.282 & 0.774 \\ \text { within R-squared } & - & 0.060 & - & 0.103 & - & 0.061 & - & 0.103 \\ \text { Observations } & 306 & 306 & 178 & 178 & 306 & 306 & 178 & 178\end{array}$

\section{Panel B: Pixel Sample}

\begin{tabular}{|c|c|c|c|c|c|c|c|c|}
\hline Institutional Quality & $\begin{array}{l}0.1211^{* * *} \\
(0.0449)\end{array}$ & $\begin{array}{c}0.0432 \\
(0.0272)\end{array}$ & $\begin{array}{l}0.1130^{* * *} \\
(0.0425)\end{array}$ & $\begin{array}{c}0.0321 \\
(0.0235)\end{array}$ & $\begin{array}{l}0.1551^{* * *} \\
(0.0472)\end{array}$ & $\begin{array}{c}0.069 \\
(0.0453)\end{array}$ & $\begin{array}{l}0.1453 * * * \\
(0.0469)\end{array}$ & $\begin{array}{c}0.0564 \\
(0.0420)\end{array}$ \\
\hline Adjusted R-squared & 0.186 & 0.401 & 0.165 & 0.365 & 0.201 & 0.401 & 0.178 & 0.366 \\
\hline within R-squared & - & 0.052 & - & 0.056 & - & 0.052 & - & 0.057 \\
\hline Observations & 18920 & 18920 & 26801 & 26801 & 18920 & 18920 & 26801 & 26801 \\
\hline Ethnicity Fixed Effects & No & Yes & No & Yes & No & Yes & No & Yes \\
\hline Pop. Dens. \& Area & Yes & Yes & Yes & Yes & Yes & Yes & Yes & Yes \\
\hline
\end{tabular}

The table reports cross-sectional and within-ethnicity OLS estimates associating regional development, as reflected in satellite light density at night, with contemporary national institutions, as reflected in World Bank's Governance Matters rule of law index (in columns (1)-(4)) and control of corruption index (in columns (5)-(8)). In Panel A the unit of analysis is the country-ethnic homeland. The dependent variable is the log (0.01 + light density at night from satellite in 2007-2008) at the ethnicity-country level. In Panel B the unit of analysis is pixels of 0.125 x 0.125 decimal degrees within partitioned ethnicities. The dependent variable is a dummy variable that takes the value one if the pixel is lit in 2007-2008 and zero otherwise.

In columns (1), (2), (5), and (6) we exclude from the estimation ethnic areas and pixels within 50 kilometers from each side of the national border (total 100 kilometers). In columns (3), (4), (7), and (8) we exclude from the estimation ethnic areas and pixels within 25 kilometers from each side of the national border (total 50 kilometers). Odd-numbered columns report cross-sectional specifications. Even-numbered columns report within-ethnicity estimates, where we include a vector of ethnicity fixed effects (constants not reported). In all specifications we control for the log (area) and log (population density) at the country-ethnicity level (in Panel A) or at the pixellevel (in Panel B). Besides the overall adjusted R-squared, the table also reports the within R-squared (defined as the difference of the overall R-squared minus the overall R-squared of a model simply with ethnicity fixed effects). The Data Appendix gives detailed variable definitions and data sources. $* * *, * *$, and * indicate statistical significance at the 1\%, 5\%, and 10\% level, respectively. 
Appendix Table 12: Contemporary National Institutions and Regional Development across and within Partitioned Ethnic Groups

Sensitivity Analysis. Dropping Each Time a Different African Region

\begin{tabular}{|c|c|c|c|c|c|c|c|c|c|c|}
\hline & \multicolumn{10}{|c|}{ Excluding } \\
\hline & \multicolumn{2}{|c|}{ North Africa } & \multicolumn{2}{|c|}{ South Africa } & \multicolumn{2}{|c|}{ Central Africa } & \multicolumn{2}{|c|}{ Eastern Africa } & \multicolumn{2}{|c|}{ Western Africa } \\
\hline & $\frac{\text { Rule of Law }}{\text { (1) }}$ & $\frac{\text { Corruption }}{(2)}$ & $\frac{\text { Rule of Law }}{\text { (3) }}$ & $\frac{\text { Corruption }}{(4)}$ & $\frac{\text { Rule of Law }}{\text { (5) }}$ & $\frac{\text { Corruption }}{(6)}$ & $\frac{\text { Rule of Law }}{\text { (7) }}$ & $\frac{\text { Corruption }}{(8)}$ & $\frac{\text { Rule of Law }}{\text { (9) }}$ & $\frac{\text { Corruption }}{(10)}$ \\
\hline & \multicolumn{10}{|c|}{ Panel A: Country-Ethnicity Sample } \\
\hline $\begin{array}{l}\text { Institutional Quality } \\
\text { Double-clustered s.e. }\end{array}$ & $\begin{array}{c}0.2353 \\
(0.1891)\end{array}$ & $\begin{array}{l}0.3383^{*} \\
(0.2018)\end{array}$ & $\begin{array}{c}0.1105 \\
(0.2964)\end{array}$ & $\begin{array}{c}0.0846 \\
(0.3911)\end{array}$ & $\begin{array}{c}0.2531 \\
(0.2801)\end{array}$ & $\begin{array}{c}0.3344 \\
(0.3158)\end{array}$ & $\begin{array}{c}0.1635 \\
(0.2552)\end{array}$ & $\begin{array}{c}0.2675 \\
(0.2783)\end{array}$ & $\begin{array}{c}0.2502 \\
(0.2152)\end{array}$ & $\begin{array}{c}0.2744 \\
(0.2655)\end{array}$ \\
\hline Adjusted R-squared & 0.779 & 0.780 & 0.785 & 0.786 & 0.811 & 0.811 & 0.815 & 0.816 & 0.828 & 0.827 \\
\hline Within R-squared & 0.068 & 0.069 & 0.052 & 0.052 & 0.069 & 0.069 & 0.062 & 0.063 & 0.056 & 0.056 \\
\hline \multirow[t]{2}{*}{ Observations } & 485 & 485 & 418 & 418 & 376 & 376 & 410 & 410 & 339 & 339 \\
\hline & \multicolumn{10}{|c|}{ Panel B: Pixel Sample } \\
\hline $\begin{array}{l}\text { Institutional Quality } \\
\text { Double-clustered s.e. }\end{array}$ & $\begin{array}{c}0.0278 \\
(0.0176)\end{array}$ & $\begin{array}{l}0.0448 \\
(0.0282)\end{array}$ & $\begin{array}{c}-0.012 \\
(0.0177)\end{array}$ & $\begin{array}{l}-0.0282 \\
(0.0207)\end{array}$ & $\begin{array}{l}0.0087 \\
(0.0274)\end{array}$ & $\begin{array}{c}0.0254 \\
(0.0426)\end{array}$ & $\begin{array}{c}0.0335 \\
(0.0231)\end{array}$ & $\begin{array}{c}0.0558 \\
(0.0354)\end{array}$ & $\begin{array}{l}0.0340 * \\
(0.0184)\end{array}$ & $\begin{array}{l}0.0484 \\
(0.0317)\end{array}$ \\
\hline Adjusted R-squared & 0.271 & 0.272 & 0.345 & 0.345 & 0.369 & 0.369 & 0.356 & 0.357 & 0.366 & 0.366 \\
\hline Within R-squared & 0.062 & 0.063 & 0.047 & 0.047 & 0.069 & 0.069 & 0.063 & 0.064 & 0.062 & 0.062 \\
\hline Observations & 38438 & 38438 & 30517 & 30517 & 29692 & 29692 & 31801 & 31801 & 30388 & 30388 \\
\hline Ethnicity Fixed Effects & Yes & Yes & Yes & Yes & Yes & Yes & Yes & Yes & Yes & Yes \\
\hline Pop. Dens. \& Area & Yes & Yes & Yes & Yes & Yes & Yes & Yes & Yes & Yes & Yes \\
\hline
\end{tabular}


The table reports within-ethnicity OLS estimates associating regional development with contemporary national institutions, as reflected in World Bank’s Governance Matters rule of law index (in odd-numbered columns) and control of corruption index (in even-numbered columns) in areas of partitioned ethnicities. In Panel A the unit of analysis is the countryethnic homeland. The dependent variable is the $\log (0.01+$ light density at night from satellite in 2007-2008). In Panel B the unit of analysis is pixels of $0.125 \mathrm{x} 0.125$ decimal degrees (around 12 x 12 kilometers) within partitioned ethnicities. The dependent variable is a dummy variable that takes the value one if the pixel is lit in 2007-2008 and zero otherwise. In all specifications we control for log (population density in 2000) and log land area at the country-ethnicity level (in Panel A) or at the pixel-level (in Panel B). In columns (1)-(2) we exclude ethnic groups in North Africa. In columns (3)-(4) we exclude ethnic groups in Southern Africa. In columns (5)-(6) we exclude ethnic groups in Central Africa. In columns (7)-(8) we exclude ethnic groups in Eastern Africa. In columns (9)-(10) we exclude ethnic groups in Western Africa. The regional classification follows Nunn (2007). Besides the overall adjusted R-squared, the table also reports the within R-squared (defined as the difference of the overall R-squared minus the overall R-squared of a model simply with ethnicity fixed effects). The Data Appendix gives detailed variable definitions and data sources. ***, **, and * indicate statistical significance at the $1 \%$, $5 \%$, and $10 \%$ level, respectively. 


\section{Appendix Table 13: National Institutions and Regional Development at the Pixel Level across and within African Borders \\ Sensitivity Analysis. Border-Fixed-Effects Estimates}

\begin{tabular}{|c|c|c|c|c|c|c|c|c|}
\hline \multirow{3}{*}{ Sample } & \multicolumn{4}{|c|}{ Rule of Law } & \multicolumn{4}{|c|}{ Control of Corruption } \\
\hline & \multicolumn{2}{|c|}{ Full } & \multicolumn{2}{|c|}{ Local - $50 \mathrm{~km}$} & \multicolumn{2}{|c|}{ Full } & \multicolumn{2}{|c|}{ Local - $50 \mathrm{~km}$} \\
\hline & (1) & (2) & (3) & (4) & (5) & (6) & (7) & (8) \\
\hline
\end{tabular}

\section{Panel A: Country-Ethnicity Sample}

$\begin{array}{lcccccccc}\text { Institutional Quality } & 0.6875^{* * *} & 0.0995 & 0.6635^{* * *} & 0.0668 & 0.8590^{* * *} & 0.1272 & 0.8454 * * * & 0.0964 \\ & (0.2048) & (0.1305) & (0.2104) & (0.1684) & (0.2438) & (0.1642) & (0.2458) & (0.1946) \\ & & & & & & & & \\ \text { Adjusted R-squared } & 0.329 & 0.655 & 0.303 & 0.633 & 0.339 & 0.655 & 0.316 & 0.634 \\ \text { within R-squared } & - & 0.172 & - & 0.179 & - & 0.172 & - & 0.180 \\ \text { Observations } & 440 & 440 & 436 & 436 & 440 & 440 & 436 & 436\end{array}$

Panel B: Pixel Sample

\begin{tabular}{|c|c|c|c|c|c|c|c|c|}
\hline Institutional Quality & $\begin{array}{l}0.1095^{* * *} \\
(0.0409)\end{array}$ & $\begin{array}{c}0.0229 \\
(0.0173)\end{array}$ & $\begin{array}{l}0.0994^{* * *} \\
(0.0384)\end{array}$ & $\begin{array}{c}0.0192 \\
(0.0161)\end{array}$ & $\begin{array}{l}0.1415 * * * \\
(0.0466)\end{array}$ & $\begin{array}{c}0.0361 \\
(0.0272)\end{array}$ & $\begin{array}{l}0.1292 * * * \\
(0.0471)\end{array}$ & $\begin{array}{c}0.0294 \\
(0.0247)\end{array}$ \\
\hline Adjusted R-squared & 0.155 & 0.314 & 0.134 & 0.280 & 0.167 & 0.314 & 0.144 & 0.280 \\
\hline within R-squared & — & 0.077 & - & 0.079 & - & 0.077 & _ & 0.079 \\
\hline Observations & 40209 & 40209 & 21289 & 21289 & 40209 & 40209 & 21289 & 21289 \\
\hline Border Fixed Effects & No & Yes & No & Yes & No & Yes & No & Yes \\
\hline Number of Borders & 81 & 81 & 81 & 81 & 81 & 81 & 81 & 81 \\
\hline Pop. Dens. \& Area & Yes & Yes & Yes & Yes & Yes & Yes & Yes & Yes \\
\hline
\end{tabular}

The table reports OLS estimates associating regional development with contemporary national institutions, as reflected in World Bank's Governance Matters rule of law index (in columns (1)-(4)) and control of corruption index (in columns (5)-(8)) in areas of partitioned ethnicities. In Panel A the dependent variable is the $\log (0.01+$ light density at night from satellite) at the ethnicity-country level. In Panel B the dependent variable is a dummy variable that takes the value one if the pixel is lit and zero otherwise. In columns (1), (2), (5), and (6) we use the entire partitioned homeland. In columns (3), (4), (7), and (8) we focus on areas and pixels within 25 kilometers on each side of the national border (total 50 kilometers). Odd-numbered columns report cross-sectional specifications. Even-numbered columns report border fixed effects estimates (border constants not reported). In all specifications we control for log (population density) and log land area at the country-ethnicity level (in Panel A) or at the pixel-level (in Panel B). Besides the overall adjusted Rsquared, the table also reports the within R-squared (defined as the difference of the overall R-squared minus the overall R-squared of a model simply with border fixed effects). The Data Appendix gives detailed variable definitions and data sources. Below the estimates we report in parentheses double-clustered standard errors at the country and ethno-linguistic family dimensions. $* * *$, **, and $*$ indicate statistical significance at the $1 \%, 5 \%$, and $10 \%$ level, respectively. 


\section{Appendix Table 14: Contemporary National Institutions and Regional Development. Using Micro-Data from the 2005 Afrobarometer Surveys across and within Partitioned Ethnic Groups}

\begin{tabular}{|c|c|c|c|c|c|c|c|c|c|c|}
\hline & \multicolumn{2}{|c|}{ Satellite Light Density } & \multicolumn{2}{|c|}{ Electricity Grid } & \multicolumn{2}{|c|}{ Piped Water } & \multicolumn{2}{|c|}{ Sewage System } & \multicolumn{2}{|c|}{ Schooling Years } \\
\hline & (1) & (2) & (3) & (4) & (5) & (6) & (7) & (8) & (9) & $(10)$ \\
\hline & \multicolumn{10}{|c|}{ Panel A: Rule of Law Index } \\
\hline $\begin{array}{l}\text { Institutional Quality } \\
\text { Double-clustered s.e. }\end{array}$ & $\begin{array}{c}1.7514^{* * * *} \\
(0.6360)\end{array}$ & $\begin{array}{l}-0.2200 \\
(0.9616)\end{array}$ & $\begin{array}{c}0.1706 \\
(0.1550)\end{array}$ & $\begin{array}{l}-0.0234 \\
(0.1808)\end{array}$ & $\begin{array}{c}0.2034 \\
(0.1326)\end{array}$ & $\begin{array}{l}-0.0468 \\
(0.1672)\end{array}$ & $\begin{array}{l}0.1376 \\
(0.1262)\end{array}$ & $\begin{array}{c}0.0174 \\
(0.1292)\end{array}$ & $\begin{array}{c}0.5372 \\
(0.4200)\end{array}$ & $\begin{array}{c}0.1998 \\
(0.9214)\end{array}$ \\
\hline \multirow[t]{2}{*}{ Adjusted R-squared } & 0.355 & 0.603 & 0.037 & 0.252 & 0.048 & 0.243 & 0.037 & 0.254 & 0.041 & 0.354 \\
\hline & \multicolumn{10}{|c|}{ Panel B: Control of Corruption Index } \\
\hline $\begin{array}{l}\text { Institutional Quality } \\
\text { Double-clustered s.e. }\end{array}$ & $\begin{array}{c}2.3027 * * * \\
(0.4036)\end{array}$ & $\begin{array}{c}0.4802 \\
(1.1352)\end{array}$ & $\begin{array}{c}0.2526 * * \\
(0.1236)\end{array}$ & $\begin{array}{c}0.0629 \\
(0.2157)\end{array}$ & $\begin{array}{c}0.2666 * * * \\
(0.0884)\end{array}$ & $\begin{array}{l}-0.0267 \\
(0.1893)\end{array}$ & $\begin{array}{c}0.1894 \\
(0.1179)\end{array}$ & $\begin{array}{c}0.1182 \\
(0.1865)\end{array}$ & $\begin{array}{c}0.6196 \\
(0.3990)\end{array}$ & $\begin{array}{c}0.3337 \\
(1.0193)\end{array}$ \\
\hline Adjusted R-squared & 0.440 & 0.604 & 0.093 & 0.253 & 0.099 & 0.243 & 0.081 & 0.258 & 0.063 & 0.356 \\
\hline Enumeration Areas (Obs.) & 464 & 464 & 464 & 464 & 409 & 409 & 440 & 440 & 467 & 467 \\
\hline Ethnicity Fixed Effects & No & Yes & No & Yes & No & Yes & No & Yes & No & Yes \\
\hline Population Density & Yes & Yes & Yes & Yes & Yes & Yes & Yes & Yes & Yes & Yes \\
\hline
\end{tabular}

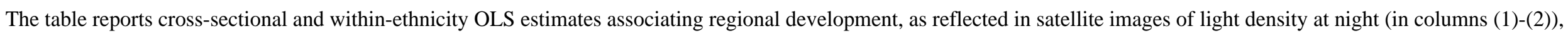
various public goods provision measures (in columns (3)-(8)) and education (in columns (9)-(10)), with contemporary national institutions, as reflected in World Bank's

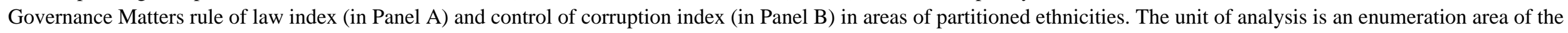

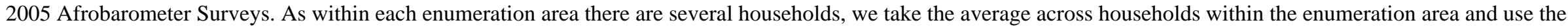

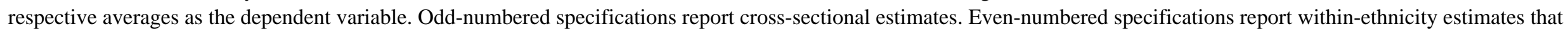
include a vector of ethnicity fixed effects (constants not reported).

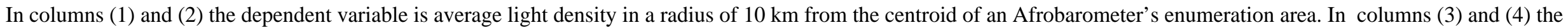

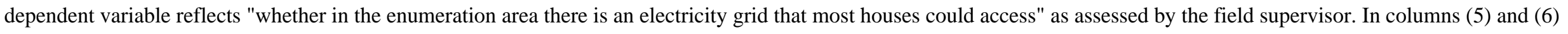

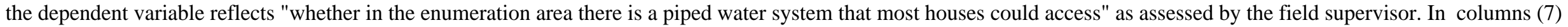

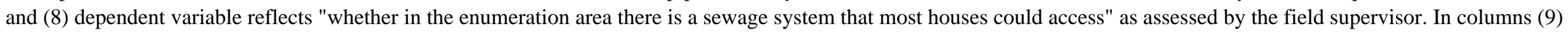

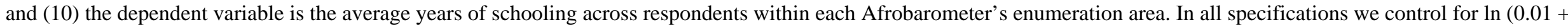
population density in a $10 \mathrm{~km}$ radius of the enumeration area).

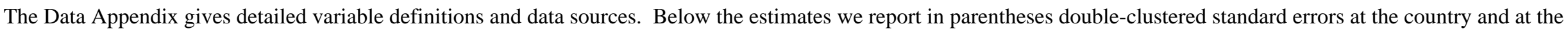
ethnicity level dimensions. ***, **, and * indicate statistical significance at the $1 \%, 5 \%$, and $10 \%$ level, respectively. 


\section{Appendix Table 15: National Institutions and Regional Development at the Border. Regression Discontinuity (RD) Estimates. RD Polynomial in Latitude and Longitude}

\begin{tabular}{|c|c|c|c|c|c|c|}
\hline \multirow[b]{2}{*}{ Latitude - Logitude Polynomial } & \multicolumn{3}{|c|}{ Rule of Law } & \multicolumn{3}{|c|}{ Control of Corruption } \\
\hline & Linear & 2nd-order & 3rd-order & Linear & 2nd-order & 3rd-order \\
\hline & (1) & $(2)$ & (3) & (4) & (5) & (6) \\
\hline $\begin{array}{l}\text { High Institutional Quality } \\
\text { Double-clustered s.e. }\end{array}$ & $\begin{array}{l}0.0140 \\
(0.0123)\end{array}$ & $\begin{array}{c}0.0149 \\
(0.0127)\end{array}$ & $\begin{array}{c}0.015 \\
(0.0127)\end{array}$ & $\begin{array}{c}0.0087 \\
(0.0129)\end{array}$ & $\begin{array}{c}0.0095 \\
(0.0131)\end{array}$ & $\begin{array}{c}0.0098 \\
(0.0127)\end{array}$ \\
\hline $\begin{array}{l}\text { Adjusted R-squared } \\
\text { within R-squared } \\
\text { Observations }\end{array}$ & $\begin{array}{l}0.351 \\
0.068 \\
38680\end{array}$ & $\begin{array}{l}0.351 \\
0.068 \\
38680\end{array}$ & $\begin{array}{r}0.351 \\
0.068 \\
38680\end{array}$ & $\begin{array}{c}0.351 \\
0.068 \\
38680\end{array}$ & $\begin{array}{l}0.351 \\
0.068 \\
38680\end{array}$ & $\begin{array}{l}0.351 \\
0.068 \\
38680\end{array}$ \\
\hline $\begin{array}{l}\text { Ethnicity Fixed Effects } \\
\text { Pixel Area \& Pop. Dens. }\end{array}$ & $\begin{array}{l}\text { Yes } \\
\text { Yes }\end{array}$ & $\begin{array}{l}\text { Yes } \\
\text { Yes }\end{array}$ & $\begin{array}{l}\text { Yes } \\
\text { Yes }\end{array}$ & $\begin{array}{l}\text { Yes } \\
\text { Yes }\end{array}$ & $\begin{array}{l}\text { Yes } \\
\text { Yes }\end{array}$ & $\begin{array}{l}\text { Yes } \\
\text { Yes }\end{array}$ \\
\hline
\end{tabular}

The table reports within-ethnicity regression discontinuity (RD) estimates using a two-dimensional RD polynomial in latitude and longitude (approach follows Dell (2010)). Estimation is performed across the two major partitions of each ethnic group. In columns (1) and (4) we simply control for each pixel's latitude and longitude. In columns (2) and (5) we include a second-order RD polynomial in latitude and longitude. In columns (3) and (6) we include a third-order RD polynomial in latitude and longitude. The high institutional quality indicator takes on the value of one for pixels falling in the country with the higher value in the rule of law index (in columns (1)-(3)) or in the control of corruption index (in columns (4)-(6)). All specifications include ethnicity fixed effects (constants not reported), the log of pixel-level population density and the log of pixel surface area. The Data Appendix gives detailed variable definitions and data sources. Besides the overall adjusted R-squared, the table also reports the within R-squared (defined as the difference of the overall R-squared minus the overall R-squared of a model simply with ethnicity fixed effects). Below the estimates we report in parentheses double-clustered standard errors at the country and at the ethnolinguistic level dimensions. ${ }^{* * *},{ }^{* *}$, and $*$ indicate statistical significance at the $1 \%, 5 \%$, and $10 \%$ level, respectively. 


\section{Appendix Table 16: Regional Heterogeneity on the Role of Contemporary National Institutions on Regional Development}

within Partitioned Ethnic Groups

Estimation Restricted to Partitioned Ethnic Homelands within

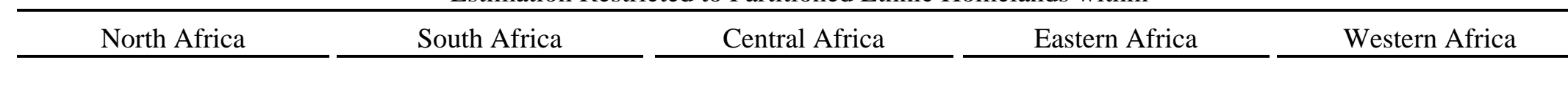

$\underline{\text { Rule of Law }}$ Corruption $\underline{\text { Rule of Law }} \underline{\text { Corruption }} \underline{\text { Rule of Law }} \underline{\text { Corruption }} \underline{\text { Rule of Law }} \underline{\text { Corruption }} \underline{\text { Rule of Law }} \underline{\text { Corruption }}$

(4)

(5)

(6)

(7)

(8)

(9)

\begin{tabular}{|c|c|c|c|c|c|c|c|c|c|c|}
\hline $\begin{array}{l}\text { High Institutional Quality } \\
\text { Double-clustered s.e. }\end{array}$ & $\begin{array}{l}-0.1111^{* *} \\
(0.0524)\end{array}$ & $\begin{array}{l}-0.0687 \\
(0.0611)\end{array}$ & $\begin{array}{l}0.0518^{* *} \\
(0.0226)\end{array}$ & $\begin{array}{r}0.0738 * * \\
(0.0352)\end{array}$ & $\begin{array}{r}0.0307 * * \\
(0.0156)\end{array}$ & $\begin{array}{c}0.0340^{* * *} \\
(0.0129)\end{array}$ & $\begin{array}{l}-0.0074 \\
(0.0131)\end{array}$ & $\begin{array}{l}-0.0075 \\
(0.0130)\end{array}$ & $\begin{array}{l}-0.0083 \\
(0.0240)\end{array}$ & $\begin{array}{l}-0.0324 \\
(0.0228)\end{array}$ \\
\hline Adjusted R-squared & 0.517 & 0.511 & 0.342 & 0.345 & 0.126 & 0.127 & 0.151 & 0.151 & 0.269 & 0.270 \\
\hline Observations & 1637 & 1637 & 7297 & 7297 & 7665 & 7665 & 6046 & 6046 & 9286 & 9286 \\
\hline Split Ethnicities & 9 & 9 & 28 & 28 & 36 & 36 & 30 & 30 & 64 & 64 \\
\hline Ethnicity Fixed Effects & Yes & Yes & Yes & Yes & Yes & Yes & Yes & Yes & Yes & Yes \\
\hline Pop. Dens \& Area & Yes & Yes & Yes & Yes & Yes & Yes & Yes & Yes & Yes & Yes \\
\hline
\end{tabular}

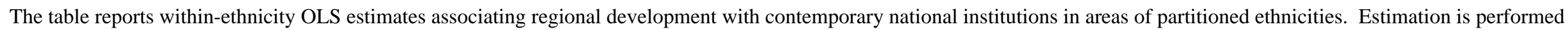

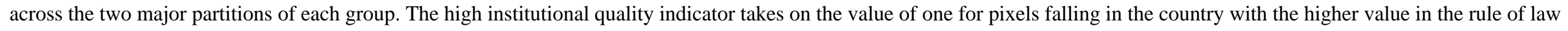

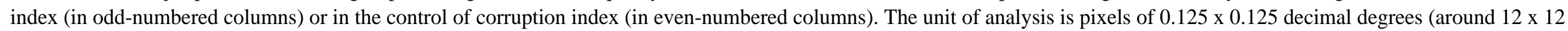

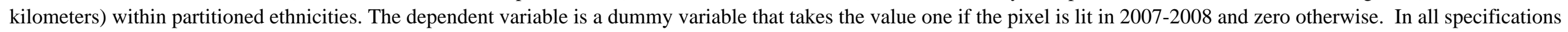

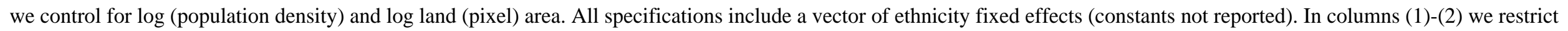

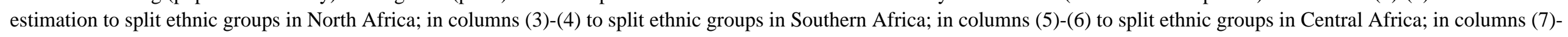

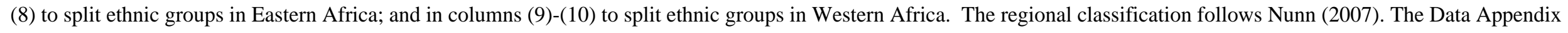

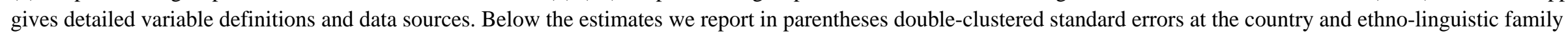
dimensions. $* * *, * *$, and $*$ indicate statistical significance at the $1 \%, 5 \%$, and $10 \%$ level, respectively. 


\section{Appendix Table 17: Regional Heterogeneity on the Role of Contemporary National Institutions on Regional Development within Partitioned Ethnic Groups in Areas Far and Close to the Capital Cities}

\begin{tabular}{|c|c|c|c|c|c|c|c|c|c|c|}
\hline & \multicolumn{10}{|c|}{ Estimation Restricted to Partitioned Ethnic Homelands within } \\
\hline & \multicolumn{2}{|c|}{ North Africa } & \multicolumn{2}{|c|}{ South Africa } & \multicolumn{2}{|c|}{ Central Africa } & \multicolumn{2}{|c|}{ Eastern Africa } & \multicolumn{2}{|c|}{ Western Africa } \\
\hline & $\frac{\text { Close }}{(1)}$ & $\frac{\text { Far }}{(2)}$ & $\frac{\text { Close }}{(3)}$ & $\frac{\text { Far }}{(4)}$ & $\frac{\text { Close }}{(5)}$ & $\frac{\text { Far }}{(6)}$ & $\frac{\text { Close }}{(7)}$ & $\frac{\text { Far }}{(8)}$ & $\frac{\text { Close }}{(9)}$ & $\frac{\text { Far }}{(10)}$ \\
\hline $\begin{array}{l}\text { High Rule of Law } \\
\text { Double-clustered s.e. }\end{array}$ & $\begin{array}{c}0.1628 * * * \\
(0.0153)\end{array}$ & $\begin{array}{c}-0.0987 * * * \\
(0.0357)\end{array}$ & $\begin{array}{l}0.0906 * \\
(0.0540)\end{array}$ & $\begin{array}{r}0.0595 * * \\
(0.0301)\end{array}$ & $\begin{array}{r}0.0372 * * \\
(0.0182)\end{array}$ & $\begin{array}{c}0.0161 \\
(0.0153)\end{array}$ & $\begin{array}{c}0.0153 \\
(0.0253)\end{array}$ & $\begin{array}{l}-0.0156 \\
(0.0154)\end{array}$ & $\begin{array}{c}0.0549 \\
(0.0744)\end{array}$ & $\begin{array}{l}-0.0479 \\
(0.0316)\end{array}$ \\
\hline $\begin{array}{l}\text { Adjusted R-squared } \\
\text { Observations }\end{array}$ & $\begin{array}{c}0.140 \\
383\end{array}$ & $\begin{array}{c}0.330 \\
908\end{array}$ & $\begin{array}{c}0.376 \\
3048\end{array}$ & $\begin{array}{l}0.150 \\
1673\end{array}$ & $\begin{array}{l}0.158 \\
3764\end{array}$ & $\begin{array}{l}0.047 \\
2790\end{array}$ & $\begin{array}{l}0.192 \\
1555\end{array}$ & $\begin{array}{l}0.120 \\
3592\end{array}$ & $\begin{array}{l}0.338 \\
2265\end{array}$ & $\begin{array}{l}0.220 \\
4909\end{array}$ \\
\hline $\begin{array}{l}\text { Split Ethnicities } \\
\text { Ethnicity Fixed Effects } \\
\text { Pop. Dens \& Area }\end{array}$ & $\begin{array}{c}2 \\
\text { Yes } \\
\text { Yes }\end{array}$ & $\begin{array}{c}7 \\
\text { Yes } \\
\text { Yes }\end{array}$ & $\begin{array}{l}14 \\
\text { Yes } \\
\text { Yes }\end{array}$ & $\begin{array}{l}11 \\
\text { Yes } \\
\text { Yes }\end{array}$ & $\begin{array}{l}15 \\
\text { Yes } \\
\text { Yes }\end{array}$ & $\begin{array}{l}15 \\
\text { Yes } \\
\text { Yes }\end{array}$ & $\begin{array}{c}9 \\
\text { Yes } \\
\text { Yes }\end{array}$ & $\begin{array}{l}21 \\
\text { Yes } \\
\text { Yes }\end{array}$ & $\begin{array}{l}24 \\
\text { Yes } \\
\text { Yes }\end{array}$ & $\begin{array}{l}38 \\
\text { Yes } \\
\text { Yes }\end{array}$ \\
\hline
\end{tabular}

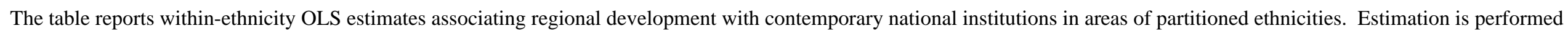

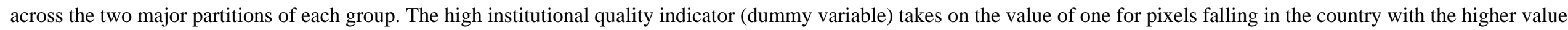

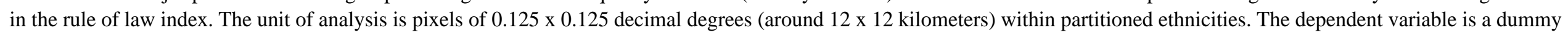

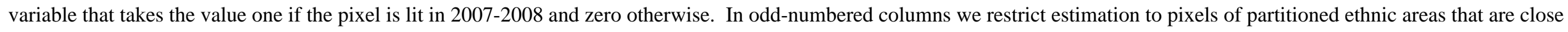

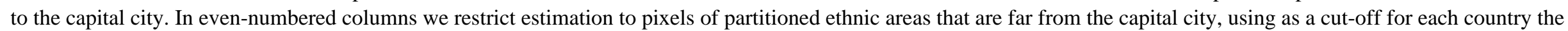

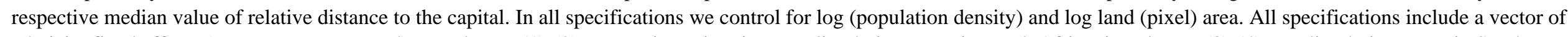

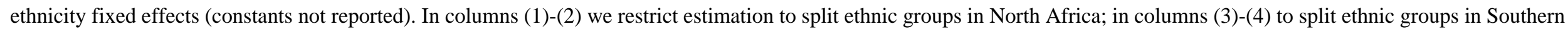

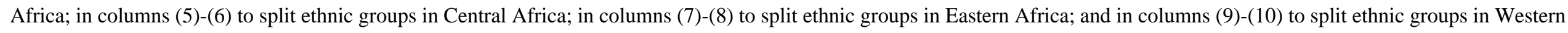

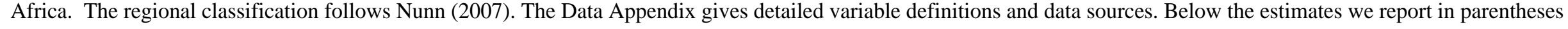

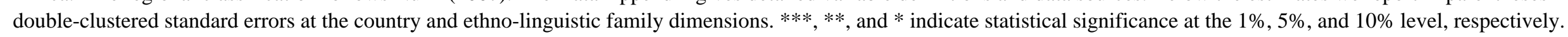


Appendix Table 18 - Heterogeneity: National Institutions and Regional Development within Partitioned Ethnicities Close and Far from the Capital Cities

\begin{tabular}{|c|c|c|c|c|c|c|c|c|}
\hline & \multicolumn{4}{|c|}{ Absolute Distance to the Capital } & \multicolumn{4}{|c|}{ Relative Distance to the Capital } \\
\hline & \multicolumn{2}{|c|}{ Rule of Law } & \multicolumn{2}{|c|}{ Control of Corruption } & \multicolumn{2}{|c|}{ Rule of Law } & \multicolumn{2}{|c|}{ Control of Corruption } \\
\hline & (1) & (2) & (3) & (4) & (5) & (6) & (7) & (8) \\
\hline $\begin{array}{l}\text { Institutional Quality } \\
\text { Double-clustered s.e. }\end{array}$ & $\begin{array}{c}0.0063 \\
(0.0184)\end{array}$ & $\begin{array}{c}0.0155 \\
(0.0212)\end{array}$ & $\begin{array}{c}0.0127 \\
(0.0291)\end{array}$ & $\begin{array}{c}0.0173 \\
(0.0292)\end{array}$ & $\begin{array}{c}0.0026 \\
(0.0188)\end{array}$ & $\begin{array}{c}0.0169 \\
(0.0212)\end{array}$ & $\begin{array}{c}0.0093 \\
(0.0278)\end{array}$ & $\begin{array}{c}0.0201 \\
(0.0277)\end{array}$ \\
\hline $\begin{array}{l}\text { Close } \\
\text { Double-clustered s.e. }\end{array}$ & $\begin{array}{c}-0.1433 * * * \\
(0.0515)\end{array}$ & $\begin{array}{l}-0.0893 \\
(0.0803)\end{array}$ & $\begin{array}{c}-0.1450 * * * \\
(0.0508)\end{array}$ & $\begin{array}{l}-0.1138 \\
(0.0813)\end{array}$ & $\begin{array}{l}-0.0534 \\
(0.0552)\end{array}$ & $\begin{array}{l}-0.0136 \\
(0.0670)\end{array}$ & $\begin{array}{l}-0.0545 \\
(0.0562)\end{array}$ & $\begin{array}{l}-0.0297 \\
(0.0682)\end{array}$ \\
\hline $\begin{array}{l}\text { Institutional Quality x Close } \\
\text { Double-clustered s.e. }\end{array}$ & $\begin{array}{r}0.0446 * * \\
(0.0213)\end{array}$ & $\begin{array}{r}0.0467 * * \\
(0.0214)\end{array}$ & $\begin{array}{r}0.0520 * * \\
(0.0245)\end{array}$ & $\begin{array}{r}0.0561 * * \\
(0.0245)\end{array}$ & $\begin{array}{r}0.0508 * * \\
(0.0242)\end{array}$ & $\begin{array}{r}0.0483 * * \\
(0.0202)\end{array}$ & $\begin{array}{r}0.0581 * * \\
(0.0283)\end{array}$ & $\begin{array}{r}0.0545 * * \\
(0.0253)\end{array}$ \\
\hline $\begin{array}{l}\text { Adjusted R-squared } \\
\text { within R-squared }\end{array}$ & $\begin{array}{l}0.347 \\
0.064\end{array}$ & $\begin{array}{l}0.355 \\
0.072\end{array}$ & $\begin{array}{l}0.347 \\
0.064\end{array}$ & $\begin{array}{l}0.355 \\
0.072\end{array}$ & $\begin{array}{l}0.346 \\
0.063\end{array}$ & $\begin{array}{l}0.355 \\
0.072\end{array}$ & $\begin{array}{l}0.346 \\
0.063\end{array}$ & $\begin{array}{l}0.355 \\
0.072\end{array}$ \\
\hline Observations & 40209 & 38680 & 40209 & 38680 & 40209 & 38680 & 40209 & 38680 \\
\hline Number of Ethnicities & 220 & 220 & 220 & 220 & 220 & 220 & 220 & 220 \\
\hline Ethnicity Fixed Effects & Yes & Yes & Yes & Yes & Yes & Yes & Yes & Yes \\
\hline Pop. Dens. \& Area & Yes & Yes & Yes & Yes & Yes & Yes & Yes & Yes \\
\hline Location \& Geography & No & Yes & No & Yes & No & Yes & No & Yes \\
\hline
\end{tabular}




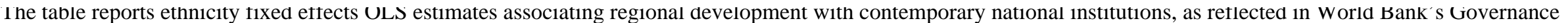

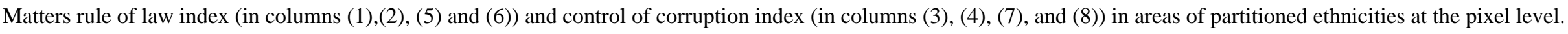

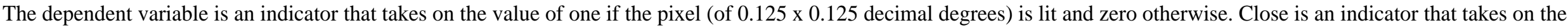

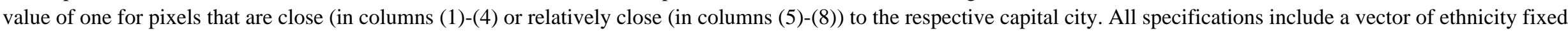

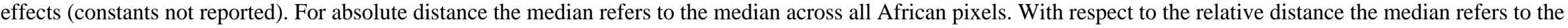
respective within-country median.

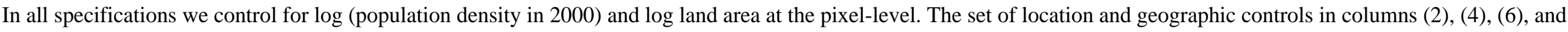

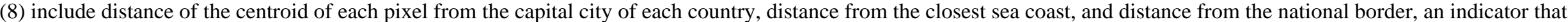

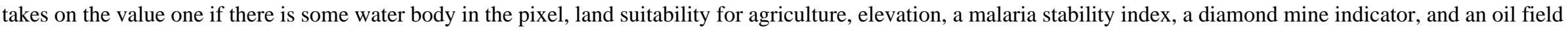

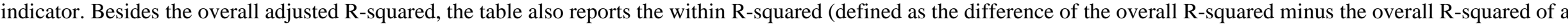
model simply with ethnicity fixed effects).

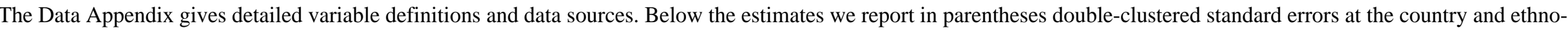
linguistic family dimensions. ${ }^{* * *},{ }^{* *}$, and * indicate statistical significance at the $1 \%, 5 \%$, and $10 \%$ level, respectively. 


\section{Appendix Table 19 - Heterogeneity: National Institutions and Regional Development within Partitioned Ethnicities Sensitivity Analysis: Dropping Each Time a Different African Region}

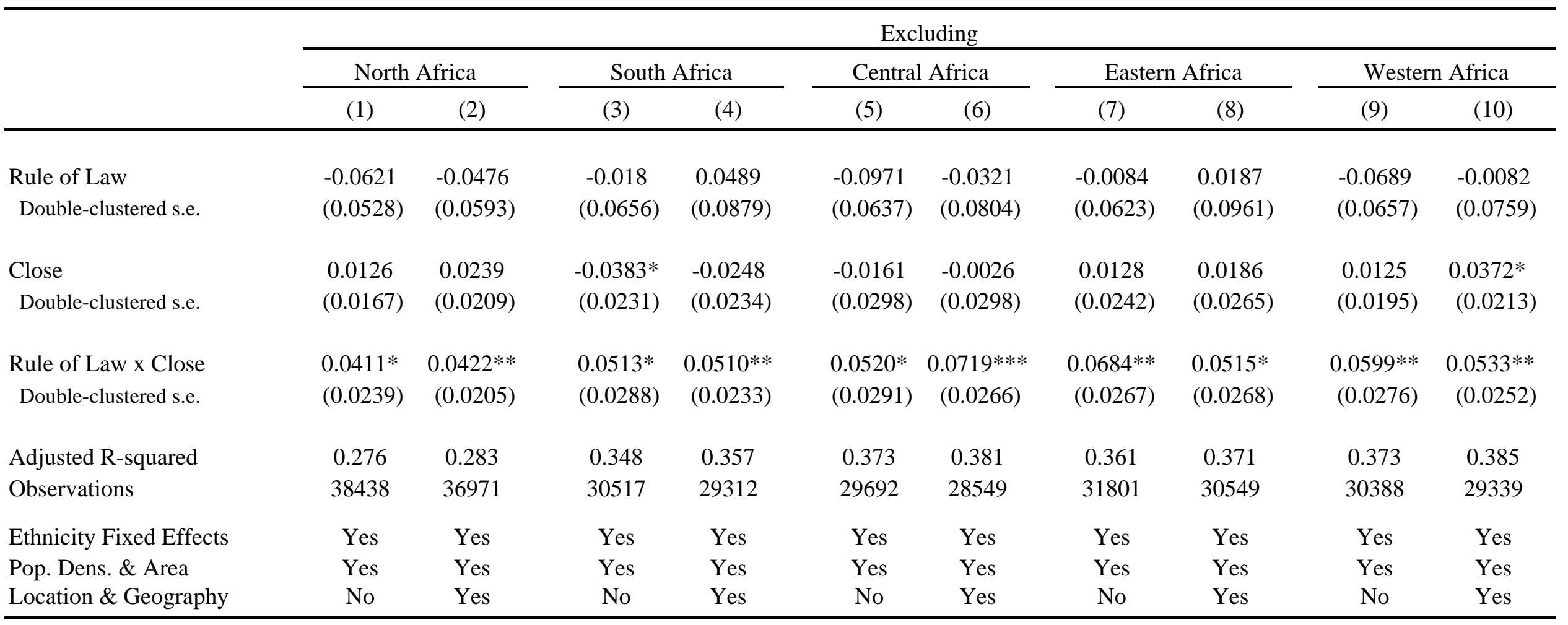

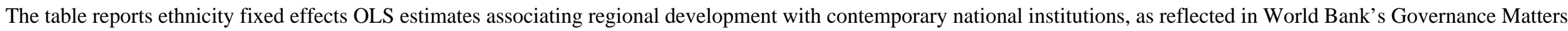

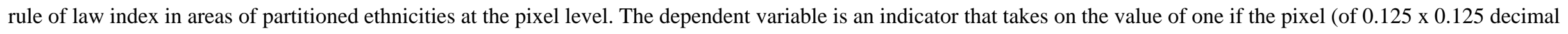
degrees) is lit and zero otherwise.

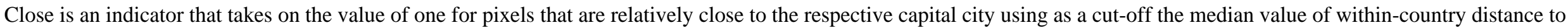
the capital. All specifications include a vector of ethnicity fixed effects (constants not reported).

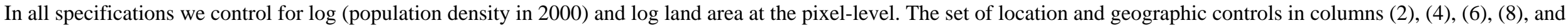

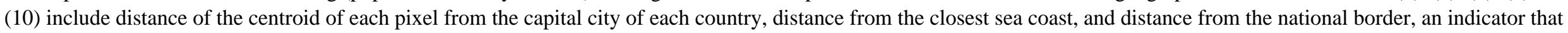

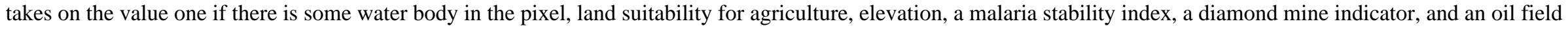

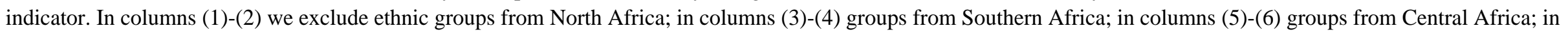
columns (7)-(8) groups from Eastern Africa; and in columns (9)-(10) groups from Western Africa. The regional classification follows Nunn (2007).

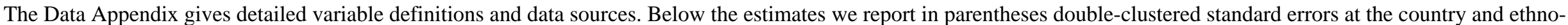
linguistic family dimensions. ${ }^{* * *}, * *$, and $*$ indicate statistical significance at the $1 \%, 5 \%$, and $10 \%$ level, respectively. 


\section{Appendix Table 20: Contemporary National Institutions and Regional Development within Partitioned Ethnic Groups Sensitivity Analysis. Dropping Each Time a Different African Region}

\begin{tabular}{|c|c|c|c|c|c|c|c|c|c|c|}
\hline & \multicolumn{10}{|c|}{ Estimation Excluding Partitioned Ethnic Homelands in } \\
\hline & \multicolumn{2}{|c|}{ North Africa } & \multicolumn{2}{|c|}{ South Africa } & \multicolumn{2}{|c|}{ Central Africa } & \multicolumn{2}{|c|}{ Eastern Africa } & \multicolumn{2}{|c|}{ Western Africa } \\
\hline & $\frac{\text { Close }}{(1)}$ & $\frac{\text { Far }}{(2)}$ & $\frac{\text { Close }}{(3)}$ & $\frac{\text { Far }}{(4)}$ & $\frac{\text { Close }}{(5)}$ & $\frac{\text { Far }}{(6)}$ & $\frac{\text { Close }}{(7)}$ & $\frac{\text { Far }}{(8)}$ & $\frac{\text { Close }}{(9)}$ & $\frac{\mathrm{Far}}{(10)}$ \\
\hline $\begin{array}{l}\text { High Rule of Law } \\
\text { Double-clustered s.e. }\end{array}$ & $\begin{array}{r}0.0617 * * \\
(0.0241)\end{array}$ & $\begin{array}{l}-0.0088 \\
(0.0154)\end{array}$ & $\begin{array}{r}0.0502 * * \\
(0.0231)\end{array}$ & $\begin{array}{l}-0.0260 \\
(0.0159)\end{array}$ & $\begin{array}{l}0.0569 * \\
(0.0339)\end{array}$ & $\begin{array}{l}-0.0218 \\
(0.0180)\end{array}$ & $\begin{array}{c}0.0744 * * * \\
(0.0266)\end{array}$ & $\begin{array}{l}-0.0147 \\
(0.0199)\end{array}$ & $\begin{array}{r}0.0579 * * \\
(0.0258)\end{array}$ & $\begin{array}{c}0.0162 \\
(0.0140)\end{array}$ \\
\hline $\begin{array}{l}\text { Adjusted R-squared } \\
\text { Observations }\end{array}$ & $\begin{array}{l}0.350 \\
10655\end{array}$ & $\begin{array}{c}0.181 \\
19122\end{array}$ & $\begin{array}{c}0.456 \\
7990\end{array}$ & $\begin{array}{l}0.260 \\
16752\end{array}$ & $\begin{array}{l}0.460 \\
7267\end{array}$ & $\begin{array}{l}0.260 \\
15064\end{array}$ & $\begin{array}{l}0.446 \\
9483\end{array}$ & $\begin{array}{l}0.246 \\
14664\end{array}$ & $\begin{array}{l}0.466 \\
8757\end{array}$ & $\begin{array}{l}0.231 \\
15022\end{array}$ \\
\hline $\begin{array}{l}\text { Ethnicity Fixed Effects } \\
\text { Pop. Dens \& Area }\end{array}$ & $\begin{array}{l}\text { Yes } \\
\text { Yes }\end{array}$ & $\begin{array}{l}\text { Yes } \\
\text { Yes }\end{array}$ & $\begin{array}{l}\text { Yes } \\
\text { Yes }\end{array}$ & $\begin{array}{l}\text { Yes } \\
\text { Yes }\end{array}$ & $\begin{array}{l}\text { Yes } \\
\text { Yes }\end{array}$ & $\begin{array}{l}\text { Yes } \\
\text { Yes }\end{array}$ & $\begin{array}{l}\text { Yes } \\
\text { Yes }\end{array}$ & $\begin{array}{l}\text { Yes } \\
\text { Yes }\end{array}$ & $\begin{array}{l}\text { Yes } \\
\text { Yes }\end{array}$ & $\begin{array}{l}\text { Yes } \\
\text { Yes }\end{array}$ \\
\hline
\end{tabular}

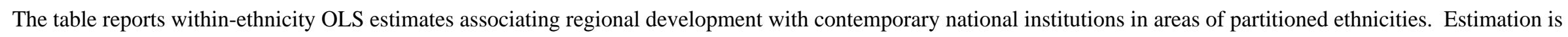

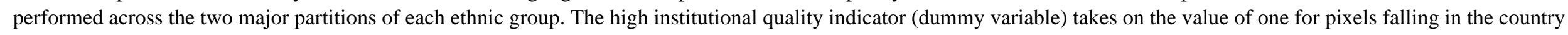

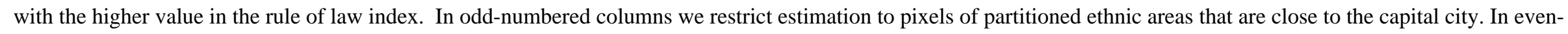

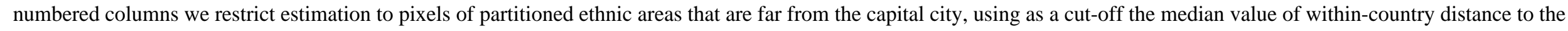

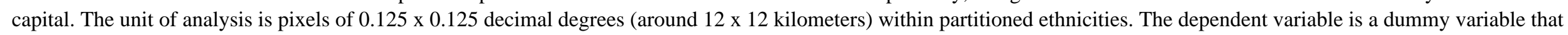

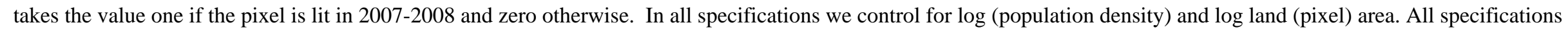

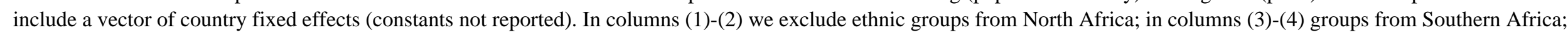

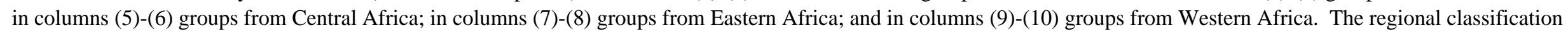

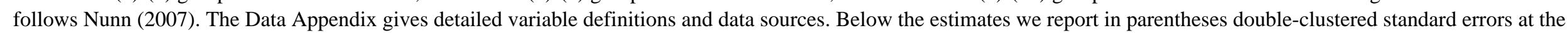
country and ethno-linguistic family dimensions. ***, **, and * indicate statistical significance at the $1 \%$, 5\%, and $10 \%$ level, respectively. 


\section{Appendix Table 21: Heterogeneity - National Institutions and Regional Development within Partitioned Ethnicities Close and Far from the Capital Cities Alternative Measures of National Institutions from World Bank's Governance Indicators}

\begin{tabular}{|c|c|c|c|c|c|c|c|c|c|c|c|c|}
\hline & \multicolumn{3}{|c|}{ Bureaucratic Quality } & \multicolumn{3}{|c|}{ Regulatory Quality } & \multicolumn{3}{|c|}{ Voice and Accountability } & \multicolumn{3}{|c|}{ Political Stability } \\
\hline & All & Close & Far & All & Close & Far & All & Close & Far & All & Close & Far \\
\hline & (1) & (2) & (3) & (4) & (5) & (6) & (7) & (8) & (9) & $(10)$ & $(11)$ & $(12)$ \\
\hline $\begin{array}{l}\text { Institutional Quality } \\
\text { Double-clustered s.e. }\end{array}$ & $\begin{array}{c}0.0368 \\
(0.0244)\end{array}$ & $\begin{array}{c}0.1094 * * \\
(0.0494)\end{array}$ & $\begin{array}{c}0.0232 \\
(0.0165)\end{array}$ & $\begin{array}{l}0.0250 * \\
(0.0149)\end{array}$ & $\begin{array}{c}0.0793 * * \\
(0.0374)\end{array}$ & $\begin{array}{l}0.0184^{*} \\
(0.0110)\end{array}$ & $\begin{array}{l}0.0301 * \\
(0.0175)\end{array}$ & $\begin{array}{c}0.0771 * * \\
(0.0379)\end{array}$ & $\begin{array}{c}0.0152 \\
(0.0148)\end{array}$ & $\begin{array}{c}0.0011 \\
(0.0094)\end{array}$ & $\begin{array}{c}0.0226 \\
(0.0244)\end{array}$ & $\begin{array}{l}-0.0051 \\
(0.0117)\end{array}$ \\
\hline Adjusted R-squared & 0.342 & 0.438 & 0.236 & 0.342 & 0.437 & 0.236 & 0.342 & 0.437 & 0.235 & 0.341 & 0.434 & 0.235 \\
\hline Observations & 40209 & 11038 & 20156 & 40209 & 11038 & 20156 & 40209 & 11038 & 20156 & 40209 & 11038 & 20156 \\
\hline Ethnicity Fixed Effects & Yes & Yes & Yes & Yes & Yes & Yes & Yes & Yes & Yes & Yes & Yes & Yes \\
\hline Pop. Dens and Area & Yes & Yes & Yes & Yes & Yes & Yes & Yes & Yes & Yes & Yes & Yes & Yes \\
\hline
\end{tabular}

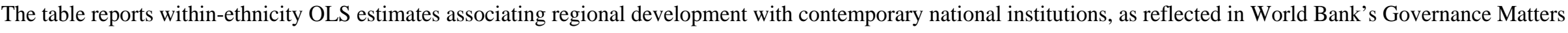

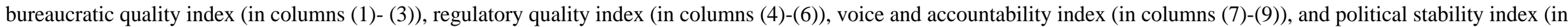

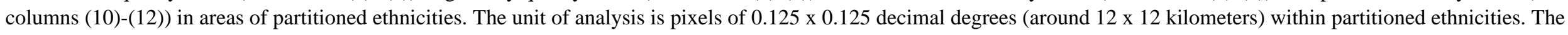

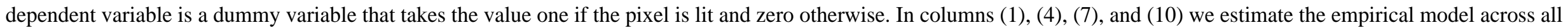

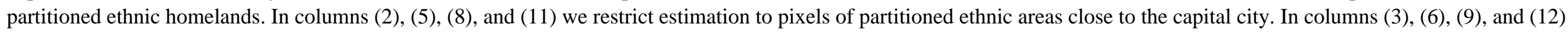

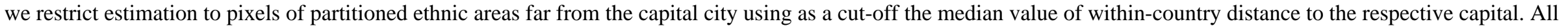

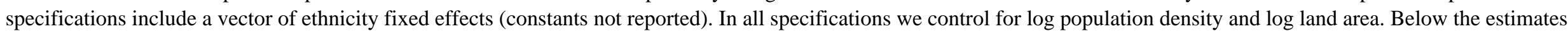

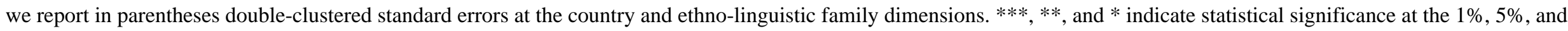
$10 \%$ level, respectively.
} 


\section{Appendix Table 22: Property Rights, Contractual Institutions and Regional Development within Partitioned Ethnicities Close and Far from the Capital Cities}

\begin{tabular}{|c|c|c|c|c|c|c|c|c|c|c|c|c|}
\hline & \multicolumn{6}{|c|}{ Property Rights Institutions } & \multicolumn{6}{|c|}{ Contractual Institutions } \\
\hline & \multicolumn{3}{|c|}{$\begin{array}{c}\text { Executive Constraints } \\
1991-2006 \\
\end{array}$} & \multicolumn{3}{|c|}{$\begin{array}{c}\text { Executive Constraints } \\
\text { at Independence }\end{array}$} & \multicolumn{3}{|c|}{$\begin{array}{c}\text { Legal Formalism - Contract } \\
\text { Log Number of Days }\end{array}$} & \multicolumn{3}{|c|}{$\begin{array}{l}\text { Legal Formalism - Contract } \\
\text { Log Number of Procedures }\end{array}$} \\
\hline & All & Close & Far & All & Close & Far & All & Close & Far & All & Close & Far \\
\hline & (1) & (2) & (3) & (4) & (5) & (6) & (7) & (8) & (9) & (10) & (11) & (12) \\
\hline $\begin{array}{l}\text { Institutional Quality } \\
\text { Double-clustered s.e. }\end{array}$ & $\begin{array}{c}0.0974 \\
(0.0621)\end{array}$ & $\begin{array}{c}0.2187 \\
(0.1510)\end{array}$ & $\begin{array}{c}0.058 \\
(0.0526)\end{array}$ & $\begin{array}{c}0.0496 \\
(0.0341)\end{array}$ & $\begin{array}{c}0.0711 \\
(0.0766)\end{array}$ & $\begin{array}{c}0.0100 \\
(0.0327)\end{array}$ & $\begin{array}{c}0.0072 \\
(0.0231)\end{array}$ & $\begin{array}{l}-0.0169 \\
(0.0716)\end{array}$ & $\begin{array}{c}0.0023 \\
(0.0342)\end{array}$ & $\begin{array}{l}-0.1419 \\
(0.0917)\end{array}$ & $\begin{array}{c}-0.4430 * * * \\
(0.1531)\end{array}$ & $\begin{array}{l}-0.0966 \\
(0.0804)\end{array}$ \\
\hline $\begin{array}{l}\text { Adjusted R-squared } \\
\text { Observations }\end{array}$ & $\begin{array}{l}0.344 \\
39037\end{array}$ & $\begin{array}{l}0.434 \\
10618\end{array}$ & $\begin{array}{l}0.238 \\
19472\end{array}$ & $\begin{array}{l}0.342 \\
40209\end{array}$ & $\begin{array}{l}0.434 \\
11038\end{array}$ & $\begin{array}{l}0.235 \\
20156\end{array}$ & $\begin{array}{r}0.334 \\
37968\end{array}$ & $\begin{array}{l}0.432 \\
10471\end{array}$ & $\begin{array}{l}0.239 \\
18899\end{array}$ & $\begin{array}{l}0.334 \\
37968\end{array}$ & $\begin{array}{l}0.434 \\
10471\end{array}$ & $\begin{array}{l}0.240 \\
18899\end{array}$ \\
\hline $\begin{array}{l}\text { Ethnicity Fixed Effects } \\
\text { Pop. Dens \& Area }\end{array}$ & $\begin{array}{l}\text { Yes } \\
\text { Yes }\end{array}$ & $\begin{array}{l}\text { Yes } \\
\text { Yes }\end{array}$ & $\begin{array}{l}\text { Yes } \\
\text { Yes }\end{array}$ & $\begin{array}{l}\text { Yes } \\
\text { Yes }\end{array}$ & $\begin{array}{l}\text { Yes } \\
\text { Yes }\end{array}$ & $\begin{array}{l}\text { Yes } \\
\text { Yes }\end{array}$ & $\begin{array}{l}\text { Yes } \\
\text { Yes }\end{array}$ & $\begin{array}{l}\text { Yes } \\
\text { Yes }\end{array}$ & $\begin{array}{l}\text { Yes } \\
\text { Yes }\end{array}$ & $\begin{array}{l}\text { Yes } \\
\text { Yes }\end{array}$ & $\begin{array}{l}\text { Yes } \\
\text { Yes }\end{array}$ & $\begin{array}{l}\text { Yes } \\
\text { Yes }\end{array}$ \\
\hline
\end{tabular}

The table reports within-ethnicity OLS estimates associating regional development with pxoxies of "property rights" institutions and "contractual” institutions in areas of partitioned ethnicities. In columns (1)-(3) we proxy property rights institutions with Polity’s executive constraints index, averaged over the period 1991-2006. In columns (4)-(6) we proxy property rights institutions with Polity's executive constraints index, averaged over the initial ten year period after independence. In columns (7)-(9) and columns (10)(12) we proxy contractual institutions with measures of legal formalism (from the work of Djankov et al. (2003), Djankov et al. (2007) and World Bank’s Doing Business Project) that measure the (log) number of days and the log number of procedures needed to resolve through courts a simple dispute.

The unit of analysis is pixels of $0.125 \times 0.125$ decimal degrees (around $12 \times 12$ kilometers) within partitioned ethnicities. The dependent variable is a dummy variable that takes the value one if the pixel is lit and zero otherwise. In columns (1), (4), (7), and (10) we estimate the empirical model across all partitioned ethnic homelands. In columns (2), (5), (8), and (11) we restrict estimation to pixels of partitioned ethnic areas that are close to the capital city. In columns (3), (6), (9), and (12) we restrict estimation to pixels of partitioned ethnic areas far from the capital city using as a cut-off the median value of within-country distance to the respective capital city.

All specifications include a vector of ethnicity fixed effects (constants not reported). In all specifications we control for log population density and log land area. Below the estimates we report in parentheses double-clustered standard errors at the country and ethno-linguistic family dimensions. ${ }^{* * *},{ }^{* *}$, and ${ }^{*}$ indicate statistical significance at the $1 \%$, $5 \%$, and $10 \%$ level, respectively. 


\section{Appendix Table 23: Access to Government Services and Distance to the Capital Afrobarometer Sample. Country-Fixed-Effects Estimates}

\begin{tabular}{|c|c|c|c|c|c|c|c|c|}
\hline & \multicolumn{4}{|c|}{ Easiness of Obtaining Identity Document } & \multicolumn{4}{|c|}{ Easiness of Obtaining Household Services } \\
\hline & (1) & $(2)$ & (3) & (4) & (5) & (6) & (7) & (8) \\
\hline $\begin{array}{l}\text { Absolute Distance } \\
\text { Double-clustered s.e. }\end{array}$ & $\begin{array}{c}-0.1349 * * \\
(0.0646)\end{array}$ & $\begin{array}{c}-0.1269 * * \\
(0.0591)\end{array}$ & & & $\begin{array}{c}-0.3638 * * * \\
(0.0782)\end{array}$ & $\begin{array}{c}-0.2483^{* * *} \\
(0.0646)\end{array}$ & & \\
\hline $\begin{array}{l}\text { Relative Distance } \\
\text { Double-clustered s.e. }\end{array}$ & & & $\begin{array}{l}-0.0882 \\
(0.0659)\end{array}$ & $\begin{array}{l}-0.0782 \\
(0.0585)\end{array}$ & & & $\begin{array}{c}-0.3636^{* * *} \\
(0.0684)\end{array}$ & $\begin{array}{c}-0.2486^{* * *} \\
(0.0586)\end{array}$ \\
\hline $\begin{array}{l}\text { Adjusted R-squared } \\
\text { Observations }\end{array}$ & $\begin{array}{l}0.135 \\
18795\end{array}$ & $\begin{array}{l}0.157 \\
18266\end{array}$ & $\begin{array}{l}0.135 \\
18795\end{array}$ & $\begin{array}{l}0.157 \\
18266\end{array}$ & $\begin{array}{l}0.094 \\
16577\end{array}$ & $\begin{array}{l}0.148 \\
16091\end{array}$ & $\begin{array}{l}0.095 \\
16577\end{array}$ & $\begin{array}{l}0.149 \\
16091\end{array}$ \\
\hline $\begin{array}{l}\text { Individual Controls } \\
\text { Country Fixed Effects }\end{array}$ & $\begin{array}{l}\text { No } \\
\text { Yes }\end{array}$ & $\begin{array}{l}\text { Yes } \\
\text { Yes }\end{array}$ & $\begin{array}{l}\text { Yes } \\
\text { Yes }\end{array}$ & $\begin{array}{l}\text { Yes } \\
\text { Yes }\end{array}$ & $\begin{array}{l}\text { Yes } \\
\text { Yes }\end{array}$ & $\begin{array}{l}\text { Yes } \\
\text { Yes }\end{array}$ & $\begin{array}{l}\text { Yes } \\
\text { Yes }\end{array}$ & $\begin{array}{l}\text { Yes } \\
\text { Yes }\end{array}$ \\
\hline
\end{tabular}

The table reports country-fixed-effects OLS estimates, associating various measures of the reach of government services, as reflected by individual responses at the Afrobarometer Surveys (3rd round) at the individual level, with distance to the capital.

The dependent variable is columns (1)-(4) is an ordered index (range from 1 to 4 ) based on individual responses on how easy it is to obtain an identity document. The dependent variable is columns (5)-(8) is an ordered (range from 1 to 4) index based on individual responses on how easy it is to obtain basic household services (like piped water, electricity or telephone). For both measures a score of 1 indicates "very difficult”, a score of 2 indicates "difficult”, a score of 3 indicates "easy” and a score of 4 indicates "very easy".

Even-numbered columns include a rich set of individual controls. The individual-level conditioning set includes age, age squared, a gender indicator variable, an urban indicator, 22 religion fixed effects, 25 occupation fixed effects, 5 living conditions fixed effects, and 9 education fixed effects. All specifications include a set of country fixed effects (constants not reported).

The Data Appendix gives detailed variable definitions and data sources. Below the estimates we report in parentheses double-clustered standard errors at the enumeration area and at the ethnicity level. ***, **, and * indicate statistical significance at the $1 \%, 5 \%$, and $10 \%$ level, respectively. 